\title{
Memory $\mathrm{CD8}^{+} \mathrm{T}$ cells mediate early pathogen-specific protection through localized delivery of chemokines and IFN $\gamma$ to clusters of inflammatory monocytes
}

Marie Boutet ${ }^{1}$, Zachary Benet ${ }^{1,2}$, Erik Guillen ${ }^{1}$, Caroline Koch ${ }^{1}$, Saidi M'Homa Soudja ${ }^{1}$, Fabien Delahaye $^{3,4}$, David Fooksman ${ }^{1,2^{*}}$ and Grégoire Lauvau ${ }^{1 *}$

${ }^{1}$ Albert Einstein College of Medicine, Department of Microbiology and Immunology, 1301 Morris Park Avenue, Bronx,

NY, USA, 10461

${ }^{2}$ Albert Einstein College of Medicine, Department of Pathology, 1300 Morris Park Avenue, Bronx, NY, USA, 10461

${ }^{3}$ Albert Einstein College of Medicine, Department of Genetics, 1301 Morris Park Avenue, Bronx, NY, USA, 10461

${ }^{4}$ Institut Pasteur de Lille, UMR1283/8199, 59000 Lille, France

*Correspondence should be addressed to GL or DF: GL: Albert Einstein College of Medicine, Department of Microbiology and Immunology, 1301 Morris Park Avenue, Price Center, Bronx, NY, 10461, USA. Ph: +1 718678 1188, Fax: +1 718678 1085, E-mail: gregoire.lauvau@einsteinmed.org

DF: Albert Einstein College of Medicine, Department of Pathology, 1300 Morris Park Avenue, Price Center, Bronx, NY, 10461, USA. Ph: +1 718678 7957, E-mail: david.fooskman@einsteinmed.org 


\section{Summary}

While cognate antigen drives clonal expansion of memory $\mathrm{CD}^{+} \mathrm{T}$ cells to achieve sterilizing immunity in immunized hosts, not much is known on how cognate antigen contributes to early mechanisms of protection before clonal expansion occurs. Herein, using distinct models of immunization, we establish that cognate antigen recognition by $\mathrm{CD}^{+} \mathrm{T}_{\mathrm{M}}$ cells on dendritic cells initiates their rapid and coordinated production of a burst of CCL3, CCL4 and XCL1 chemokines under the transcriptional control of IRF4. Using intravital microscopy imaging and in vivo monoclonal antibody labelling, we reveal that memory $\mathrm{CD}^{+} \mathrm{T}$ cells undergo antigenmediated arrest in splenic red pulp clusters of $\mathrm{CCR}^{+}$monocytes where they locally deliver both IFN $\gamma$ - and chemokine-potentiating microbicidal activities to achieve early protection. Thus, rapid and effective memory $\mathrm{CD}^{+} \mathrm{T}$ cell responses require a complex series of spatially and temporally coordinated stepwise molecular and cellular events that quickly restrict microbial pathogen growth and optimize the local delivery of effector molecules before clonal expansion occurs. 


\section{Introduction}

$\mathrm{CD} 8^{+} \mathrm{T}$ cells have the unique ability to sense and recognize antigens (Ags) derived from intracellular pathogens and tumors (Harty et al., 2000; Vesely et al., 2011; Wong and Pamer, 2003). Live attenuated vaccines using viral backbones (e.g., Vaccinia, Vesicular Stomatitis Virus) or intracellular bacteria such as Listeria monocytogenes ( $\mathrm{Lm}$ ) and Mycobacteria (BCG), are known to promote robust $\mathrm{CD}^{+} \mathrm{T}$ cell responses and establish a pool of systemic and tissueresident long-lived memory $\mathrm{CD} 8^{+} \mathrm{T}\left(\mathrm{CD} 8^{+} \mathrm{T}_{\mathrm{M}}\right)$ cells. Such $\mathrm{CD} 8^{+} \mathrm{T}_{\mathrm{M}}$ cells can rapidly react against immunizing Ags expressed in live vectors, and provide immunity against life-threatening diseases (Martin and Badovinac, 2018; Sallusto et al., 2010; Schenkel and Masopust, 2014).

Cognate Ag, cytokines and chemotactic signals contribute to optimal activation of $\mathrm{CD} 8^{+} \mathrm{T}_{\mathrm{M}}$ cells during a recall infection, systemically and at mucosal surfaces (Lauvau et al., 2016; Schenkel and Masopust, 2014). Since MHC class I (MHC-I) molecules are almost ubiquitously expressed, associated Ags can theoretically be presented by any cells, supporting the common view that $\mathrm{CD}^{+} \mathrm{T}_{\mathrm{M}}$ cells may recognize their cognate Ags and undergo subsequent activation upon triggering by any MHC-I-expressing cells. However, this view was challenged by an important study showing that dendritic cells (DCs) play a unique role in driving optimal Agdependent expansion of $\mathrm{CD}^{+} \mathrm{T}_{\mathrm{M}}$ cells during a recall infection in vaccinated mice (Zammit et al., 2005). The importance of DCs was also extended to the reactivation of tissue-resident memory $\mathrm{CD}^{+} \mathrm{T}\left(\mathrm{T}_{\mathrm{RM}}\right)$ cells (Shin et al., 2016; Wakim et al., 2008). More recent evidence using two distinct models of lung viral infections, further revealed that draining lymph node (dLN)derived $\mathrm{CD}^{+} \mathrm{T}_{\mathrm{M}}$ cells required $\mathrm{XCR} 1^{+} \mathrm{DCs}$ for Ag-dependent reactivation while $\mathrm{T}_{\mathrm{RM}}$ cells in the lung could be reactivated both by hematopoietic and non-hematopoietic-derived cells (Low et al., 2020). In models of systemic bacterial and viral infections, DCs and $\mathrm{Ly}_{6} \mathrm{C}^{+} \mathrm{CCR}^{+}$ inflammatory monocytes, are the source of multiple inflammatory cytokines, i.e., IL-12, IL-18, IL-15 and type I interferon (IFN), that drive early Ag-independent, also known as "bystander", $\mathrm{CD}^{+} \mathrm{T}_{\mathrm{M}}$ cell-reactivation and differentiation into IFN $\gamma$-secreting $\mathrm{NKG}^{+} \mathrm{D}^{+}$effector cells (Alexandre et al., 2015; Bedoui et al., 2009; Berg et al., 2003; Raue et al., 2013; Soudja et al., 2012). While such cytokine-driven activation of $\mathrm{CD}^{+} \mathrm{T}_{\mathrm{M}}$ cells contributes to innate mechanisms of protection, cognate $\mathrm{Ag}$ recognition nevertheless remains required to achieve high levels of microbial pathogen-specific immunity. Several mechanisms are likely to account for Agdependent $\mathrm{CD}^{+} \mathrm{T}_{\mathrm{M}}$ cell-mediated protection. These include direct cytolysis of infected cells, 
secretion of Ag-dependent cytokines (i.e., TNF $\alpha$ ) and, very importantly, rapid clonal expansion that ensures sufficient numbers of pathogen-specific effector memory cells are generated to effectively sterilize an infection (Harty et al., 2000; Wong and Pamer, 2003). Trafficking of $\mathrm{CD}^{+} \mathrm{T}_{\mathrm{M}}$ cells to the sites of infection via chemotaxis (e.g., CXCR3, CCR5) and adhesion (LFA1, loss of L-selectin), are also essential processes to enable rapid containment and effective elimination of microbial pathogens at portal of entry. Proof of concept studies have used models of systemic viral (Vaccinia, VSV, LCMV) and bacterial $(\mathrm{Lm})$ infections in which microbial pathogens are rapidly captured in subcapsular dLNs or splenic marginal zone CD169 ${ }^{+}$ macrophages, and drive subsequent homing of $\mathrm{CD}^{+} \mathrm{T}_{\mathrm{M}}$ cells in response to chemotactic cues (e.g., CXCL9, CXCL10) produced by innate immune and structural cells (Kastenmuller et al., 2013; Maurice et al., 2019; Sung et al., 2012). The massive Ag-independent recruitment of memory cells also leads to inflammation-driven activation of Ag-irrelevant $\mathrm{CD}^{+} \mathrm{T}_{\mathrm{M}}$ cells (Maurice et al., 2019). While comparable chemotactic mechanisms are also documented in the case of $\mathrm{CD}^{+}$and $\mathrm{CD}^{+} \mathrm{T}_{\mathrm{RM}}$ cells in models of skin and vaginal viral infections, initiation of the rapid mucosal immune response by $\mathrm{T}_{\mathrm{RM}}$ cells is largely dependent on initial cognate $\mathrm{Ag}$ recognition, leading to the establishment of a rapid antiviral state that restrict pathogen spreading (Ariotti et al., 2014; Iijima and Iwasaki, 2014; Schenkel et al., 2014; Schenkel et al., 2013). There is, however, still very little knowledge on which early transcriptional gene expression and effector program is specifically triggered in $C D 8^{+} \mathrm{T}_{\mathrm{M}}$ cells upon early cognate $\mathrm{Ag}$ recognition and how this enables memory $\mathrm{CD}^{+} \mathrm{T}$ cells to mediate the rapid control of pathogen growth and spreading in situ in immunized hosts.

Using mice immunized with $L m$, we previously reported that IFN $\gamma$ signaling to innate phagocytes, namely $\mathrm{CCR}^{+}$monocytes and neutrophils, promotes their maturation into TNF $\alpha-$ and reactive oxygen species (ROS)-producing microbicidal effector cells, which accounts for significant protection in both spleen and liver of vaccinated hosts (Narni-Mancinelli et al., 2007; Narni-Mancinelli et al., 2011; Soudja et al., 2014). Yet, in these models of systemic vaccination, as well as others (Kupz et al., 2012; Raue et al., 2013), IFN $\gamma$ is largely secreted by the $\mathrm{CD}^{+} \mathrm{T}_{\mathrm{M}}$ cells independent of cognate antigen while protection occurs within hours post challenge infection and before $\mathrm{CD}^{+} \mathrm{T}_{\mathrm{M}}$ cells even undergo clonal expansion (Narni-Mancinelli et al., 2007; Narni-Mancinelli et al., 2011). In the current work, we dissected the cellular and molecular mechanisms by which cognate antigen programs and orchestrates early $\mathrm{CD}^{+} \mathrm{T}_{\mathrm{M}}$ cell-mediated 
pathogen-specific protection in vaccinated hosts undergoing a recall infection. We took advantage of our experimental system in which protection requires cognate $\mathrm{Ag}$ recognition but IFN $\gamma$, a major protective cytokine in vivo, is secreted with no need of cognate $\mathrm{Ag}$, Our results are consistent with a model in which $\mathrm{CD}^{+} \mathrm{T}_{\mathrm{M}}$ cells migrate to and arrest in infection foci where blood-derived phagocytes, here $\mathrm{Ly} 6 \mathrm{C}^{+}$monocytes, have already been accumulating, to license them with highly effective microbicidal functions for pathogen containment and killing. 


\section{Results}

\section{Cognate antigen versus inflammation triggers a broad range of functional pathways in memory $\mathrm{CD8}^{+} \mathrm{T}$ cells}

To understand how cognate antigen orchestrates $\mathrm{CD}^{+} \mathrm{T}_{\mathrm{M}}$ cell early reactivation and programming in situ, we conducted a genome-wide transcriptional analysis of pathogen-specific memory cells undergoing reactivation in the presence or in the absence of their cognate antigen (Ag) (Figure 1). Naïve Ova ${ }_{257-264} / \mathrm{K}^{\mathrm{b}}$-specific OT-I and $\mathrm{gB}_{498-505} / \mathrm{K}^{\mathrm{b}}$-specific $\mathrm{gBT}$-I TCR transgenic T cells were adoptively transferred to WT C57BL/6 (B6) mice that were immunized the next day with Listeria monocytogenes $(\mathrm{Lm})$ expressing both $\mathrm{T}$ cell epitopes (Lm-Ova-gB). Six weeks later, immunized mice were challenged with $L m$ expressing Ova only ( $L m$-Ova) and we monitored OT-I and gBT-I $\mathrm{T}_{\mathrm{M}}$ cell activation (Figure 1A). This experimental set-up enabled us to track memory cells that either "see" (OT-I, Ag/Infl.-activated) or do not "see" (gBT-I, Infl.activated) their cognate Ag. The memory cells were flow-sorted from $8 \mathrm{hr}$-challenged or control unchallenged mice, and subjected to transcriptomic analysis (Figure 1B). Two-dimensional principal component analysis (PCA) (Figure 1B, left panel) and hierarchical clustering (Figure $1 \mathrm{~B}$, right panel) revealed that OT-I $\mathrm{T}_{\mathrm{M}}$ cells (Ag/Infl.-activated) clustered separately from gBT-I (Infl.-activated) and resting $\mathrm{T}_{\mathrm{M}}$ (unchallenged) cells that grouped close together. Thus, cognate Ag triggering drives a significantly distinct transcriptional profile in the memory $\mathrm{CD}^{+} \mathrm{T}$ cells. A total of 1,837 genes were differentially expressed $(\mathrm{p}<0.05$, fold change $>1.5)$ in activated $(\mathrm{Ag} / \mathrm{Infl} .+$ Infl. $)$ versus resting $\mathrm{T}_{\mathrm{M}}$ cells, with the vast majority $(1,454$, i.e., $~ 79 \%)$ driven by $\mathrm{Ag}$ stimulation only and a smaller proportion triggered by inflammatory signals only (227, i.e., $\sim 12 \%$ ) (Figure 1C and Table S1). Only 156 genes (i.e., 9\%) among the differentially expressed genes, were common between Ag- and inflammation-activated $\mathrm{CD}^{+} \mathrm{T}_{\mathrm{M}}$ cells. While $\mathrm{Ag}$ stimulation induced similar numbers of up- and down-regulated genes, respectively 703 and 751, inflammation favored the expression of a higher proportion of downregulated genes (152 vs 75 genes) including genes involved in cell adhesion and migration (Cd44, Cd27, Itgax, S1pr5 ; Figure 1D, Table S1). Commonly genes were similarly distributed between up and downregulation. Further analysis of the genes differentially expressed in Ag- versus inflammation-stimulated $\mathrm{CD}^{+} \mathrm{T}_{\mathrm{M}}$ cells using biological process gene-ontology (BP-GO) pathway analysis, revealed that cognate Ag, but not inflammation, promoted a wide range of biological functions related to TCR signaling, leukocyte differentiation, apoptosis and cytokine 
expression (Figure 1E and Table S2). To achieve deeper understanding into the molecular mechanisms by which Ag stimulation modulates the early programming of $\mathrm{CD}^{+} \mathrm{T}_{\mathrm{M}}$ cells, we plotted the fold change over respective adjusted p-values of all differentially expressed genes (Figure 1F). The most expressed genes in Ag-activated $\mathrm{CD}^{+} \mathrm{T}_{\mathrm{M}}$ cells encoded for chemokines and cytokines (Ccl4, Ccl3, Xcll and Tnfa), important transcriptional regulators (Nr4a3, Nr4al, Nfat5, Zbtb32 and Irf4) and proteins involved in proliferation/survival (Tnfsf14 and Map2k3) and cell cycle (Erg2). Of note, expression of genes encoding adhesion molecules were largely downregulated (Itgb6, Itgb3 and Cdh1) (Figure 1F). In summary, cognate Ag stimulation endows $\mathrm{CD}^{+} \mathrm{T}_{\mathrm{M}}$ cells with a robust early multifunctional gene expression program, among which the most significantly upregulated genes encode for chemokines and a specific set of transcription factors.

\section{Memory $\mathrm{CD8}^{+} \mathrm{T}$ cells produce an early and coordinated burst of chemokines upon cognate antigen recognition}

To validate chemokine-encoding gene upregulation in cognate Ag-stimulated $\mathrm{CD}^{+} \mathrm{T}_{\mathrm{M}}$ cells (Figure 1F), we monitored CCL3, CCL4 and XCL1 chemokine accumulation in Ag (OT-I) versus inflammation (gBT-I) triggered $\mathrm{T}_{\mathrm{M}}$ cells from mice primary immunized with $L m$-Ova-gB, and challenged 6 weeks later with Lm-Ova for 8, 16, 32 and 72 hrs (Figure 2). As early as $\sim 4$ hrs post challenge infection, OT-I, but not gBT-I $\mathrm{T}_{\mathrm{M}}$ cells, accumulated detectable levels of the 3 chemokines, peaking between 12 and 16 hrs post-infection with 30-40\% chemokine ${ }^{+}$OT-I $\mathrm{T}_{\mathrm{M}}$ cells (Figure 2A). As expected (Berg et al., 2003; Kupz et al., 2012; Raue et al., 2013; Soudja et al., 2012), both $\mathrm{T}_{\mathrm{M}}$ cells expressed IFN $\gamma$ independent of cognate Ag stimulation.Substantial levels of chemokines (CCL3) and IFN $\gamma$ could be measured in short-term culture supernatants of splenocytes (without brefeldin A) isolated from $8 \mathrm{hrs} \mathrm{Lm-Ova-challenged} \mathrm{versus} \mathrm{unchallenged}$ mice, indicative of their active secretion (Figure S1A). By 32 hrs, chemokine secretion was terminated, and OT-I $\mathrm{T}_{\mathrm{M}}$ cells underwent robust clonal expansion (Figure 2B). To further define which subset of $\mathrm{CD}^{+} \mathrm{T}_{\mathrm{M}}$ cells (Gerlach et al., 2016) among central (CX3CR1 ${ }^{\text {low }} \mathrm{CD} 27^{\mathrm{hi}}, \mathrm{T}_{\mathrm{CM}}$ ), peripheral $\left(\mathrm{CX} 3 \mathrm{CR} 1^{\mathrm{int}} \mathrm{CD} 27^{\mathrm{hi}}, \mathrm{T}_{\mathrm{PM}}\right)$ or effector $\left(\mathrm{CX} 3 \mathrm{CR} 1{ }^{\text {hi }} \mathrm{CD} 27^{\text {low }}, \mathrm{T}_{\mathrm{EM}}\right) \mathrm{CD}^{+} \mathrm{T}_{\mathrm{M}}$ cells produced chemokines and IFN $\gamma$, we flow-sorted these populations and incubated them with their cognate $\mathrm{Ag}$ in vitro (Figure $2 \mathrm{C}$ and $\mathrm{S} 1 \mathrm{~B}$ ). While both OT-I $\mathrm{T}_{\mathrm{CM}}$ and $\mathrm{T}_{\mathrm{PM}}$ accumulated significantly more chemokines and $\mathrm{IFN} \gamma$ than $\mathrm{T}_{\mathrm{EM}}$ counterparts, they could nevertheless all 
produce them. To next validate results in endogenous non-TCR transgenic CD8 ${ }^{+} \mathrm{T}_{\mathrm{M}}$ cells and naturally presented epitopes, we immunized WT B6 mice $\left(\mathrm{H} 2^{\mathrm{b}}\right)$ that also express the $\mathrm{K}^{\mathrm{d}}$ molecule $\left(\mathrm{B} 6-\mathrm{K}^{\mathrm{d}}\right)$ with $L m-\mathrm{gB}$, allowing for the tracking of both $L m$-derived $\mathrm{LLO}_{91-99} / \mathrm{K}^{\mathrm{d}}$ and p60 $217-225 / \mathrm{K}^{\mathrm{d}}$ as well as HSV-2-derived $\mathrm{gB}_{497-505} / \mathrm{K}^{\mathrm{d}}$ specific $\mathrm{CD}^{+} \mathrm{T}_{\mathrm{M}}$ cells, using the corresponding tetramers (Tet) (Figure 2D). Six weeks post vaccination, mice were challenged with either $L m-g B$ or $L m-L_{L} \mathrm{O}_{S e r 92}$ that lacks the $L_{L O} \mathrm{O}_{91-99}$ epitope, and we monitored endogenous tetramer-specific $\mathrm{CD}^{+} \mathrm{T}_{\mathrm{M}}$ cell production of chemokines in the presence or the absence of their respective cognate Ags. After $L m$-gB challenge, e.g., when all $\mathrm{T}_{\mathrm{M}}$ cell cognate Ags were present, $\mathrm{gB}_{498-505} / \mathrm{K}^{\mathrm{b}}$, p60 ${ }_{217-225} / \mathrm{K}^{\mathrm{d}}$ and $\mathrm{LLO}_{91-99} / \mathrm{K}^{\mathrm{d}}$ tet $^{+} \mathrm{CD}{ }^{+} \mathrm{T}_{\mathrm{M}}$ cells expressed

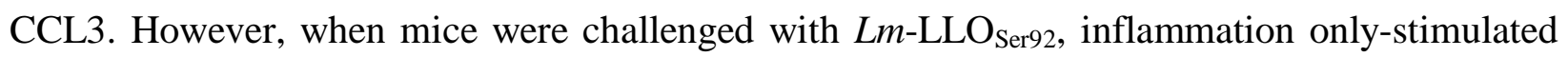
$\mathrm{LLO}_{91-99} / \mathrm{K}^{\mathrm{d}}$ - and $\mathrm{gB}_{498-505} / \mathrm{K}^{\mathrm{b}}$-specific $\mathrm{CD}^{+} \mathrm{T}_{\mathrm{M}}$ cells expressed IFN $\gamma$ but no chemokines while Ag-triggered $\mathrm{p} 60_{217-225} / \mathrm{K}^{\mathrm{d}}$-specific $\mathrm{CD}^{+} \mathrm{T}_{\mathrm{M}}$ cells accumulated both CCL3 and IFN $\gamma$. We next extended findings to $\mathrm{CD}^{+} \mathrm{T}_{\mathrm{M}}$ cells induced with a different vaccination model, by immunizing mice grafted with OT-I cells with Ova-expressing vesicular stomatitis virus (VSV-Ova), challenged them six weeks later with either $L m$-Ova or $L m$, and quantified chemokine and IFN $\gamma$ production (Figure 2E). Likewise upon immunization with $L m, \mathrm{CD}^{+} \mathrm{T}_{\mathrm{M}}$ cells induced after $V S V$ vaccination also induced a rapid and coordinated burst of Ag-dependent chemokines and Agindependent IFN $\gamma$ accumulation, peaking at 16 hrs post-challenge infection, with $40-60 \%$ of chemokine/IFN $\gamma^{+}$OT-I T $\mathrm{T}_{\mathrm{M}}$ cells. Thus, altogether these data establish that across distinct mouse models of immunization (bacteria, virus) and multiple $\mathrm{CD}^{+} \mathrm{T}$ cell epitopes, cognate $\mathrm{Ag}$ recognition triggers a rapid and early coordinated burst of chemokine production by $\mathrm{CD}^{+} \mathrm{T}_{\mathrm{M}}$ cells.

\section{IRF4 exerts transcriptional control over chemokine production by memory $\mathrm{CD8}^{+} \mathbf{T}$ cells}

Cognate Ag stimulation induces upregulation of CCL3, CCL4 and XCL1 chemokineencoding genes in $\mathrm{CD}^{+} \mathrm{T}_{\mathrm{M}}$ cells and their subsequent secretion, suggesting a common transcriptional mechanism of regulation. Our transcriptomic analysis revealed several genes involved in the regulation of transcription, such as the transcription factor IRF4, that are upregulated upon cognate Ag recognition. Since IRF4 expression in $\mathrm{T}$ cells is directly proportional to the strength of TCR signals (Man et al., 2013; Yao et al., 2013), we expected that, if indeed IRF4 controlled chemokine expression, lowering TCR signaling should lead to a 
proportional and concomitant loss of IRF4 and chemokine expression by $\mathrm{CD}^{+} \mathrm{T}_{\mathrm{M}}$ cells. To test this possibility, we used $L m$ expressing three different Ova $257-264$ (SIINFEKL) altered peptide ligands (APLs) in which the original asparagine amino acid in position 4 of the peptide (N4) is replaced by either a glutamine (Q4), a threonine (T4) or a valine (V4), decreasing OT-I TCR signaling by factors of $\sim 20,70$ and 700 times, respectively (Zehn et al., 2009). Mice grafted with OT-I and gBT-I cells were immunized with $L m$-Ova-gB, and 6 weeks later, either left unchallenged or challenged with $L m$ expressing each Ova APL or control Lm-Ova (N4). We next monitored the secretion of chemokines and IFN $\gamma 16$ hrs later (Figure 3A). Decreasing OT-I TCR signaling led to a proportional loss of chemokine-producing T cells (CCL3, CCL4 and XCL1), which also directly correlated with the loss of IRF4 expression (Figure 3B). As expected, inflammation-stimulated gBT-I $\mathrm{T}_{\mathrm{M}}$ cells neither produced chemokines nor expressed IRF4, while IFN $\gamma$ production remained comparable across all challenge conditions, in both cognate Ag (OTI) and inflammation (gBT-I) triggered $\mathrm{CD}^{+} \mathrm{T}_{\mathrm{M}}$ cells. To ensure that IRF4 up-regulation during endogenous pathogen-specific polyclonal $\mathrm{CD}^{+} \mathrm{T}_{\mathrm{M}}$ cell response, was comparable to that of OTI TCR transgenic $\mathrm{T}$ cells, we next used the same immunization/challenge approach as in Figure 2C. Here, $\mathrm{gB}_{498-505} / \mathrm{K}^{\mathrm{b}}, \mathrm{p} 60_{217-225} / \mathrm{K}^{\mathrm{d}}$ and $\mathrm{LLO}_{91-99} / \mathrm{K}^{\mathrm{d}}$ tet ${ }^{+} \mathrm{CD} 8^{+} \mathrm{T}_{\mathrm{M}}$ cells underwent the most robust upregulation of IRF4 expression during challenge infection in presence their respective cognate Ag (Figure 3C). These results collectively indicate a direct correlation between the strength of TCR signaling and the proportion of chemokine-producing $\mathrm{CD}^{+} \mathrm{T}_{\mathrm{M}}$ cells. Furthermore, in vitro "challenge" of OT-I $\mathrm{T}_{\mathrm{M}}$ cells isolated from Lm-Ova-immunized mice with the SIINFKEL epitope in the presence or absence of broad inhibitors of either translation (cycloheximide) or transcription (Actinomycin D), suggested that most of the CCL3 in Agstimulated $\mathrm{T}_{\mathrm{M}}$ cells was being rapidly transcribed $(>60 \%)$ (Figure 3D) while only a smaller proportion was stored as mRNA $(\sim 30 \%)$ but none as protein, a result also consistent with recent reports (Davenport et al., 2020; Eberlein et al., 2020). Taken together, these data support the hypothesis that IRF4 acts as a transcriptional regulator of chemokine expression downstream of TCR signaling.

To establish whether IRF4 controls CCL3, CCL4 and XCL1 chemokine expression in CD8 ${ }^{+}$ $\mathrm{T}_{\mathrm{M}}$ cells, we blocked IRF4 in OT-I $\mathrm{T}_{\mathrm{M}}$ cells, and quantified their production of chemokines. Through in vitro SIINFKEL peptide challenge of OT-I $\mathrm{T}_{\mathrm{M}}$ cells isolated from Lm-Ovaimmunized mice with the chemical inhibitor SCG-CBP30, which selectively inhibits 
bromodomain-containing transcription factors like IRF4 (Figure 3E), we found that IRF4 expression in OT-I $\mathrm{T}_{\mathrm{M}}$ cells was prevented, and the proportion of chemokine ${ }^{+}$cells was significantly decreased (by $\sim 80 \%$ ) compared to incubation with peptide-only. To confirm and

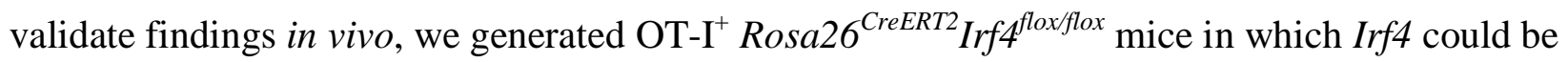

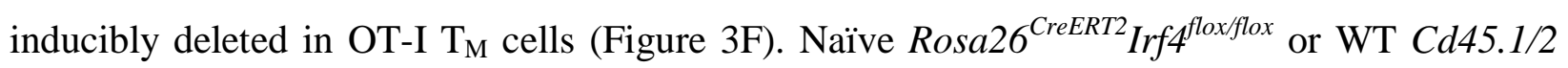
OT-I cells were co-transferred to WT Cd45.1 ${ }^{+/+}$recipient mice then immunized with Lm-Ova, and 6 weeks later, mice either received tamoxifen (Tx) or vehicle for 5 days before Lm-Ova recall infection. In Tx-treated groups, the proportion of Rosa $26^{\text {CreERT2 Irff floxflox }}$ OT-I T ${ }_{\mathrm{M}}$ cells secreting chemokines (CCL3), was significantly decreased compared to that of WT counterparts (by $\sim 45 \%$ ), yet both of these genotypes secreted comparable amounts of CCL3 in mock-treated mice. Expression levels of IRF4 was also diminished in Tx- but not mock-treated Rosa $26^{\text {CreERT2 } I r f 4^{\text {floxflox }} \text { OT-I T }} \mathrm{T}_{\mathrm{M}}$ cells, further validating this result (Figure 3G). In conclusion, our data demonstrate that IRF4 is a master transcriptional regulator of the coordinated and simultaneous burst of CCL3, CCL4 and XCL1 chemokines produced by Ag-activated CD8 ${ }^{+} \mathrm{T}_{\mathrm{M}}$ cells in vitro and in vivo.

\section{Monocyte clustering occurs independent from cognate antigen or IFN $\gamma$-signaling}

We previously showed that $\mathrm{CD}^{+} \mathrm{T}_{\mathrm{M}}$ cell-mediated control of $\mathrm{Lm}$ growth during recall infection occurs within only few hours ( $~ 6-8 \mathrm{hrs})$ and correlates with their rapid localization with clustered $\mathrm{Ly}_{6} \mathrm{C}^{+} / \mathrm{CCR} 2^{+}$monocytes and neutrophils in the splenic red pulp (RP) of infected mice, at portal of bacterial entry (Bajenoff et al., 2010; Narni-Mancinelli et al., 2011; Soudja et al., 2014). Thus, we hypothesized that $\mathrm{CD}^{+} \mathrm{T}_{\mathrm{M}}$ cell-derived chemokines produced in response to cognate $\mathrm{Ag}$ recognition, orchestrate monocyte homing and clustering to rapidly prevent pathogen spreading and help deliver local IFN $\gamma$. To gain deeper understanding of this process, we first monitored the kinetic of $\mathrm{Ly} \mathrm{C}^{+}$monocyte clustering in the $\mathrm{RP}$ of $L m$-vaccinated mice undergoing a recall infection (Figure $\mathrm{S} 2 \mathrm{~A}$ ). $C c r 2^{\mathrm{CFP}}$ mice, in which all CCR2 ${ }^{+} \mathrm{Ly}_{6 \mathrm{C}^{+}}$monocytes express the CFP reporter protein, were grafted with OT-I cells and immunized with Lm-Ova. Six weeks later, mice were left unchallenged or challenged with $L m$-Ova and spleens harvested 3, 6, 16 and $40 \mathrm{hrs}$ later for whole organ tile reconstruction using multi-photon laser scanning microscopy that only enables to visualize splenic RP (Figure S2A). Already by 3 hrs postchallenge infection, few clusters of $\mathrm{CCR}^{+}$monocytes were detected, with their proportion 
increasing from $6 \mathrm{hrs}$ to their peak at $16 \mathrm{hrs}$, and with clusters still present by $40 \mathrm{hrs}$. Of note, peak clustering of monocytes at $16 \mathrm{hrs}$ correlated with that of chemokines produced by the $\mathrm{T}_{\mathrm{M}}$ cells (Figures S2A and 2A). Unexpectedly, however, unimmunized mice challenged with LmOva, which do not control the infection compared to immunized counterpart (Figure S2B), still developed comparable numbers and volume of $\mathrm{CCR} 2^{+}$monocyte clusters $16 \mathrm{hrs}$ post-infection (Figure 4A). This result indicated that the presence of immunization-induced memory cells is not essential for monocyte homing and clustering to occur, though they may still alter monocyte functions. To better investigate the role of $\mathrm{CD}^{+} \mathrm{T}_{\mathrm{M}}$ cells and cognate $\mathrm{Ag}$ in monocyte cluster formation, we adoptively transferred OT-I $\mathrm{T}_{\mathrm{M}}$ cells in $C c r 2^{\mathrm{CFP}}$ WT mice subsequently challenged with Lm or Lm-Ova, and monitored monocyte clustering in spleen RP (Figure 4B). For this, we took advantage of a heterologous prime/boost immunization strategy of mice grafted with OT-I cells, primed with VSV-Ova, and challenged with Lm-Ova to generate sufficiently high numbers of OT-I $\mathrm{T}_{\mathrm{M}}$ cells for purification and transfer. Whether cognate Ag was present or not, the proportion and volume of monocyte clusters at the peak (16 hr) remained comparable, a result that we also confirmed in WT $C c r 2^{\mathrm{CFP}}$ mice grafted with OT-I cells, immunized with VSV-Ova and challenged with either $L m$ or $L m$-Ova 6 weeks later (Figure S3A). Lastly, since IFN $\gamma$ signaling is an essential contributor to vaccinated host protective responses (Soudja et al., 2014), we tested if it may direct monocyte clustering. For this, we adoptively transferred OT-I $\mathrm{T}_{\mathrm{M}}$ cell in Ifngr $^{-/}$mice that we next challenged with $\mathrm{Lm}$ or $\mathrm{Lm}$-Ova (Figure 4C). Since monocytes in Ifngr ${ }^{-/-}$mice did not express CFP, we tracked them using intravenous injection of anti-Ly6C-PE $\mathrm{mAb} 16$ hrs prior to imaging, which co-labels all detectable clustered $\mathrm{CFP}^{+}$monocytes (Figure $\mathrm{S} 3 \mathrm{~B}$ ). As before, whether cognate $\mathrm{Ag}$ (Ova) and IFN $\gamma$ signaling were present or not, the proportion and volume of monocyte clusters at $16 \mathrm{hrs}$ were also comparable. Hence, taken together, these data establish that monocyte homing and clustering occurs largely independent of the presence of $\mathrm{Ag}$-specific $\mathrm{CD} 8^{+} \mathrm{T}_{\mathrm{M}}$ cells and IFN $\gamma$ signaling.

\section{Cognate antigen on dendritic cells but not monocytes, control $\mathrm{CD8}^{+} \mathrm{T}_{\mathrm{M}}$ cell-production of chemokines and arrest in monocyte clusters}

While monocyte homing and clustering still occurred in unimmunized mice, these clusters could nevertheless be necessary to mount a protective recall response in immunized mice. Thus we pursued the hypothesis that monocyte clustering is functionally important, and may act as 
local "hubs" in which $\mathrm{CD}^{+} \mathrm{T}_{\mathrm{M}}$ cells arrest and deliver IFN $\gamma$ and other effector molecules to them, as well as to other innate immune cells recruited to these clusters -i.e., neutrophils, NK cells (Bajenoff et al., 2010; Soudja et al., 2014). We used intravital imaging microscopy (IVM) of spleen RP in $C c r 2^{\mathrm{CFP}}$ living mice undergoing a recall infection (Figure 5A and Movies S1, S2, S3). Mice transferred with OT-I $\left(\mathrm{Td}^{+}\right)$and $\mathrm{gBT}-\mathrm{I}\left(\mathrm{GFP}^{+}\right)$cells, were immunized with Lm-Ova-gB and challenged 6 weeks later with either Lm-Ova, Lm or Lm-Ova-gB. In Lm-Ova-challenged mice, in which only OT-I $\mathrm{T}_{\mathrm{M}}$ cells recognize their cognate $\mathrm{Ag}$, most OT-I $\mathrm{T}_{\mathrm{M}}$ cells localized in the cluster of monocytes $\left(\mathrm{CFP}^{+}\right)$and arrested, or only exhibited very limited motility (Track velocity $1.93 \mu \mathrm{m} / \mathrm{min}$ ) (Figures 5A, Movie S1 and Figure S4A). In contrast, gBT-I T $\mathrm{M}_{\mathrm{M}}$ cells were more motile (track velocity $4.01 \mu \mathrm{m} / \mathrm{min}$ ), yet were enriched in the monocyte clusters similarly to OT-I cell counterparts (Figure S4B). Both $\mathrm{T}_{\mathrm{M}}$ cells speed also decreased inside compared to outside monocyte clusters, collectively suggesting that non-cognate Ag signals impact their homing to and motility in the clusters (Figure 5A). As expected, in Lm-Ova-gB-challenged mice, where both $\mathrm{T}_{\mathrm{M}}$ cells recognize their cognate Ag, OT-I and gBT-I $\mathrm{T}_{\mathrm{M}}$ cells arrested in the clusters while simultaneously exhibiting higher motility outside of clusters (Movie S2 and Figure S4B). Moreover, in $\mathrm{Lm}$-challenged mice in which no cognate $\mathrm{Ag}$ was present, both $\mathrm{T}_{\mathrm{M}}$ cells exhibited the same pattern of enriched localization inside versus outside the clusters, and comparable speeds (Movie S3 and Figure S4A, B). Thus, cognate-Ag signals induce Ag-specific $\mathrm{T}_{\mathrm{M}}$ cell arrest in $\mathrm{Ly} 6 \mathrm{C} / \mathrm{CCR} 2^{+}$monocyte clusters where IFN $\gamma$ is detected in $\mathrm{T}_{\mathrm{M}}$ cells (Bajenoff et al., 2010; Soudja et al., 2014), indicating that a potential functional interaction between $\mathrm{T}_{\mathrm{M}}$ cells and monocytes is occurring in these clusters. In addition, the fact that even non-cognate Ag-specific $\mathrm{T}_{\mathrm{M}}$ cell speed was reduced inside compared to outside of clusters, suggested that the clusters were conductive of a qualitatively distinct, possibly hypoxic, local microenvironment (Waite et al., 2011).

Since $\mathrm{T}_{\mathrm{M}}$ cells arrest in monocyte clusters in the presence of cognate Ag, and $\mathrm{T}$ cells arrest in response to Ag recognition (Bousso and Robey, 2003; Mempel et al., 2004; Stoll et al., 2002), we postulated that monocytes may present Ag to them. To test this possibility, we generated mixed bone-marrow $(\mathrm{BM})$ chimera mice in which selective elimination of $\mathrm{K}^{\mathrm{d}}$-dependent cognate $\mathrm{Ag}$ presentation by $\mathrm{Ly}_{6 \mathrm{C}}{ }^{+}$monocytes can be achieved. Here, lethally irradiated $\mathrm{K}^{\mathrm{d}}$-expressing B6 mice $\left(\mathrm{B} 6-\mathrm{K}^{\mathrm{d}}\right)$ were reconstituted with $C c r 2^{D T R} \mathrm{~K}^{\mathrm{d}} \mathrm{BM}$ and either i) B6-K $\mathrm{K}^{\mathrm{d}}\left(\mathrm{K}^{\mathrm{d}}\right)$ or ii) B6 (WT) BM (1:1 ratio), producing $C c r 2^{D T R} \mathrm{~K}^{\mathrm{d}} / \mathrm{WT}$ mice and $C c r 2^{D T R} \mathrm{~K}^{\mathrm{d}} / \mathrm{K}^{\mathrm{d}}$ chimeras. In these 
mice, diphtheria toxin (DT) injection eliminates $\mathrm{CCR} 2^{+} \mathrm{K}^{\mathrm{d}}$ monocytes while DTR ${ }^{\text {neg }}\left(\mathrm{K}^{\mathrm{d}}\right.$ or WT) $\mathrm{CCR}^{+}$monocytes remain, respectively (Figure S3C). Chimeras were immunized with $L m-\mathrm{gB}$ and treated with DT prior to $L m$-gB challenge infection, and we monitored both $\mathrm{LLO}_{91-99} / \mathrm{K}^{\mathrm{d}}$ and $\mathrm{gB}_{498-505} / \mathrm{K}^{\mathrm{b}} \mathrm{Tet}^{+} \mathrm{CD}^{+} \mathrm{T}_{\mathrm{M}}$ cells for Ag-dependent chemokine (CCL3) and Ag-independent IFN $\gamma$ production (Figure 5B). The proportion of Ag-stimulated $\left(\mathrm{CCL3}^{+}\right) \mathrm{LLO}_{91-99} / \mathrm{K}^{\mathrm{d}}$ tet $^{+} \mathrm{CD}^{+} \mathrm{T}_{\mathrm{M}}$ cells was the same whether CCR2 ${ }^{+}$monocytes could present the $\mathrm{LLO}_{91-99} / \mathrm{K}^{\mathrm{d}} \mathrm{Ag}$ (in DT-treated $C c r 2^{D T R} \mathrm{~K}^{\mathrm{d}} / \mathrm{K}^{\mathrm{d}}$ chimeras) or not (in DT-treated $C c r 2^{D T R} \mathrm{~K}^{\mathrm{d}} / \mathrm{WT}$ chimeras). Yet, the frequency of IFN $\gamma^{+}$cells was equivalent, confirming that $\mathrm{LLO}_{91-99} / \mathrm{K}^{\mathrm{d}}$ tet $^{+} \mathrm{CD}^{+} \mathrm{T}_{\mathrm{M}}$ cells underwent comparable Ag-independent activation in all groups. No differences in the proportion of CCL3 ${ }^{+}$ and of IFN $\gamma^{+} \mathrm{gB}_{498-505} / \mathrm{K}^{\mathrm{b}}$ tet $^{+} \mathrm{CD}^{+} \mathrm{T}_{\mathrm{M}}$ cells were measured between the various experimental conditions, ruling out a possible impact of DT-induced deletion on $\mathrm{T}_{\mathrm{M}}$ cell activation. Thus, Ag presentation by splenic CCR2 ${ }^{+} / \mathrm{Ly} 6 \mathrm{C}^{+}$monocytes is not required for $\mathrm{Ag}$-dependent $\mathrm{CD}^{+} \mathrm{T}_{\mathrm{M}}$ cell-activation during recall infection.

Dendritic cells (DCs) quickly uptake Lm (Edelson et al., 2011; Neuenhahn et al., 2006) and contribute to $\mathrm{CD}^{+} \mathrm{T}_{\mathrm{M}}$ cell-reactivation (Zammit et al., 2005). Using $\mathrm{K}^{\mathrm{d}} / \mathrm{WT}$ and $C d 11 c^{D T R}$ $\mathrm{K}^{\mathrm{d}} / \mathrm{WT}$ chimera mice, in which DT injection eliminates $\mathrm{CD} 11 \mathrm{c}^{+} \mathrm{K}^{\mathrm{d}}$ DCs while $\mathrm{DTR}^{\text {neg }}$ (WT or $\mathrm{K}^{\mathrm{d}}$ ) CD11 $\mathrm{c}^{+}$DCs remain (Figure S3D), we tested whether CD11c ${ }^{+}$DC presented cognate Ag to $\mathrm{T}_{\mathrm{M}}$ cells after immunization/challenge with Lm-Ova (Figure 5C). A significant decrease ( 40\%) in $\mathrm{CCL}^{+} \mathrm{CD}^{+} \mathrm{T}_{\mathrm{M}}$ cells was only measured for $\mathrm{LLO}_{91-99} / \mathrm{K}^{\mathrm{d}}$ but not $\mathrm{Ova}_{257-264} / \mathrm{K}^{\mathrm{b}}$ tet ${ }^{+} \mathrm{CD}^{+} \mathrm{T}_{\mathrm{M}}$ cells, while the proportion of IFN $\gamma^{+}$cells remained equivalent between the different groups of chimeras. Thus, taken together, these data indicate that splenic CD11 ${ }^{+}$DCs but not CCR2 ${ }^{+}$ monocytes, selectively present cognate $\mathrm{Ag}$ to $\mathrm{CD}^{+} \mathrm{T}_{\mathrm{M}}$ cells.

\section{Cognate Ag stimulation of $\mathrm{CD8}^{+} \mathrm{T}_{\mathrm{M}}$ cells potentiates monocyte effector functions in the clusters}

Cognate $\mathrm{Ag}$ enables $\mathrm{CD}^{+} \mathrm{T}_{\mathrm{M}}$ cell arrest in monocyte clusters and their concomitant production of a chemokine burst. If, as hypothesized, $\mathrm{CD}^{+} \mathrm{T}_{\mathrm{M}}$ cell arrest in these clusters is functionally important for local delivery of chemokines and IFN $\gamma$, we predicted that in the presence of cognate Ag, these cells should produce more effector cytokines (Figure 6A). To test this model, we immunized mice transferred with OT-I $\mathrm{T}_{M}$ cells with VSV-Ova. Six weeks later, mice were challenged with either Lm-Ova or Lm, and we monitored TNF $\alpha$ and CXCL9 
production in monocytes and neutrophils. In the presence of cognate $\mathrm{Ag}$ recognition (Lm-Ova challenge), the proportion of monocytes and neutrophils producing TNF $\alpha$ and CXCL9 was significantly increased (factor of $\sim 3$ ) compared to mice challenged without cognate $\mathrm{Ag}(\mathrm{Lm})$. Interestingly, CCR5 and XCR1 expression on monocytes (but not on neutrophils) was significantly increased after the challenge infection, suggesting monocytes become more responsive to chemokine signaling during infection (Figure 6B). We next directly assessed if adding recombinant CCL4 or XCL1 chemokines, which respectively bind CCR5/CCR1 and $\mathrm{XCR} 1$, to monocytes and neutrophils isolated from secondary challenged mice, enhanced their production of TNFo ex vivo. After incubation with rCCL3, rCCL4 and rXCL1, monocytes from challenged mice accumulated intracellular TNF $\alpha$ in 15, 20 and $40 \%$ of total monocytes, respectively, and in a dose-dependent manner (Figure 6C and S5A, B). Incubation of naïve splenocytes with rCCL3 also induced a significant proportion of $\mathrm{TNF}^{+}$monocytes $(\sim 30 \%)$ compared to unstimulated counterparts, though this was substantially less than after heat-killed Lm (HKLm) stimulation, a known robust trigger of monocyte activation (Figure S5C). Neutrophils, however, largely failed to respond to chemokine restimulation ex vivo, in line with their low levels of cell-surface expression of chemokine receptors (10-15 times lower than monocytes), rather implicating a chemokine-independent mechanism for their activation (Figure S5D). Blocking CCR5 and CCR1 with chemical inhibitors during co-incubation with recombinant chemokines prevented TNF $\alpha$ production by monocytes, ruling out any CCR1/CCR5-independent activation mechanisms (Figures 6C and S5A). Incubation with HKLm induced $40-50 \%$ of them to express TNF $\alpha$, a proportion similar to that measured in monocytes incubated with rXCL1 or the combination of chemokines.

Since both cognate $\mathrm{Ag}$ and $\mathrm{CD}^{+} \mathrm{T}_{\mathrm{M}}$ cell-derived IFN $\gamma$ are required for optimal monocyte production of TNFo (Figure 6A, (Soudja et al., 2014)), we further hypothesized that IFN $\gamma$ signaling triggers chemokine receptor upregulation on monocytes, making them more responsive to the chemokines released upon cognate Ag stimulation (Figure 6D). We tested this idea by cotransferring WT and Ifngr ${ }^{-/} \mathrm{BM}$ into WT recipient mice immediately challenged with $\mathrm{Lm}$, and monitored CCR5 and XCR1 chemokine receptor expression 16 hrs later. While we could detect CCR5- and XCR1-expressing WT monocytes, Ifngrl ${ }^{-/}$monocytes failed to upregulate expression of these receptors, indicating that IFN $\gamma$ signaling likely modulates cell-surface expression of CCR5 and XCR1 on monocytes. Hence, these results collectively establish that the 
same chemokines produced by $\mathrm{Ag}$-stimulated $\mathrm{CD}^{+} \mathrm{T}_{\mathrm{M}}$ cells can directly signal to chemokine receptors expressed on monocytes, to further enhance their ability to produce TNF $\alpha$, a cytokine that is absolutely required for host protective memory responses against secondary $\mathrm{Lm}$ infection (Narni-Mancinelli et al., 2007; Neighbors et al., 2001).

We next formally asked whether $\mathrm{Ly} 6 \mathrm{C}^{+}$monocyte activation in vivo was spatially restricted to their clusters. For this, we sought to measure the activation of monocytes inside versus outside the clusters. Similar Lm-induced clusters of myeloid cells have been reported to exclude dextrans suggesting they were not diffusive (Waite et al., 2013). Therefore, we stained monocytes in vivo using anti-Ly6C-PE mAb injected $1 \mathrm{hr}$ prior to spleen harvest ( $1 \mathrm{hr}$ labelling), which we found labels all $\mathrm{Ly}_{6 \mathrm{C}^{+}}$splenocytes that are not within established clusters, in contrast to injecting antiLy6C-PE mAb at the time of challenge infection (16 hrs labelling), prior to cluster formation (Figures S6A and S3B). With the $1 \mathrm{hr}$ labelling approach, $>90 \%$ of Ly6C $\mathrm{C}^{+}$monocytes exhibited equivalent Ly6C-PE staining in unchallenged mice (no clusters), while $\sim 40 \%$ of them had lower Ly6C-PE staining in challenged mice, a proportion consistent with that of clustered monocytes in our microscopy quantifications (Figures S6B, 4A and S2A). With this approach, we could determine whether monocyte activation was dependent on localization within clusters during recall infection (Figure 6E and S6C). A significantly higher proportion of Ly6C-PE ${ }^{\text {low }}$ (clustered) compared to Ly6C-PE ${ }^{\text {hi }}$ (non-clustered) monocytes expressed higher levels of ICAM-1, CD86 and intracellular CXCL9 and TNF $\alpha$, demonstrating that monocytes undergo robust activation within the clusters, and consistent with local delivery of activating chemokines and IFN $\gamma$ by $\mathrm{CD}^{+} \mathrm{T}_{\mathrm{M}}$ cells.

\section{Cognate antigen stimulation and IFN $\gamma$ signaling are both required for memory $\mathrm{CD8}^{+} \mathrm{T}^{\mathrm{T}}$ cell-dependent protection of immunized mice}

Since both cognate $\mathrm{Ag}$ stimulation and IFN $\gamma$-signaling are required for $\mathrm{CD}^{+} \mathrm{T}_{\mathrm{M}}$ celldependent protection of immunized hosts against challenge infection, we next assessed the relative contribution of both mechanisms. We adoptively transferred OT-I $\mathrm{T}_{\mathrm{M}}$ cells to naïve WT or Ifngr $1^{-/}$mice that were further challenged with a lethal dose of $\mathrm{Lm}$ (no cognate Ag) or $\mathrm{Lm}$ Ova (with cognate Ag)(Figure 7A). Control groups did not receive any OT-I T $\mathrm{T}_{\mathrm{M}}$ cells. Bacterial titers in spleens and livers were next quantified $24 \mathrm{hrs}$ later. While as expected, transfer of OT-I $\mathrm{T}_{\mathrm{M}}$ cells confer significant levels of protection to WT recipient mice against Lm-Ova challenge 
(considered $100 \%$ ), protection was reduced to $\sim 40 \%$ in both organs when challenged with $\mathrm{Lm}$ (no cognate Ag). These findings were also recapitulated in WT mice primary immunized with VSV-Ova, and challenged 6 weeks later with either Lm or Lm-Ova (Figure S5A). Interestingly, however, OT-I $\mathrm{T}_{\mathrm{M}}$ cell-transfer in Ifngr $^{-/}$mice only conferred modest protection against challenge with $L m$ or $L m$-Ova, with over $60 \%$ protection loss compared to WT mice. Yet, in $L m$ Ova (but not $L m$ ) challenged Ifngrl ${ }^{-/}$mice, OT-I $\mathrm{T}_{\mathrm{M}}$ cells still efficiently recognized their cognate Ag and produced chemokines (Figure S7B). Consistent with these results, monocyte and neutrophil production of TNF $\alpha$ and CXCL9 effector cytokine/chemokine in WT or Ifngrl ${ }^{-/}$mice that received OT-I $\mathrm{T}_{\mathrm{M}}$ cells was significantly reduced when cognate $\mathrm{Ag}$ was absent $(\mathrm{Lm}$ challenge) or IFN $\gamma$-signaling (Ifngr ${ }^{-/}$) was disrupted (Figure 7B). Taken together, these results indicate that cognate $\mathrm{Ag}$ stimulation and IFN $\gamma$-signaling are both required to achieve optimal protection and that neither of these signals are individually sufficient. 


\section{Discussion}

This study provides an in depth cellular and molecular analysis of how cognate Ag orchestrates the activation of memory $\mathrm{CD}^{+} \mathrm{T}$ cells for rapid protection against a recall infection in vaccinated hosts in vivo. We reveal that cognate $\mathrm{Ag}$ recognition by $\mathrm{CD}^{+} \mathrm{T}_{\mathrm{M}}$ cells, which occurs selectively on CD11 $\mathrm{c}^{\text {hi }}$ DCs, leads to a much broader gene expression program than inflammation/cytokine-only stimulated counterparts, with multiple pathways affected within only few hours post-stimulation. We also found that IRF4, downstream and proportional to TCR signaling strength, transcriptionally controls the most significantly upregulated cluster of genes in $\mathrm{CD}^{+} \mathrm{T}_{\mathrm{M}}$ cells that encode for the chemotactic molecules CCL3, CCL4 and XCL1. CD8 ${ }^{+} \mathrm{T}_{\mathrm{M}}$ cell-derived chemokines together with IFN $\gamma$ then act synergistically to potentiate $\mathrm{Ly}_{6} \mathrm{C}^{+}$ monocyte antimicrobial effector functions and host protection. This result underlines that chemokines can act as key effector molecules priming innate immune cells, a role distinct from their usual cellular recruitment. Lastly, we demonstrate that this process is spatially restricted to non-diffusive splenic red pulp clusters of $\mathrm{Ly}_{6 \mathrm{C}^{+}}$monocytes, in which $\mathrm{CD}^{+} \mathrm{T}_{\mathrm{M}}$ cells arrest upon cognate Ag recognition, to locally deliver activating chemokines and IFN $\gamma$ to the clustered monocytes, efficiently restraining microbial pathogen spreading and growth.

The current results highlight the importance of rapid microbial pathogen containment, a notion that has been elegantly illustrated in prior reports (Kastenmuller et al., 2013; Sung et al., 2012). First line cellular responders such as splenic marginal zone and LN subcapsular macrophages were reported to rapidly uptake and/or sense microbial pathogens (bacteria, viruses), to subsequently provide chemotactic cues that attract prepositioned memory -but not naïve- $\mathrm{CD}^{+} \mathrm{T}$ cells rapidly to the sites of infection. Consistent with these results, intravenously inoculated $\mathrm{Lm}$ bacteria are rapidly cleared from the blood by marginal zone CD169 ${ }^{+}$ macrophages and DCs localized in the splenic RP (Bajenoff et al., 2010; Edelson et al., 2011; Muraille et al., 2005; Neuenhahn et al., 2006; Perez et al., 2017). Following rapid pathogen capture by tissue-resident sentinel cells, a body of evidence suggests that $\mathrm{CD} 8^{+} \mathrm{T}_{\mathrm{M}}$ cells home to infectious foci via CXCR3 and/or CCR5 and associated CXCL10, CXCL9 and CCL5 chemokines produced in response to local inflammatory cues such as interferons (Kohlmeier et al., 2010; Kohlmeier et al., 2011; Slutter et al., 2013). A large majority of $\mathrm{CD}^{+} \mathrm{T}_{\mathrm{M}}$ cells express CXCR3 and CCR5, thus can be readily mobilized for rapid migration, independent from cognate 
Ag encounter (Maurice et al., 2019). These cells can produce IFN $\gamma$ in response to cytokines (Kupz et al., 2012; Raue et al., 2013; Soudja et al., 2012), further increasing local chemokine levels in a feedforward positive loop of rapid amplification of the $\mathrm{CD}^{+} \mathrm{T}_{\mathrm{M}}$ cell response. We report in the current study, that cognate Ag recognition promotes a broad activation program in $\mathrm{CD}^{+} \mathrm{T}_{\mathrm{M}}$ cells, which includes the early expression of a potent set of chemokines. This finding led us to propose that cognate Ag-triggered $\mathrm{CD} 8^{+} \mathrm{T}_{\mathrm{M}}$ cells would amplify the initial chemotactic cues, and act as powerful recruiting orchestrators of both adaptive and innate immune cells, setting the stage for more effective microbial pathogen clearance. Yet and unexpectedly, our results did not support such a model. Rather, we revealed that $\mathrm{Ly}_{6 \mathrm{C}}{ }^{+} / \mathrm{CCR} 2^{+}$monocytes form clusters in the splenic RP independently from cognate $\mathrm{Ag}$ and $\mathrm{CD}^{+} \mathrm{T}_{\mathrm{M}}$ cells, most likely in response to other infection-driven cues. Adhesion molecules such as ICAM-1, CD11b and CD44, and perhaps not chemotaxis, could be mediating $\mathrm{Ly}_{6} \mathrm{C}^{+}$monocyte trafficking to sites of infection as it was shown in the liver of primary Lm-infected mice (Shi et al., 2010). Consistent with this idea, we also noted a strong upregulation of ICAM-1 on clustered monocytes in spleen RP. Using IVM imaging, we further revealed that, as expected (Bousso and Robey, 2003; Mempel et al., 2004; Stoll et al., 2002), $\mathrm{CD}^{+} \mathrm{T}_{\mathrm{M}}$ cells arrest upon cognate Ag recognition, which occurs in monocyte clusters, where they promote their activation through the localized delivery of chemokines and IFN $\gamma$. This collectively supports a model where $\mathrm{CD}^{+} \mathrm{T}_{\mathrm{M}}$ cells only intervene as "late" activators of an already well-coordinated innate immune response, rather than as initial orchestrators of the early steps of that response.

In a previous study using IVM imaging to explore $L m$ infection foci that form in subcapsular DCs (scDCs) of the splenic RP following primary infection (day 5 post-infection), Lm-specific effector $\mathrm{CD}^{+} \mathrm{T}$ cells were shown to migrate to sites of infection where a mixture of myelomonocytic cells (MMC), that include $\mathrm{Ly} 6 \mathrm{C}^{+}$monocytes and neutrophils, accumulate (Waite et al., 2011). These MMCs drastically reduced blood flow access to the sites of infection and restricted $\mathrm{Lm}$ growth. $\mathrm{Lm}$-specific $\mathrm{CD}^{+} \mathrm{T}$ cells were also shown by IVM imaging to undergo both Ag-dependent arrest and Ag-independent reduced motility in the scDC/MMC Lmcontaining clusters, similarly to our observations. Yet, this study did not address the role that arrested effector $\mathrm{CD}^{+} \mathrm{T}$ cells may play in these clusters. Disappearance of $\mathrm{Lm}$ was associated with effector $\mathrm{CD}^{+} \mathrm{T}$ cells regaining motility, but evidence for direct $\mathrm{Lm}$-infected killing could not be documented. Together with the large dependence on MMC for Lm clearance, these data 
suggested that, like in the setting of the recall response, non-cytolytic T cell-dependent effector mechanisms were essential. In addition to promoting the local expression of microbicial activities in clustered monocytes, it seems therefore conceivable that the delivery of effector molecules by Ag-arrested $\mathrm{CD}^{+} \mathrm{T}_{\mathrm{M}}$ cells may also restrict permeability and blood flow in these clusters, to ultimately enhance rapid and effective $L m$ containment and killing.

Lm killing and vaccinated host protection during recall infection require $\mathrm{TNF} \alpha$, which Ly6C $^{+} / \mathrm{CCR} 2^{+}$monocytes are a major source (Nakane et al., 1989; Narni-Mancinelli et al., 2007; Neighbors et al., 2001). TNF $\alpha$ directly triggers microbicidal reactive oxygen species (ROS) both from monocytes and neutrophils and ROS promotes antimicrobial autophagy (Narni-Mancinelli et al., 2011). While we previously showed that IFN $\gamma$ signaling to $\mathrm{Ly}_{6} \mathrm{C}^{+}$monocytes directly induces TNF $\alpha$ production by these cells (Soudja et al., 2014), we now report that both IFN $\gamma$ signaling and cognate Ag stimulation, and thus chemokine delivery, need to act synergistically to achieve protection of immunized hosts. We also found that IFN $\gamma$ signaling contributes to chemokine receptor upregulation on monocytes, and robust upregulation of ICAM-1 on the monocytes that altogether may increase cell-cell communication and/or adhesion with $\mathrm{T}_{M}$ cells leading to the "sealing" of monocyte clusters for rapid and effective $L m$ clearance. While we did not monitor neutrophil dynamics here, neutrophils are well known to undergo massive recruitment and activation in infected spleens, and we and others have shown previously that they cluster with $\mathrm{Ly}_{6 \mathrm{C}^{+}}$monocytes and $\mathrm{CD}^{+} \mathrm{T}_{\mathrm{M}}$ cells at infection foci (Alexandre et al., 2015; Bajenoff et al., 2010; Soudja et al., 2014). However, and in contrast to $\mathrm{Ly}^{+} \mathrm{C}^{+}$monocytes, neutrophils neither express nor upregulate high levels of CCR1 and CCR5, suggesting that CD8 ${ }^{+}$ $\mathrm{T}_{\mathrm{M}}$ cell-derived chemokines are unlikely to account for activating neutrophils in this setting. Fine-tuning of monocyte activation in response to local chemokine levels may however regulate their secretion of TNF $\alpha$, which directly promotes ROS production and pathogen killing.

Another important finding in our study relates to the rapid, transcriptionally controlled and coordinated production of CCL3, CCL4 and XCL1 chemokines by $\mathrm{CD}^{+} \mathrm{T}_{\mathrm{M}}$ cells induced upon vaccination with both $L m$ and $V S V$ in response to cognate Ag recognition. These results are consistent with two recent reports that utilized multiple models of acute and chronic infections, as well as ex vivo stimulation assays, and outline that the robust chemokine signature is a key and important feature of both Ag-stimulated effector and memory $\mathrm{CD}^{+} \mathrm{T}$ cells (Davenport et al., 
2020; Eberlein et al., 2020). $\mathrm{CD}^{+} \mathrm{T}_{\mathrm{M}}$ cells undergoing repetitive in vivo stimulations were also reported to significantly upregulate genes encoding for these chemokines (Wirth et al., 2010). Our study further reveal that CCL3, CCL4 and XCL1 chemokines produced by cognate Agstimulated $\mathrm{CD}^{+} \mathrm{T}_{\mathrm{M}}$ cells, are directly under the control of the IRF4 transcriptional regulator, a known amplifying rheostat downstream of TCR signaling (Man et al., 2013). IRF4 may indeed enable the graded production of these chemokines by $\mathrm{CD}^{+} \mathrm{T}_{\mathrm{M}}$ cells, proportionally to the strength of TCR signaling, and this could represent a mechanism to limit tissue-associated damages, when weak epitopes are presented to Ag-specific $\mathrm{CD}^{+} \mathrm{T}_{\mathrm{M}}$ cells. In the context of strong epitope stimulation, however, our results suggest that chemokines are secreted concomitantly to $\mathrm{CD}^{+} \mathrm{T}_{\mathrm{M}}$ cells arrest in monocyte clusters, promoting their increased production of TNF $\alpha$ both in vitro and in vivo. The fact that both IFN $\gamma$ signaling and cognate Ag recognition, are required for vaccinated host protection is consistent with a key role for chemokines in potentiating clustered monocyte antimicrobial functions. These findings also highlight that chemokines can prime innate immune cell effector functions, clearly delineating a role distinct from usual chemotaxis.

While our study focuses on systemic and SLO-derived memory $\mathrm{CD}^{+} \mathrm{T}$ cell responses, multiple evidence suggest that the current mechanisms are also relevant in the context of tissueresident memory $\mathrm{CD}^{+} \mathrm{T}$ cell responses. In several models of viral infection (skin, vagina, lung), $\mathrm{T}_{\mathrm{RM}}$ cells -both $\mathrm{CD}^{+}$and $\mathrm{CD}^{+}$- quickly initiate and orchestrate a rapid mucosal response upon cognate Ag encounter, through local production of IFN $\gamma$ and subsequent CXCL9 (Ariotti et al., 2014; Beura et al., 2018; Iijima and Iwasaki, 2014; Kohlmeier et al., 2009; Kohlmeier et al., 2010; Schenkel et al., 2014). As discussed earlier, CXCL9 enables migration of more circulating $\mathrm{T}_{\mathrm{M}}$ cells to sites of infection, enhancing the activation of local DCs and NK cells and the establishment of an IFN $\gamma$-driven antiviral state providing broad protective immunity against unrelated microbial pathogens. In these studies, reactivation of $\mathrm{CD}^{+} \mathrm{T}_{\mathrm{M}}$ cells and the production of activating IFN $\gamma$ required cognate $\mathrm{Ag}$ recognition, yet many reports monitoring systemic $\mathrm{CD}^{+}$ $\mathrm{T}_{\mathrm{M}}$ cells, have also established that $\mathrm{CD}^{+} \mathrm{T}_{\mathrm{M}}$ cells in SLO undergo cytokine-mediated activation (Bedoui et al., 2009; Berg et al., 2003; Maurice et al., 2019; Raue et al., 2013; Soudja et al., 2012). This seemingly discrepant result may be a reflection of tissue-specific mechanisms. In fact, it was recently shown that $\mathrm{LN} \mathrm{CD} 8^{+} \mathrm{T}_{\mathrm{M}}$ cells strictly require cognate $\mathrm{Ag}$ to be presented by 
$\mathrm{XCR}^{+}$DCs while lung $\mathrm{T}_{\mathrm{RM}}$ can be reactivated by both hematopoietic and non-hematopoietic cells (Low et al., 2020). Here, cognate Ag presentation by hematopoietic versus nonhematopoietic-derived cells to $\mathrm{CD}^{+} \mathrm{T}_{\mathrm{RM}}$ cells was also proposed to dictate distinct functional outcomes with hematopoietic-derived APCs restraining an excessive inflammatory program in $\mathrm{CD}^{+} \mathrm{T}_{\mathrm{RM}}$ cells, presumably as a safeguard mechanism against collateral tissue damages. Interestingly, non-hematopoietic Ag presentation was associated with a proliferative program, and largely prevented cytokine-mediated activation of $\mathrm{CD}^{+} \mathrm{T}_{\mathrm{RM}}$ cells. It is noteworthy this study used the Nur $77^{\mathrm{GFP}}$ reporter system a read out of TCR-dependent cognate Ag stimulation, thereby only focusing on early Ag-dependent $\mathrm{CD}^{+} \mathrm{T}_{\mathrm{M}}$ cell-expression programs. Other reports using complex biological read-outs (e.g., proliferation, protection) have supported a more prominent role for recruited or tissue-resident DCs in the reactivation of $\mathrm{CD}^{+} \mathrm{T}_{\mathrm{RM}}$ cells, raising the possibility that different memory cell-intrinsic mechanisms of regulation may be specifically programmed upon DC- versus non-hematopoietic cell-mediated activation (Shin et al., 2016; Wakim et al., 2008).

In conclusion, this work provides a detailed analysis of how cognate Ag stimulation induces early changes in systemic $\mathrm{CD}^{+} \mathrm{T}$ cell memory, and how these changes enable the rapid control of microbial pathogen in vaccinated hosts in situ. Perhaps contrasting with the widely accepted view, our results suggest that memory $\mathrm{CD}^{+} \mathrm{T}$ cells are not essential in orchestrating the initial immune response. The initiating response is largely regulated by tissue-specific cues and innate immune cells before $\mathrm{CD}^{+} \mathrm{T}_{\mathrm{M}}$ cells intervene to make the innate cellular effector response highly effective. The findings also reveal that a combination of cells $\left(\mathrm{T}_{\mathrm{M}}\right.$ cells, monocytes, neutrophils, DCs) and signals (Ag, IFN $\gamma$, chemokines) are needed to achieve early protection, which suggests many levels of fine tuning are possible to make such response the most efficient and less damaging to vaccinated host. 


\section{REFERENCES}

Alexandre, Y.O., Ghilas, S., Sanchez, C., Le Bon, A., Crozat, K., and Dalod, M. (2015). XCR1+ dendritic cells promote memory CD8+ $\mathrm{T}$ cell recall upon secondary infections with Listeria monocytogenes or certain viruses. J Exp Med.

Ariotti, S., Hogenbirk, M.A., Dijkgraaf, F.E., Visser, L.L., Hoekstra, M.E., Song, J.Y., Jacobs, H., Haanen, J.B., and Schumacher, T.N. (2014). T cell memory. Skin-resident memory CD8(+) T cells trigger a state of tissue-wide pathogen alert. Science 346, 101-105.

Bajenoff, M., Narni-Mancinelli, E., Brau, F., and Lauvau, G. (2010). Visualizing early splenic memory CD8+ $T$ cells reactivation against intracellular bacteria in the mouse. PLoS One 5, e11524.

Bedoui, S., Whitney, P.G., Waithman, J., Eidsmo, L., Wakim, L., Caminschi, I., Allan, R.S., Wojtasiak, M., Shortman, K., Carbone, F.R., et al. (2009). Cross-presentation of viral and self antigens by skin-derived CD103+ dendritic cells. Nat Immunol 10, 488-495.

Berg, R.E., Crossley, E., Murray, S., and Forman, J. (2003). Memory CD8+ T cells provide innate immune protection against Listeria monocytogenes in the absence of cognate antigen. $\mathrm{J}$ Exp Med 198, 1583-1593.

Beura, L.K., Mitchell, J.S., Thompson, E.A., Schenkel, J.M., Mohammed, J., Wijeyesinghe, S., Fonseca, R., Burbach, B.J., Hickman, H.D., Vezys, V., et al. (2018). Intravital mucosal imaging of CD8(+) resident memory $\mathrm{T}$ cells shows tissue-autonomous recall responses that amplify secondary memory. Nat Immunol 19, 173-182.

Bousso, P., and Robey, E. (2003). Dynamics of CD8+ T cell priming by dendritic cells in intact lymph nodes. Nat Immunol 4, 579-585.

Bray, N.L., Pimentel, H., Melsted, P., and Pachter, L. (2016). Near-optimal probabilistic RNAseq quantification. Nat Biotechnol 34, 525-527.

Davenport, B., Eberlein, J., Nguyen, T.T., Victorino, F., van der Heide, V., Kuleshov, M., Ma'ayan, A., Kedl, R., and Homann, D. (2020). Chemokine Signatures of Pathogen-Specific T Cells II: Memory T Cells in Acute and Chronic Infection. J Immunol.

Dobin, A., Davis, C.A., Schlesinger, F., Drenkow, J., Zaleski, C., Jha, S., Batut, P., Chaisson, M., and Gingeras, T.R. (2013). STAR: ultrafast universal RNA-seq aligner. Bioinformatics 29, 15-21.

Eberlein, J., Davenport, B., Nguyen, T.T., Victorino, F., Jhun, K., van der Heide, V., Kuleshov, M., Ma'ayan, A., Kedl, R., and Homann, D. (2020). Chemokine Signatures of Pathogen-Specific T Cells I: Effector T Cells. J Immunol.

Edelson, B.T., Bradstreet, T.R., Hildner, K., Carrero, J.A., Frederick, K.E., Kc, W., Belizaire, R., Aoshi, T., Schreiber, R.D., Miller, M.J., et al. (2011). CD8alpha(+) Dendritic Cells Are an Obligate Cellular Entry Point for Productive Infection by Listeria monocytogenes. Immunity 35, 236-248.

Gerlach, C., Moseman, E.A., Loughhead, S.M., Alvarez, D., Zwijnenburg, A.J., Waanders, L., Garg, R., de la Torre, J.C., and von Andrian, U.H. (2016). The Chemokine Receptor CX3CR1 Defines Three Antigen-Experienced CD8 T Cell Subsets with Distinct Roles in Immune Surveillance and Homeostasis. Immunity 45, 1270-1284.

Harty, J.T., Tvinnereim, A.R., and White, D.W. (2000). CD8+ T cell effector mechanisms in resistance to infection. Annu Rev Immunol 18, 275-308.

Hohl, T.M., Rivera, A., Lipuma, L., Gallegos, A., Shi, C., Mack, M., and Pamer, E.G. (2009). Inflammatory monocytes facilitate adaptive CD4 $\mathrm{T}$ cell responses during respiratory fungal infection. Cell Host Microbe 6, 470-481.

lijima, N., and Iwasaki, A. (2014). T cell memory. A local macrophage chemokine network sustains protective tissue-resident memory CD4 T cells. Science 346, 93-98. 
Kastenmuller, W., Brandes, M., Wang, Z., Herz, J., Egen, J.G., and Germain, R.N. (2013). Peripheral Prepositioning and Local CXCL9 Chemokine-Mediated Guidance Orchestrate Rapid Memory CD8(+) T Cell Responses in the Lymph Node. Immunity.

Kohlmeier, J.E., Cookenham, T., Miller, S.C., Roberts, A.D., Christensen, J.P., Thomsen, A.R., and Woodland, D.L. (2009). CXCR3 directs antigen-specific effector CD4+ T cell migration to the lung during parainfluenza virus infection. J Immunol 183, 4378-4384.

Kohlmeier, J.E., Cookenham, T., Roberts, A.D., Miller, S.C., and Woodland, D.L. (2010). Type I interferons regulate cytolytic activity of memory CD8(+) $\mathrm{T}$ cells in the lung airways during respiratory virus challenge. Immunity 33, 96-105.

Kohlmeier, J.E., Reiley, W.W., Perona-Wright, G., Freeman, M.L., Yager, E.J., Connor, L.M., Brincks, E.L., Cookenham, T., Roberts, A.D., Burkum, C.E., et al. (2011). Inflammatory chemokine receptors regulate CD8(+) $\mathrm{T}$ cell contraction and memory generation following infection. J Exp Med 208, 1621-1634.

Kupz, A., Guarda, G., Gebhardt, T., Sander, L.E., Short, K.R., Diavatopoulos, D.A., Wijburg, O.L., Cao, H., Waithman, J.C., Chen, W., et al. (2012). NLRC4 inflammasomes in dendritic cells regulate noncognate effector function by memory CD8(+) T cells. Nat Immunol.

Lauvau, G., Boutet, M., Williams, T.M., Chin, S.S., and Chorro, L. (2016). Memory CD8(+) T Cells: Innate-Like Sensors and Orchestrators of Protection. Trends Immunol 37, 375-385.

Lauvau, G., Vijh, S., Kong, P., Horng, T., Kerksiek, K., Serbina, N., Tuma, R.A., and Pamer, E.G. (2001). Priming of memory but not effector CD8 T cells by a killed bacterial vaccine. Science 294, 1735-1739.

Love, M.I., Huber, W., and Anders, S. (2014). Moderated estimation of fold change and dispersion for RNA-seq data with DESeq2. Genome Biol 15, 550.

Low, J.S., Farsakoglu, Y., Amezcua Vesely, M.C., Sefik, E., Kelly, J.B., Harman, C.C.D., Jackson, R., Shyer, J.A., Jiang, X., Cauley, L.S., et al. (2020). Tissue-resident memory T cell reactivation by diverse antigen-presenting cells imparts distinct functional responses. J Exp Med 217.

Man, K., Miasari, M., Shi, W., Xin, A., Henstridge, D.C., Preston, S., Pellegrini, M., Belz, G.T., Smyth, G.K., Febbraio, M.A., et al. (2013). The transcription factor IRF4 is essential for TCR affinity-mediated metabolic programming and clonal expansion of T cells. Nat Immunol 14, 1155-1165.

Martin, M.D., and Badovinac, V.P. (2018). Defining Memory CD8 T Cell. Front Immunol 9, 2692. Maurice, N.J., McElrath, M.J., Andersen-Nissen, E., Frahm, N., and Prlic, M. (2019). CXCR3 enables recruitment and site-specific bystander activation of memory CD8(+) T cells. Nature communications 10, 4987.

Mempel, T.R., Henrickson, S.E., and Von Andrian, U.H. (2004). T-cell priming by dendritic cells in lymph nodes occurs in three distinct phases. Nature 427, 154-159.

Mueller, S.N., Heath, W., McLain, J.D., Carbone, F.R., and Jones, C.M. (2002). Characterization of two TCR transgenic mouse lines specific for herpes simplex virus. Immunol Cell Biol 80, 156-163.

Muraille, E., Giannino, R., Guirnalda, P., Leiner, I., Jung, S., Pamer, E.G., and Lauvau, G. (2005). Distinct in vivo dendritic cell activation by live versus killed Listeria monocytogenes. Eur J Immunol 35, 1463-1471.

Nakane, A., Minagawa, T., Kohanawa, M., Chen, Y., Sato, H., Moriyama, M., and Tsuruoka, N. (1989). Interactions between endogenous gamma interferon and tumor necrosis factor in host resistance against primary and secondary Listeria monocytogenes infections. Infect Immun 57, 3331-3337.

Narni-Mancinelli, E., Campisi, L., Bassand, D., Cazareth, J., Gounon, P., Glaichenhaus, N., and Lauvau, G. (2007). Memory CD8+ T cells mediate antibacterial immunity via CCL3 activation of TNF/ROI+ phagocytes. J Exp Med 204, 2075-2087. 
Narni-Mancinelli, E., Soudja, S.M., Crozat, K., Dalod, M., Gounon, P., Geissmann, F., and Lauvau, G. (2011). Inflammatory Monocytes and Neutrophils Are Licensed to Kill During Memory Responses In Vivo. PLoS Pathog 29.

Neighbors, M., Xu, X., Barrat, F.J., Ruuls, S.R., Churakova, T., Debets, R., Bazan, J.F., Kastelein, R.A., Abrams, J.S., and O'Garra, A. (2001). A critical role for interleukin 18 in primary and memory effector responses to Listeria monocytogenes that extends beyond its effects on Interferon gamma production. J Exp Med 194, 343-354.

Neuenhahn, M., Kerksiek, K.M., Nauerth, M., Suhre, M.H., Schiemann, M., Gebhardt, F.E., Stemberger, C., Panthel, K., Schroder, S., Chakraborty, T., et al. (2006). CD8alpha+ dendritic cells are required for efficient entry of Listeria monocytogenes into the spleen. Immunity 25, 619-630.

Perez, O.A., Yeung, S.T., Vera-Licona, P., Romagnoli, P.A., Samji, T., Ural, B.B., Maher, L., Tanaka, M., and Khanna, K.M. (2017). CD169(+) macrophages orchestrate innate immune responses by regulating bacterial localization in the spleen. Sci Immunol 2.

Raue, H.P., Beadling, C., Haun, J., and Slifka, M.K. (2013). Cytokine-mediated programmed proliferation of virus-specific CD8(+) memory T cells. Immunity 38, 131-139.

Sallusto, F., Lanzavecchia, A., Araki, K., and Ahmed, R. (2010). From vaccines to memory and back. Immunity 33, 451-463.

Schenkel, J.M., Fraser, K.A., Beura, L.K., Pauken, K.E., Vezys, V., and Masopust, D. (2014). T cell memory. Resident memory CD8 T cells trigger protective innate and adaptive immune responses. Science 346, 98-101.

Schenkel, J.M., Fraser, K.A., Vezys, V., and Masopust, D. (2013). Sensing and alarm function of resident memory CD8(+) T cells. Nat Immunol 14, 509-513.

Schenkel, J.M., and Masopust, D. (2014). Tissue-resident memory T cells. Immunity 41, 886897.

Shi, C., Velazquez, P., Hohl, T.M., Leiner, I., Dustin, M.L., and Pamer, E.G. (2010). Monocyte trafficking to hepatic sites of bacterial infection is chemokine independent and directed by focal intercellular adhesion molecule-1 expression. J Immunol 184, 6266-6274.

Shin, H., Kumamoto, Y., Gopinath, S., and Iwasaki, A. (2016). CD301b+ dendritic cells stimulate tissue-resident memory CD8+ T cells to protect against genital HSV-2. Nature communications 7, 13346.

Slutter, B., Pewe, L.L., Kaech, S.M., and Harty, J.T. (2013). Lung airway-surveilling CXCR3(hi) memory CD8(+) T cells are critical for protection against influenza A virus. Immunity 39, 939948.

Soudja, S.M., Chandrabos, C., Yakob, E., Veenstra, M., Palliser, D., and Lauvau, G. (2014). Memory-T-Cell-Derived Interferon-gamma Instructs Potent Innate Cell Activation for Protective Immunity. Immunity 40, 974-988.

Soudja, S.M., Ruiz, A.L., Marie, J.C., and Lauvau, G. (2012). Inflammatory Monocytes Activate Memory CD8(+) T and Innate NK Lymphocytes Independent of Cognate Antigen during Microbial Pathogen Invasion. Immunity 37, 549-562.

Stoll, S., Delon, J., Brotz, T.M., and Germain, R.N. (2002). Dynamic imaging of T cell-dendritic cell interactions in lymph nodes. Science 296, 1873-1876.

Sung, J.H., Zhang, H., Moseman, E.A., Alvarez, D., lannacone, M., Henrickson, S.E., de la Torre, J.C., Groom, J.R., Luster, A.D., and von Andrian, U.H. (2012). Chemokine guidance of central memory $\mathrm{T}$ cells is critical for antiviral recall responses in lymph nodes. Cell 150, 12491263.

Vesely, M.D., Kershaw, M.H., Schreiber, R.D., and Smyth, M.J. (2011). Natural innate and adaptive immunity to cancer. Annu Rev Immunol 29, 235-271.

Waite, J.C., Leiner, I., Lauer, P., Rae, C.S., Barbet, G., Zheng, H., Portnoy, D.A., Pamer, E.G., and Dustin, M.L. (2011). Dynamic imaging of the effector immune response to listeria infection in vivo. PLoS Pathog 7, e1001326. 
Waite, J.C., Vardhana, S., Shaw, P.J., Jang, J.E., McCarl, C.A., Cameron, T.O., Feske, S., and Dustin, M.L. (2013). Interference with $\mathrm{Ca}(2+)$ release activated $\mathrm{Ca}(2+)$ (CRAC) channel function delays T-cell arrest in vivo. Eur $\mathrm{J}$ Immunol 43, 3343-3354.

Wakim, L.M., Waithman, J., van Rooijen, N., Heath, W.R., and Carbone, F.R. (2008). Dendritic cell-induced memory T cell activation in nonlymphoid tissues. Science 319, 198-202.

Wang, L., Wang, S., and Li, W. (2012). RSeQC: quality control of RNA-seq experiments. Bioinformatics 28, 2184-2185.

Wirth, T.C., Xue, H.H., Rai, D., Sabel, J.T., Bair, T., Harty, J.T., and Badovinac, V.P. (2010). Repetitive antigen stimulation induces stepwise transcriptome diversification but preserves a core signature of memory CD8(+) T cell differentiation. Immunity 33, 128-140.

Wong, P., and Pamer, E.G. (2003). CD8 T cell responses to infectious pathogens. Annu Rev Immunol 21, 29-70.

Yao, S., Buzo, B.F., Pham, D., Jiang, L., Taparowsky, E.J., Kaplan, M.H., and Sun, J. (2013). Interferon regulatory factor 4 sustains CD8(+) $\mathrm{T}$ cell expansion and effector differentiation. Immunity 39, 833-845.

Zammit, D.J., Cauley, L.S., Pham, Q.M., and Lefrancois, L. (2005). Dendritic cells maximize the memory CD8 T cell response to infection. Immunity 22, 561-570.

Zehn, D., Lee, S.Y., and Bevan, M.J. (2009). Complete but curtailed T-cell response to very lowaffinity antigen. Nature 458, 211-214. 


\section{EXPERIMENTAL PROCEDURES}

\section{Ethics Statement}

This study was carried out in strict accordance with the recommendations by the animal use committee at the Albert Einstein College of Medicine. All efforts were made to minimize suffering and provide humane treatment to the animals included in the study.

Mice

All mice were bred in our SPF animal facility at the Albert Einstein College of Medicine. We used wild-type (WT) C57BL/6J (B6) 6-8 weeks old male or female mice, congenic CD45.1 ${ }^{+/+}$ (JAX\#002014), B6-K ${ }^{\mathrm{d}}$ (Lauvau et al., 2001), OT-I ${ }^{+}$(JAX\#003831) crossed to Rosa26-Actintomato-stop $^{\text {loxP/loxP(or flffl)-GFP }}\left(\mathrm{Td}^{+}\right)(\mathrm{JAX} \# 007576), \mathrm{gBT}^{+}{ }^{+}$(kind gift Francis Carbone (Mueller et al., 2002)) crossed to $U B C^{G F P / G F P}$ (JAX\#004353) or to CD45.1 $1^{+/+}$mice, $C c r 2^{\text {DTR-CFP/WT }}$ (kind gift Eric Pamer (Hohl et al., 2009)), Itgax/Cd11 $c^{\text {DTR/WT }}$ (JAX\#004509), Rosa26 ${ }^{\text {Cre-ERT2 }}$ (JAX\#008463), Irf4 $4^{\text {loxP/loxP (or flfl) }}\left(\mathrm{JAX \# 009380),} \mathrm{Ifngrl}{ }^{\text {-/ }}\right.$ (JAX\#003288) purchased from the Jackson labs unless otherwise indicated. All mice are on the B6 genetic background unless otherwise specified.

\section{Microbial pathogens and mouse infections}

Listeria monocytogenes $(\mathrm{Lm})$ : Mice were inoculated with $\mathrm{Lm}, \mathrm{Lm}$ expressing the ovalbumin (Lm-Ova, kind gift H. Shen, U Penn) or Ova and Herpes Simplex Virus 2 (HSV-2) glycoprotein B 498-505 epitope ( Lm-Ova-gB, kind gift D. Zehn, TUM), all expressed under the LLO/Hly promoter. All Lm were prepared after passaging into WT B6 mice, by growing to log phase $\left(\mathrm{OD}_{600} \sim 0.3-0.4\right)$ and kept as frozen aliquots for single use in $-80^{\circ} \mathrm{C}$. For infections, bacteria were grown to a logarithmic phase (OD600 0.05-0.15) in broth heart infusion medium, diluted in PBS

to infecting concentration and injected intravenously (i.v). We used $0.1 \times \mathrm{LD}_{50}$, i.e., $10^{4} \mathrm{Lm}$ CFUs for primary immunizations, and $10^{6} \mathrm{Lm}$ CFUs for secondary challenge infections ( 6 wks later). All Lm are on the 10403s genetic background.

Vesicular Stomatitis Virus (VSV): Single use frozen aliquots of VSV encoding Ova (VSV-Ova, gift Kamal Khanna, NYU) kept at $-80^{\circ} \mathrm{C}$ were thawed and diluted in cold PBS right before mouse primary i.v. infections with $2 \times 10^{5}$ PFUs. For secondary challenge infections of $V S V$ immunized mice ( $\sim 6$ wks later), we used $10^{6} \mathrm{Lm}$ CFUs.

\section{Preparation of cell suspensions for flow cytometry and adoptive transfers}


Spleens were dissociated on a nylon mesh and lysed in red blood cells (RBC) lysis buffer (0.83\% $\mathrm{NH}_{4} \mathrm{Cl} \mathrm{vol} / \mathrm{vol}$ ), prior to incubation in HBSS medium with 4,000 U/mL collagenase I and 0.1 $\mathrm{mg} / \mathrm{mL}$ DNase I. BM cells were obtained by flushing femur with complete medium (RPMI 1640, 10\% FBS, 1\% Penicillin/Streptomycin, 55 $\mu \mathrm{M} \beta$-mercaptoethanol, 1mM Sodium Pyruvate, 1X Glutamax, 1X non-essential amino acids) containing 10\% FCS.

\section{Cell-staining for FACS analysis}

Cell suspensions were incubated with 2.4G2 Fc Block and stained in PBS 1\%FCS, 2mM EDTA, $0.02 \%$ sodium azide with fluorescently tagged Abs purchased from eBioscience, BD Biosciences, R\&D systems, or BioLegend (See Table S3) or in same instance tetramers. For tetramers, biotinylated monomers $(1 \mathrm{mg} / \mathrm{mL})$ obtained from the NIH tetramer Core Facility were conjugated with PE-labeled Streptavidin $(1 \mathrm{mg} / \mathrm{mL})$ as follow: $6.4 \mu \mathrm{L}$ of PE-Streptavidin were added to $10 \mu \mathrm{L}$ of monomers every 15 min 4 times on ice. Newly generated tetramers (1/400$1 / 500$ dilution) were then used to stain spleen cells for $1 \mathrm{hr}$ at $4^{\circ} \mathrm{C}$. For IRF4 transcription factor (TF) intracellular staining (IRF4), cells were fixed in eBioscience Fixation/Permeabilization buffer prior to anti-IRF4 mAb staining in eBioscience Permeabilization buffer for $30 \mathrm{~min}$. For intracellular cytokine staining (ICS), cells were first incubated for $4 \mathrm{hrs}$ at $37^{\circ} \mathrm{C} / 5 \% \mathrm{CO}_{2}$ in complete medium 10\% FCS, with Golgi Plug/Golgi Stop. Next, cells were stained for cellsurface marker expression and fixed in IC fixation buffer (eBioscience) prior to permeabilization $\sim 1 \mathrm{~h}$ in presence of Abs against intracellular cytokines (IFN $\gamma, \mathrm{TNF} \alpha$ ) and chemokines (CXCL9,

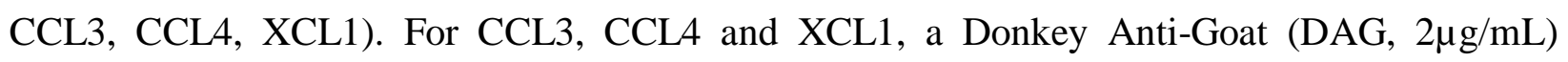
secondary Ab was used. Data acquisition was done using a FACSAria III flow cytometer. All flow cytometry data were analyzed using FlowJo v9 software (TreeStar).

\section{Adoptive $\mathbf{T}$ cell and monocyte transfers}

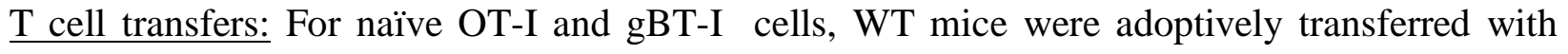
$\sim 1,000$ OT-I $\mathrm{Td}^{+}$and 50,000 $\mathrm{gBT}-\mathrm{I}$ cells isolated from the spleen of OT-I $\mathrm{Td}^{+}$and $\mathrm{gBT}-\mathrm{I}$ CD45. $1^{+/+}$mice. The next day, mice were immunized with $L m$-Ova-gB. Immunized mice were next used $\sim 6$ wks later to investigate OT-I and gBT-I $\mathrm{T}_{\mathrm{M}}$ cell reactivation by FACS and IVM. For adoptive transfers of OT-I memory cells, WT mice were first adoptively transferred with $\sim 1,000$ naive OT-I Td ${ }^{+}$cells as above, immunized the next day with $V S V$-Ova and challenged 2 wks later with $10^{4} \mathrm{Lm}$-Ova. After $\sim 4$ wks, spleens were harvested and $\mathrm{CD} 8^{+} \mathrm{T}$ cells $\mathrm{CD} 8^{+} \mathrm{T}$ cells were negatively selected from spleen using anti-CD4, anti-CD11b, anti-MHC II, anti-TER119, 
anti-B220 and anti-CD19 mAbs (Table S3), which all were added and incubated at $5 \mu \mathrm{g} / \mathrm{mL}$ for $30 \mathrm{~min}$ at $4 \mathrm{C}$. Cells were then washed and incubated with anti-rat $\mathrm{Ab}$ magnetic beads at 1 bead/target cell for $40 \mathrm{~min}$ at 4C (Dynabeads sheep anti-rat IgG, Invitrogen). Cells were sorted into $3 \mathrm{~mL}$ of complete media (RPMI 1640, 10\% FBS, 1\% Penicillin/Streptomycin, $55 \mu \mathrm{M} \beta$-mercaptoethanol, 1mM Sodium Pyruvate, 1X Glutamax, 1X non-essential amino acids) using a 4 laser BD FACS Aria III cell sorter. $2 \times 10^{5}$ OT-I $\mathrm{T}_{\mathrm{M}}$ cells were transferred to either WT, $C \mathrm{cr} 2^{\mathrm{CFP}}$ or $\mathrm{Ifngrl}^{-/}$recipient mice further challenged with $10^{6} \mathrm{Lm}$ or $\mathrm{Lm}$-Ova for analysis of memory functions, protection or IVM.

Monocyte transfers for chemokine receptor expression analysis: $5 \times 10^{6} \mathrm{BM}$ cells from WT $\mathrm{CD} 45.1^{+/-}$and Ifngrl $1^{-/-} \mathrm{CD} 45.2^{+/+}$donors were co- transferred to mice immunized with Lm-Ova 6 wks before, and further challenged or not with $\mathrm{Lm}$. Spleen cells were next stained for chemokine receptor expression on monocytes from BM donor derived cells.

\section{Generation of bone-marrow chimera mice}

Lethally irradiated $(1,200 \mathrm{rads}) \mathrm{B} 6-\mathrm{K}^{\mathrm{d}}$ mice were immediately reconstituted with a total of $2 \times 10^{6} \mathrm{BM}$ cells isolated from i) $\mathrm{C} c r 2^{D T R} \mathrm{~K}^{\mathrm{d}}$ and $\mathrm{K}^{\mathrm{d}}$, ii) $\mathrm{C} c r 2^{D T R} \mathrm{~K}^{\mathrm{d}}$ and $\mathrm{WT}$, iii) $\mathrm{Cd} 11 c^{D T R} \mathrm{~K}^{\mathrm{d}}$ and WT, iv) $\mathrm{K}^{\mathrm{d}}$ and WT mice, at a 7:3 ratio, respectively. Donor BM cells were depleted of CD8 and CD4 T cells from WT BM cells using anti-CD8 $\beta$ (clone H35) and anti-CD4 (clone GK1.5) mAbs prior to reconstitution. Chimerism of reconstituted mice was checked $\sim 6$ wks later in the blood, prior to immunizations.

\section{In vivo treatments}

Monocytes and DCs depletion: $\mathrm{CCR}^{+}$and $\mathrm{CD} 1 \mathrm{c}^{+}$cells were depleted from diphtheria toxin receptor (DTR)-expressing mice upon intraperitoneal (i.p.) injection of $10 \mathrm{ng} / \mathrm{g}$ of mouse body weight of diphtheria toxin (DT, Calbiochem) $12 \mathrm{hrs}$ prior to $\mathrm{Lm}$ challenge infection.

Irf4 depletion: 4-hydroxytamoxifen (Tx) (4-OHT, \#T5648, Sigma-Aldrich) was dissolved in sunflower oil to a concentration of $10 \mathrm{mg} / \mathrm{mL}$ for i.p. injection. 3,000 OT-I-Rosa26$C r e^{E R T 2} \operatorname{Irf} 4^{f l / f l}$ and 1,000 OT-I Irf4 ${ }^{\mathrm{WT}}$ were co-transferred to WT B6 mice which were immunized with $L m$-Ova the next day. Six weeks later, and prior to challenge, mice were treated with Tx (100 $\mu \mathrm{L}, 1 \mathrm{mg} /$ injection) or vehicle $(100 \mu \mathrm{L}$ of sunflower oil) for 5 days and $24 \mathrm{hrs}$ after the last Tx injection, mice were challenged with $L m$-Ova.

Ly6C-PE antibody for monocyte staining in situ: For IVM analysis, 10 $\mu$ g of Ly6C-PE (Clone HK1.4, Rat IgG2a, Biolegend) mAb was inoculated to mice i.v. at the time of Lm challenge or 1 


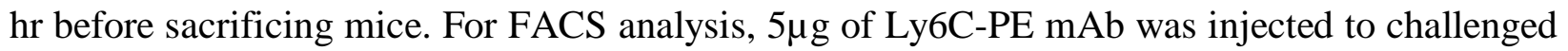
mice $1 \mathrm{hr}$ prior to the sacrifice.

\section{In vitro activation assays}

Quantification of CCL3 and IFN- $\gamma$ secretion: $10^{6}$ splenocytes from mice immunized with $\mathrm{Lm}$ Ova and challenged or not 6 wks later with $\mathrm{Lm}$-Ova for $16 \mathrm{hrs}$, were incubated in 96-flat bottom wells with complete medium only or in presence of Golgi Plug/Stop for $4 \mathrm{hrs}$ at $37^{\circ} \mathrm{C}$. CCL3 (Thermofisher) and IFN- $\gamma$ (Biolegend) production in culture supernatants was then quantified by ELISA.

Measure of chemokines expression by ex vivo restimulated OT-I T $\underline{T}_{M}$ cells: Splenocytes from mice immunized with $L m$-Ova 6 wks prior were co-incubated with SIINFEKL peptide $\left(10^{8} \mathrm{M}\right)$ with Golgi Plug/Stop and i) with or without cycloheximide (Translation inhibitor, $10 \mu \mathrm{g} / \mathrm{mL}$, Sigma-Aldrich) or Actinomycin D (Transcription inhibitor, $8 \mu \mathrm{M}$, Sigma-Aldrich) for 1, 2, 3 and $4 \mathrm{hrs}$ in complete medium at $37^{\circ} \mathrm{C}$; ii) with the SCG-CBP30 IRF4 inhibitor (Selleckchem, $20 \mu \mathrm{M})$. Cells were next stained as described above including for intracellular expression of CCL3 and/or CCL4 and XCL1.

Measure of TNF $\alpha$ expression in ex vivo stimulated monocytes and neutrophils: $10^{4}$ monocytes or neutrophils FACS-sorted (Aria III) from mice primary immunized and challenged with Lm-Ova 6 wks later for $16 \mathrm{hrs}$ were co-incubated in 96-round bottom wells and complete medium, with HKLm, rCCL3, rCCL4, rXCL1 or the combination of the three recombinant chemokines, in presence of Golgi Plug/Stop for $4 \mathrm{hrs}$ at $37^{\circ} \mathrm{C}$ before staining for cell surface and intracellular markers for FACS analysis. In CCR5 and CCR1 blocking experiments, cells were incubated with

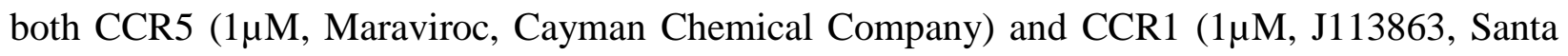
Cruz) chemical inhibitors or control DMSO 30 min prior to adding recombinant chemokines or HKLm.

\section{RNA-Sequencing}

Samples and library preparation: 1,000 OT-I Td ${ }^{+}$and 1,000 gBT-I CD45.1 ${ }^{+/+} \mathrm{T}_{\mathrm{M}}$ cells were flowpurified (FACS Aria III) following the same procedure as for the adoptive $T_{M}$ cell transfers described before, from 6 wks Lm-Ova-gB-immunized mice either left unchallenged or challenged with Lm-Ova. $\mathrm{T}_{\mathrm{M}}$ cells were directly sorted into $1 \mathrm{X}$ lysis buffer and cDNA was synthesized and amplified directly from intact cells using SMART-Seq v4 Ultra Low Input RNA Kit for Sequencing (Takara Bio USA) according to the manufacturer protocol. cDNA was 
isolated using the Agencourt AMPure XP Kit (Beckman Coulter, Brea, CA) and quantified using the Qubit dsDNA High Sensitivity Assay Kit (Life Invitrogen) on an Agilent 2100 Bioanalyser (Agilent Technologies, Santa Clara, CA). The library preparation was performed using the Nextera XT DNA Library Preparation Kit (Illumina Inc., San Diego, CA). Samples were sequenced to depths of up to 16.7 million single-end $75 \mathrm{nt}$ length reads per sample using the Illumina NextSeq 500/550 High Output v2 kit (75 cycles) on an Illumina NextSeq 500 Sequencing System. Image analysis, base calling, and generation of sequence reads were produced using the NextSeq Control Software v2.0 (NCS) and Real-Time Analysis Software v2 (RTA). Data was converted to FASTQ files using the bc12fastq2 v2.20 software (Illumina Inc.). Sequencing data was initially quality-checked using FastQC, before alignment and initial analysis. Reads were aligned to the Mouse reference mm10 using STAR aligner (v2.4.2a) (Dobin et al., 2013). Quantification of genes annotated in Gencode vM5 were performed using featureCounts (v1.4.3) and quantification of transcripts using Kalisto (Bray et al., 2016). QC was collected with Picard (v1.83) and RSeQC (Wang et al., 2012)(http://broadinstitute.github.io/picard/). Normalization of feature counts was done using the DESeq2 package, version 1.10.1. Prior to analysis, non-relevant batch effect (such as library preparation or sequencing batch) was identified using unsupervised principal component analysis (PCA) and analysis was corrected for batch effects through our model. Differentially expressed genes were identify using negative binomial distribution as implemented in DESeq 2 (R package (Love et al., 2014)). Significantly up and down regulated genes (DEG) were defined with an FDR step-up $p \leq 0.05$ and a fold-change $\geq \pm 1.5$. The raw data from the NCBI database (GEO GSE160280) was subsequently analysed for enrichment of GO terms and the KEGG pathways, implemented in the clusterprofiler (R package, function enrichGO or enrichKEGG) ; a pathway is considered significantly-enriched if the enrichment score is $\geq 1.5$ (equivalent to a $p \leq 0.05$ ).

\section{Intravital and Explant Imaging}

For intravital imaging, mice were anesthetized with isoflurane and the spleen was surgically exposed and elevated above the body of the mouse. A glass coverslip was carefully applied to the top of the spleen to create an imaging window. Mice were kept at $37^{\circ} \mathrm{C}$ using a custom heating platform. Imaging was performed on an Olympus FVE-1200 upright microscope using a 25X 1.04 NA objective and a Deepsee MaiTai Ti-Sapphire pulsed laser (Spectra Physics) tuned to $870 \mathrm{~nm}$. To maintain temperature and limit infiltrating light, the microscope was fitted with a 
custom-built incubator chamber heated to $37^{\circ} \mathrm{C} .512 \times 512$ Z-stack images were acquired every 60 seconds with 5 um steps. For explant imaging, mice were euthanized with $\mathrm{CO}_{2}$ and spleens immediately harvested. Spleens were affixed to coverglass using VetBond (3M) on the medulla. Tiled images were acquired using 320x320 Z-stack images with 15 um steps. Tiled images were stitched using Olympus Fluoview Software. Cell tracking, drift correction, and monocyte volume analysis was carried out using Imaris 9.2 (Bitplane).

\section{Measure of protective immunity}

$2 \times 10^{5}$ OT-I $\mathrm{T}_{\mathrm{M}}$ cells were flow-sorted as described before and adoptively transferred to WT or Ifngr $1^{-/}$mice and the next day challenged with $L m$ or Lm-Ova. Untransferred mice were used as control groups. To measure $L m$ titers, spleen and liver were harvested $24 \mathrm{hrs}$ post challenge infection and dissociated on metal screens in $10 \mathrm{~mL}$ of water/0.1\% Triton X-100 (SigmaAldrich). Serial dilutions were performed in the same buffer, and $100 \mu$ were plated onto BHI media plates. $L m$ CFU numbers were counted 24 hrs later.

\section{Statistics}

Statistical significance was calculated using an unpaired Student t test with GraphPad Prism software and two-tailed $\mathrm{p}$ values are given as: $(*) \mathrm{p}<0.1 ;(* *) \mathrm{p}<0.01 ;(* * *) \mathrm{p}<0.001 ;(* * * *)$ $\mathrm{p}<0.0001$ and (ns) $\mathrm{p}>0.1$. All $\mathrm{p}$ values of 0.05 or less were considered significant and are referred to as such in the text. 
Acknowledgments: We thank the Einstein FACS and genomic core facilities. Funding: This work was funded by the National Institute of Health Grants (NIH) AI103338, Hirschl Caulier Award to GL. MB received fellowships from FRM. ZB is the recipient of an NIH F32 fellowship HL149155. Core resources for FACS were supported by the Einstein Cancer Center (NCI cancer center support grant 2P30CA013330).

Author contribution: MB designed, performed and interpreted all experiments and assembled all Figures, and wrote the manuscript with GL. ZB and DF designed, conducted analyzed and interpreted IVM experiments and contributed to scientific discussions and manuscript editing. FD with MB and GL analyzed and interpreted all transcriptomic data. EG and CK contributed to multiple mouse experiments with MB. SS generated the $L m-\mathrm{LLO}_{\mathrm{Ser} 92}-\mathrm{Ova}$ strain. GL designed and interpreted experiments with $\mathrm{MB}$ and all other authors, contributed to Figure design and editing, and wrote the paper with MB.

Competing interests: The authors declare that no competing interests exist.

Data materials and availability: The accession number for the microarrays and RNA-seq data reported in this paper is GEO:GSE160280. All data is available in the main text or the supplementary materials. 


\section{Figure Legends:}

Figure 1. Transcriptomic profiling of antigen/inflammation- versus inflammation-activated memory $\mathrm{CD8}^{+} \mathbf{T}$ cells. (A) Schematic of experimental design. Aged-matched WT B6 female mice $\left(\mathrm{CD} 45.2^{+/+}\right)$grafted with tomato-expressing $\left(\mathrm{Td}^{+}\right)$OT-I and CD45.1 ${ }^{+/+} \mathrm{gBT}-\mathrm{I}$ cells were immunized with $10^{4} \mathrm{Lm}$-Ova-gB, and $\sim 6$ weeks later challenged or not with $10^{6} \mathrm{Lm}$-Ova. After 8 hrs, 1,000 OT-I T $\mathrm{M}$ (Ag/Infl, blue) and gBT-I T $\mathrm{T}_{\mathrm{M}}$ (Infl, purple) were flow-sorted from harvested mouse spleens based on CD8, CD3, Tomato $\left(\mathrm{Td}^{+}\right)$and CD45.1 expression and samples were prepared for RNA-seq analysis. (B) PCA plot (left panel) and clustering tree (right panel) of Ag/Infl- (OT-I) versus Infl- (gBT-I) stimulated $\mathrm{T}_{\mathrm{M}}$ cells at steady state and post challenge. Each dot represents an individual mouse and the number in parentheses indicates the percent of variance. Each set of samples (OT-I, gBT-I) was processed in 3 biologically independent replicate experiment. (C) Venn diagrams comparing the numbers of differentially expressed genes Ag/Infl- (OT-I) versus Infl- (gBT-I) stimulated $\mathrm{T}_{\mathrm{M}}$ cells from secondary challenged mice (fold change $+/-1.5$, adjusted p-value $<0.05$ ). The number of overlapping genes is specified in the green circle. (D) Bar graphs representing the number of genes up and down-regulated from the Venn diagram analysis. (E) Representation of the top Gene ontology (GO) pathway analysis between Ag/Infl- versus Infl-activated $\mathrm{T}_{\mathrm{M}}$ cells. The size and color of dots are proportional to the number of genes under a specific term and the adjusted p-value, respectively. (F) Volcano plot representing the significantly up and down-regulated genes in Ag/Infl-activated (OT-I) $\mathrm{T}_{\mathrm{M}}$ cells 8 hrs after the recall challenge infection.

Figure 2. Cognate antigen recognition triggers the rapid and coordinated production of chemokines by memory $\mathbf{C D 8}^{+} \mathbf{T}$ cells. (A-C) WT mice transferred with OT-I $\mathrm{Td}^{+}$and CD $45.1^{+/+}$gBT-I cells were immunized with $10^{4} \mathrm{Lm}$-Ova-gB and challenged $\sim 6$ weeks later with $10^{6} \mathrm{Lm}$-Ova for 2, 4, 6, 8, 16, 32 and $72 \mathrm{hrs}$. At indicated times, spleen cell suspensions incubated with Golgi Plug/Stop were stained for cell surface CD8, CD3, CD45.1 and intracellular CCL3, CCL4, XCL1 and IFN $\gamma$. (A) Graphs show the kinetic of chemokines and IFN $\gamma$ accumulation in OT-I (blue) and gBT-I (purple) $\mathrm{T}_{\mathrm{M}}$ cells and a representative overlaid dot plot of the staining. (B) Number of OT-I (blue) and gBT-I (purple) $\mathrm{T}_{\mathrm{M}}$ cells at indicated times post recall infection. (C) Subsets of OT-I $\mathrm{T}_{\mathrm{M}}$ subsets were flow-sorted from the spleens of mice transferred with naïve OT-I cells and immunized with $10^{4} \mathrm{Lm}$-Ova 6 wks before, based on 
CX3CR1 and CD27 cell surface marker expression $\left(\mathrm{T}_{\mathrm{EM}}: \mathrm{CX} 3 \mathrm{CR} 1{ }^{\text {hi }} \mathrm{CD} 27^{\text {low }}, \mathrm{T}_{\mathrm{PM}}\right.$ : $\mathrm{CX} 3 \mathrm{CR} 1{ }^{\text {int }} \mathrm{CD} 27^{\mathrm{hi}}, \mathrm{T}_{\mathrm{CM}}$ : CX3CR $1{ }^{\text {low }} \mathrm{CD} 27^{\mathrm{hi}}$ ). Sorted OT-I $\mathrm{T}_{\mathrm{M}}$ subsets were next stimulated for 4 hrs with SIINFEKL peptide $\left(10^{-8} \mathrm{M}\right)$ in vitro and stained for cell-surface CD8, CXCR3, KLRG1 and intracellular CCL3, CCL4, XCL1 and IFN $\square$. Graphs show expression level of indicated chemokine $^{+}$and IFN $\square^{+}$OT-I $\mathrm{T}_{\mathrm{M}}$ subsets with each symbol representing 1 mouse. (D) B6-K ${ }^{\mathrm{d}}$ mice were immunized with $10^{4} \mathrm{Lm}$-gB and $\sim 6$ wks later challenged with $10^{6} \mathrm{Lm}$-gB or $\mathrm{Lm}^{-}$ $\mathrm{LLO}_{\mathrm{Ser} 92}$ for $16 \mathrm{hrs}$ and endogenous memory $\mathrm{CD}^{+} \mathrm{T}$ cells were monitored using $\mathrm{gB}_{498-505} / \mathrm{K}^{\mathrm{b}}$, $\mathrm{p} 0_{217-225} / \mathrm{K}^{\mathrm{d}}$ and $\mathrm{LLO}_{91-99} / \mathrm{K}^{\mathrm{d}}$ tetramers. Data show the frequency of tetramers ${ }^{+}$cells among $\mathrm{CD}^{+} \mathrm{T}_{\mathrm{M}}$ cells and their expression of CCL3 and IFN $\gamma$ post challenge with Lm-gB or LmLLO $_{\text {Ser92. }}$ (E) Mice grafted with OT-I cells were immunized with $2 \times 10^{5}$ PFU VSV-Ova and $\sim 6$ wks later challenged with $10^{6} \mathrm{Lm}$ or $\mathrm{Lm}$-Ova for $16 \mathrm{hrs}$. Data show the frequency of CCL3, CCL4, XCL1 and IFN $\gamma$ among OT-I $\mathrm{T}_{\mathrm{M}}$ cells after Lm or Lm-Ova challenge. Representative flow cytometry dot plots are shown. Panels pool data from either 3 independent replicate experiments $(\mathrm{A}, \mathrm{C})$ or 2 independent experiments $(\mathrm{B}, \mathrm{D}, \mathrm{E})$ with $\mathrm{n}=4-8$ mice. $\mathrm{P}$-values $(*<0.05)$, $* *<0.005, * * *<0.0005$ and $* * *<0.0001)$ are indicated.

Figure 3. The transcription factor IRF4 orchestrates chemokine production by memory $\mathrm{CD8}^{+} \mathbf{T}$ cells downstream TCR-signaling. (A-B) Mice grafted with OT-I $\mathrm{Td}^{+}$and CD45.1 ${ }^{+/+}$ gBT-I cells were immunized with $10^{4} \mathrm{Lm}$-Ova-gB, and $\sim 6$ wks later challenged or not for $16 \mathrm{hrs}$ with $10^{6} \mathrm{Lm}$-Ova N4 or Lm expressing 3 different Ova APLs, namely Lm-Ova Q4, Lm-Ova T4 or Lm-Ova V4. Spleen cell suspensions were next incubated with Golgi Plug/Stop and stained for cell-surface CD8, CD3, CD45.1 and indicated intracellular chemokines and IFN $\gamma$ (A), or IRF4 (B). Graphs represent the proportion of OT-I or gBT-I $\mathrm{T}_{\mathrm{M}}$ cells expressing indicated intracellular markers after challenge with Lm-expressing N4, Q4, T4 or V4. Representative overlaid dot plots of IRF4 intracellular staining in OT-I and gBT-I T $\mathrm{T}_{\mathrm{M}}$ cells are shown in (B) . (C) B6-K $\mathrm{K}^{\mathrm{d}}$ mice were immunized with $10^{4} \mathrm{Lm}$-gB and $\sim 6$ weeks later challenged with $10^{6} \mathrm{Lm}$-gB or $\mathrm{Lm}$-LLO $\mathrm{Ser}_{2}$ for $16 \mathrm{hrs}$, and endogenous memory $\mathrm{CD}^{+} \mathrm{T}$ cells were quantified using $\mathrm{gB}_{498-505} / \mathrm{K}^{\mathrm{b}}, \mathrm{p} 60_{217-}$ ${ }_{225} / \mathrm{K}^{\mathrm{d}}$ and $\mathrm{LLO}_{91-99} / \mathrm{K}^{\mathrm{d}}$ tetramers. Bar graphs indicate the proportion of IRF4 ${ }^{+}$cells among $\mathrm{CD}^{+}$ tetramer ${ }^{+}$cells. (D, E) Splenocytes from 6 wks-immunized mice following the experimental design depicted in (A), were incubated for $6 \mathrm{hrs}$ with SIINFEKL $\left(10^{-8} \mathrm{M}\right)$ in vitro with or without either cycloheximide or actinomycin D for indicated times (D), or with an IRF4 inhibitor (SCG- 
CBP30, 20 $\mu \mathrm{M})$ for $6 \mathrm{hrs}(\mathrm{E})$. OT-I Td ${ }^{+} \mathrm{T}_{\mathrm{M}}$ cells were stained for cell-surface CD8, CD3 and intracellular CCL3, CCL4 and XCL1 and IRF4. Graphs show the proportions and/or expression level of indicated chemokine ${ }^{+}$and IRF4 ${ }^{+}$OT-I T ${ }_{\mathrm{M}}$ cells. (F, G) Rosa26 $6^{\text {CreERT2 }}$ Irff $4^{\text {flox/flox }}$ Cd45.2 $2^{+/+}$ and WT $C d 45.1^{+/-}$OT-I cells were co-transferred to $C d 45.1^{+/+}$WT recipient mice and immunized with $10^{4} \mathrm{Lm}$-Ova the next day. Six wks later, mice received Tx (1mg/day) or vehicle i.p. every day for 5 days before secondary challenge infection with $10^{6} \mathrm{Lm}$-Ova. At $16 \mathrm{hrs}$, CCL3 and IRF4 expression was determined as described above in Irff floxflox versus WT OT-I $\mathrm{T}_{\mathrm{M}}$ cells in the different experimental conditions. Representative FACS dot plots and histograms staining are shown. Panels pool the result of 2 independent replicate experiments with $n=6$ (A, B), 5 (CE) and $7(F, G)$ mice. P-values are indicated.

Figure 4. $\mathrm{Ly6C} \mathrm{CCR2}^{+}$monocyte clusters form in the splenic red pulp independent from memory $\mathrm{CD8}^{+} \mathbf{T}$ cells and IFN $\gamma$. (A) Representatives IVM tiles of reconstructed $C c r 2^{C F P}$ mouse spleens. As depicted in the schematics, mice were transferred with OT-I cells and primary and secondary challenged with Lm-Ova (panel i) or only primary immunized with Lm-Ova. $\mathrm{Ccr} 2^{\mathrm{CFP}}$ monocytes are in green and scales are indicated. Graphs show the average volume of clusters and proportion of clustered monocytes in each mouse spleen analyzed. (B, C) $2 \times 10^{5}$ OTI $\mathrm{T}_{\mathrm{M}}$ flow-sorted cells generated upon immunization with $2 \times 10^{5} \mathrm{PFU} V S V$-Ova and challenge with $10^{6} \mathrm{Lm}$-Ova, were transferred to naive $C c r 2^{C F P}$ (B) or Ifngrl ${ }^{-/}$(C) recipient mice subsequently challenged with $10^{6} \mathrm{Lm}$ or $\mathrm{Lm}$-Ova for $16 \mathrm{hrs}$. Representative IVM tiles of reconstructed mouse spleens with $\mathrm{CCR}^{+}(\mathrm{B})$ or $\mathrm{Ly}^{+} \mathrm{C}^{+}(\mathrm{C})$ monocytes in spleen's red pulp. In (C) Ifngrl ${ }^{-/}$were also co-injected with anti-Ly6C-PE ab $(10 \mu \mathrm{g})$. Graphs in $(\mathrm{B}, \mathrm{C})$ show the volume of individual clusters and the average proportion of clustered $\mathrm{Ly}^{+} \mathrm{C}^{+}$monocytes in each mouse spleen analyzed across 2 independent replicate experiments $(n=2-3)$.

Figure 5. Memory $\mathrm{CD8}^{+} \mathrm{T}$ cells arrest upon cognate $\mathrm{Ag}$ recognition presented by dendritic cells by not CCR2 ${ }^{+}$monocytes. (A) $C c r 2^{C F P}$ mice co-transferred with naïve OT-I $\mathrm{Td}^{+}$and gBT$\mathrm{I} \mathrm{GFP}^{+}$cells and immunized with $10^{4} \mathrm{Lm}$-Ova-gB were challenged $\sim 6$ wks later with Lm-Ova, and spleens from live mice were exposed and imaged $16 \mathrm{hrs}$ later using IVM imaging. A representative image (left) of OT-I (red) and gBT-I (green) $\mathrm{T}_{\mathrm{M}}$ cell localization in a cluster (white dotted line) of $\mathrm{CCR}^{+}$monocytes (blue) is shown. Autofluorescence appears in yellow. 
Also shown (center and right images) are OT-I $\mathrm{T}_{\mathrm{M}}$ cell tracks (outside, red and inside, yellow) and gBT-I $\mathrm{T}_{\mathrm{M}}$ cell tracks (outside, green and inside, purple) inside/outside the same cluster of CCR $2^{\text {CFP }}$ monocytes. Graphs represent the speed of individual OT-I and gBT-I $\mathrm{T}_{\mathrm{M}}$ cells in the monocyte cluster area (left) and inside/ outside the cluster. (B, C) Lethally irradiated (1,200 rads) B6- $\mathrm{K}^{\mathrm{d}}$ recipient mice were reconstituted with $(\mathrm{B}) \mathrm{B} 6-\mathrm{K}^{\mathrm{d}}$ or $\mathrm{WT} \mathrm{B} 6\left(\mathrm{~K}^{\mathrm{b}}\right)$ and $C c r 2^{D T R} \mathrm{~K}^{\mathrm{d}} \mathrm{BM}$ or (C) $C d 11 c^{D T R} \mathrm{~K}^{\mathrm{d}}$ or $\mathrm{K}^{\mathrm{d}}$ and $\mathrm{WT}$ B6 BM. Six weeks post reconstitution, mice were immunized with $10^{4} \mathrm{Lm}$-gB (B) or Lm-Ova (C) and 6 weeks later, challenged with $10^{6} \mathrm{Lm}$-gB $12 \mathrm{hrs}$ post diphtheria toxin (DT)-treatment. Endogenous $\mathrm{CD}^{+} \mathrm{T}_{\mathrm{M}}$ cells were monitored using $\mathrm{LLO}_{91-99} / \mathrm{K}^{\mathrm{d}}$, $\mathrm{gB}_{498-505} / \mathrm{K}^{\mathrm{b}}$ or Ova $257-264 / \mathrm{K}^{\mathrm{b}}$ tetramers. Graphs show the expression of CCL3 and IFN $\gamma$ among tetramers ${ }^{+}\left(\mathrm{Tet}^{+}\right)$cells after challenge. Each symbol corresponds to 1 individual mouse in 1 of 2 replicate experiment and p-value are shown.

Figure 6. Cognate Ag and chemokine signaling enhance monocyte effector functions. WT mice transferred with OT-I cells were immunized with $V S V$-Ova (A) or Lm-Ova (B, C) and challenged or not, 6 wks later with $L m$ or Lm-Ova. Spleens from $16 \mathrm{hr}$-challenged or unchallenged mice were harvested, and cells incubated for 4-6 hrs with brefeldin A prior to staining for expression of CD11b, Ly6C and Ly6G cell surface markers and (A) indicated intracellular effector and chemotactic markers or (B) expression of CCR1, CCR5 and XCR1 chemotactic receptors. In (C), monocytes and neutrophils from the spleens of challenged mice were flow-sorted and either stimulated or not with indicated recombinant chemokines or HKLm, with or without CCR5 and CCR1 inhibitors, prior to staining for intracellular TNF $\alpha$. (D) BM from WT $\left(\mathrm{CD} 45.1^{+/-}\right)$and Ifngr1 ${ }^{-/}\left(\mathrm{CD} 45.2^{+/+}\right)$mice were co-transferred to CD45.1 ${ }^{+/+}$recipient mice immunized with Lm-Ova 6 weeks before, and immediately challenged with $L m$. $16 \mathrm{hrs}$ later, spleen cells were stained for expression of CCR5 and XCR1 on monocytes. (E) Lm-Ova immunized mice were challenged with $L m$-Ova or not, and $1 \mathrm{hr}$ before sacrifice, $5 \mu \mathrm{g}$ Ly6C-PE $\mathrm{mAb}$ was injected i.v. to the hosts. Spleens were harvested and cells stained for cell surface CD11b, Ly6C-PerCpCy5.5, ICAM-1, CD86 and intracellular TNF $\alpha$ and CXCL9. After gating on Ly6C-PerCpCy5.5 $5^{+}$monocytes, Ly6C-PE ${ }^{\text {hi }}$ and Ly6C-PE ${ }^{\text {low }}$ monocytes were identified and further analyzed for indicated marker expression. Representative FACS dot plots are shown and bar graphs pool 2 independent replicate experiments with $\mathrm{n}=6(\mathrm{~A}, \mathrm{D})$ and $5(\mathrm{~B}, \mathrm{C}$ and $\mathrm{E})$ mice. $\mathrm{P}$ values are indicated. 


\section{Figure 7. Memory $\mathrm{CD8}^{+} \mathrm{T}$ cell-mediated protection of vaccinated hosts requires both} cognate Ag and IFN $\gamma$-signaling. $2 \times 10^{5} \mathrm{OT}-\mathrm{I} \mathrm{T}_{\mathrm{M}}$ cells induced using the depicted experimental set up (as in Figure 4B) were transferred in age- and sex-matched WT B6 or Ifngrl ${ }^{-/}$mice, and mice were next challenged with $10^{6} \mathrm{Lm}$ or Lm-Ova. (A) Control groups did not receive OT-I $\mathrm{T}_{\mathrm{M}}$ cells. Spleens and livers from challenged mice were harvested 24 hrs later and Lm CFUs determining after plating. Bar graphs show 1of 2 representative experiments with each symbol corresponding to 1 individual mouse. (B) Spleens from WT or $I f n g r 1^{-/}$mice transferred with OT-I $\mathrm{T}_{\mathrm{M}}$ cells and challenged with indicated $\mathrm{Lm}$, were harvested and cells stained for expression of cell surface CD11b, Ly6C and Ly6G and intracellular TNF $\alpha$ and CXCL9. Representative FACS dot plots are shown and bar graphs pool two representative experiments ( $n=7$ mice) and pvalues are indicated. 


\section{Supplemental Figure Legends;}

Figure S1, related to Figure 2. (A) Spleen cells were isolated from Lm-Ova-immunized mice $\left(10^{4}\right)$ that were rechallenged 6 wks later with $10^{6} \mathrm{Lm}$-Ova. At 8 hrs post challenge, spleen cells were incubated or not with Golgi Plug/Stop, before collecting supernatants 4 hrs later. CCL3 and IFN $\gamma$ were next quantified by ELISA. (B) Subsets of OT-I T $\mathrm{T}_{M}$ subsets were flow-sorted from the spleens of mice transferred with naïve OT-I cells and immunized with $10^{4} \mathrm{Lm}$-Ova 6 wks before (schematic), based on CX3CR1 and CD27 cell surface marker expression ( $\mathrm{T}_{\mathrm{EM}}$ : $\mathrm{CX} 3 \mathrm{CR} 1{ }^{\text {hi }} \mathrm{CD} 27^{\text {low }}, \mathrm{T}_{\mathrm{PM}}$ : CX3CR $1{ }^{\text {int }} \mathrm{CD} 27^{\text {hi }}, \mathrm{T}_{\mathrm{CM}}$ : CX3CR $1{ }^{\text {low }} \mathrm{CD} 27^{\text {hi }}$ ). Sorted (gates are shown) OT-I $\mathrm{T}_{\mathrm{M}}$ subsets were next stimulated for $4 \mathrm{hrs}$ with the SIINFEKL peptide $\left(10^{-8} \mathrm{M}\right)$ in vitro and stained for cell-surface CD8, CXCR3, KLRG1 and intracellular CCL3, CCL4, XCL1 and IFN $\square$. Representative dot plots with summary bar graphs (each symbol is 1 mouse) show the proportion of chemokines ${ }^{+}$or cytokines ${ }^{+}$cells among $C D 8^{+} \mathrm{T}_{\mathrm{M}}$ subsets with indicated $\mathrm{p}$-value.

Figure S2, related to Figure 4. (A) $C c r 2^{C F P}$ mice grafted with OT-I cells were immunized with $10^{4} \mathrm{Lm}$-Ova and 6 wks later challenged or not with $10^{6} \mathrm{Lm}$-Ova for 3, 6, 16 and $40 \mathrm{hrs}$. Ccr2 ${ }^{\mathrm{CFP}}$ monocytes are in green and representative mouse spleen tile reconstructions are shown. Graphs shows the volume of individual clusters and the average proportion of $\mathrm{CCR} 2^{+}$monocytes clustered in a pool of 2 independent experiments ( $n=2-5$ mice). (B) Age- and sex-matched WT B6 mice were transferred with OT-I cells and injected with PBS or immunized with $10^{4} \mathrm{Lm}$-Ova. 6 wks later, PBS-injected mice were challenged with $10^{6} \mathrm{Lm}$-Ova ("Primary"), and Lm-Ovaimmunized mice were challenged with $10^{6} \mathrm{Lm}$ or Lm-Ova ("Recall"). Bacterial titers in spleens and livers were determined 24hrs post challenge. Bar graphs represent 1 of 2 representative experiments with each symbol corresponding to an individual mouse ( $\mathrm{n}=4$ mice).

Figure S3, related to Figure 4. (A) $C c r 2^{C F P}$ mice grafted with OT-I cells were immunized with $V S V$-Ova $\left(2 \times 10^{5} \mathrm{PFU}\right)$ and 6 wks later challenged with $10^{6} \mathrm{Lm}$ or $\mathrm{Lm}$-Ova for $16 \mathrm{hrs}$. Ccr2 ${ }^{\mathrm{CFP}}$ monocytes are in green and representative tiles of reconstructed mouse spleens are shown. Graphs show the volume of individual clusters and the average proportion of $\mathrm{CCR} 2^{+}$monocytes clustered in 2 independent replicate experiments ( $\mathrm{n}=2$ mice). (B) $2 \times 10^{5}$ flow-sorted- OT-I $\mathrm{T}_{M}$ cells generated as depicted in Figure $4 \mathrm{~B}$, were transferred to naive $C c r 2^{C F P}$ that were also

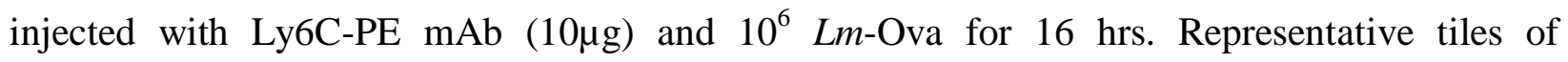


reconstructed mouse spleens in 1 of 2 replicate experiments are shown with $\mathrm{Ccr} 2^{\mathrm{CFP}}$ monocytes in green and Ly6C-PE ${ }^{+}$monocytes in red $(n=4$ mice). Green and red signals are merged in yellow.

Figure S4, related to Figure 5. $C c r 2^{C F P}$ mice were co-transferred with naïve OT-I $\mathrm{Td}^{+}$and gBT-I GFP ${ }^{+}$cells and immunized with $10^{4} \mathrm{Lm}$-Ova-gB. Six wks later, mice were challenged with $10^{6} \mathrm{Lm}$ or $\mathrm{Lm}$-Ova-gB and IVM images in the spleen of live mice were recorded $16 \mathrm{hrs}$ later. (A) Representative IVM image (right) of OT-I (red) and gBT-I (green) $\mathrm{T}_{M}$ cells localized in a cluster (delimited area by white dashed line) of CCR2 ${ }^{\mathrm{CFP}}$ monocytes (blue) are shown with autofluorescence (yellow). OT-I $\mathrm{T}_{\mathrm{M}}$ (outside, red and inside, yellow) and gBT-I $\mathrm{T}_{\mathrm{M}}$ cell tracks (outside, green and inside, purple) inside and outside the cluster of CCR2 ${ }^{\mathrm{CFP}}$ monocytes are also shown (center and left images). Graphs represent the speeds of OT-I and gBT-I T $\mathrm{T}_{\mathrm{M}}$ cells in the clusters. (B) Graph represent the density of OT-I or gBT-I $\mathrm{T}_{\mathrm{M}}$ cells inside and outside of monocyteclusters after Lm, Lm-Ova or Lm-Ova-gB challenges. (C, D) Efficiency of DTmediated depletion in indicated groups and compartments of mixed BM chimeras. Representative FACS dot plots in a pool of 2 experiments with $\mathrm{p}$-value are shown ( $\mathrm{n}=5$ mice).

Figure S5, related to Figure 6. (A, B) Mice grafted with OT-I cells were immunized with LmOva and 6 wks later challenged with $10^{6} \mathrm{Lm}$-Ova. Sixteen hrs post-challenge, monocytes and neutrophils were sorted from spleen and stimulated for 4 hrs with or without recombinant chemokines at indicated concentrations, or with HKLm and with or without CCR1/5 inhibitors (depicted in Figure 6C). Cells were next stained for cell surface expression of CD11b, Ly6C, Ly6G and intracellular TNF $\alpha$. Representative FACS dot plots are shown. (B) Graphs show $\mathrm{TNF}^{+}$monocytes and neutrophils frequency after $4 \mathrm{hrs}$ incubation with recombinant chemokines (1 and $0.3 \mu \mathrm{g}$ ) or HKLm. Bar graphs (each symbol is 1 mouse) represent the pool of 2 independent replicate experiments with p-values indicated. (C) Splenocytes from WT naive mice injected with PBS were stimulated in vitro with HKLm or rCCL3 $(1 \mu \mathrm{g})$. Cells were stained as above. Representative FACS dot plots with summary bar graphs (each symbol is 1 mouse) with indicated p-value are shown. (D) $\mathrm{TNF} \alpha$ expression in flow-sorted neutrophils as depicted in Figure 6C, incubated with CCR5 and CCR1 inhibitors or DMSO vehicle. Bar graphs (each 
symbol is 1 mouse) represent the pool of 2 independent replicate experiments with p-values indicated.

Figure S6, related to Figure 6. (A-B) $L m$-Ova-immunized mice were co-transferred with naive OT-I Td ${ }^{+}$cells and challenged or not $\sim 6$ wks later with $L m$-Ova for $16 \mathrm{hrs}$. $1 \mathrm{hr}$ before sacrifice, mice were injected i.v. with Ly6C-PE mAb. (A) Representative tiles of reconstructed mouse spleens in 1 of 2 replicate experiments are shown with Ccr2 ${ }^{\mathrm{CFP}}$ monocytes in green and Ly6C$\mathrm{PE}^{+}$monocytes in red. Green and red signals are merged in yellow. Bar graphs represent the intensity of Ly6C-PE staining (MFI) on non-clustered and clustered monocytes at 1 or $16 \mathrm{hrs}$ post Ly6C-PE mAb injection across 2 replicate experiments $(\mathrm{n}=2-4$ mice). $r$ corresponds to the ratio of MFI between clustered and non-clustered monocytes. (B) Gating strategy to identify by flow cytometry Ly6C-PE ${ }^{\text {hi }}$ and Ly6C-PE ${ }^{\text {low }}$ monocytes, after gating on Ly6C-PerCpCy5.5 monocytes following the experimental design as described above. (C) Representative dot plots and FACS histograms of cell-surface ICAM-1 and CD86 expression on Ly6C-PE ${ }^{\text {hi }}$ and Ly6C$\mathrm{PE}^{\text {low }}$ monocytes are shown. Bar graphs pool 2 independent replicate experiments with each symbol corresponding to one mouse and indicated $\mathrm{p}$-value $(\mathrm{n}=5$ mice).

Figure S7, related to Figure 7. (A) Mice were immunized with $2 \times 10^{5} \mathrm{PFU} V S V$-Ova or injected with PBS, and $\sim 6$ wks later challenged with $10^{6} \mathrm{Lm}$ or $\mathrm{Lm}$-Ova. Spleens and livers from challenged mice were harvested $24 \mathrm{hrs}$ later and $\mathrm{Lm}$ CFUs determined after plating. Bar graphs show 1 of 2 representative experiments with each symbol corresponding to 1 individual mouse. (B) $2 \times 10^{5}$ OT-I $\mathrm{T}_{\mathrm{M}}$ cells induced using the depicted experimental set up, were transferred in Ifngr $1^{-/}$mice, and mice were next challenged with $10^{6} \mathrm{Lm}$ or $\mathrm{Lm}$-Ova for $16 \mathrm{hrs}$. OT-I Td ${ }^{+} \mathrm{T}_{\mathrm{M}}$ cells were stained for cell surface CD8, CD3 and intracellular CCL4 and IFN $\gamma$. Representative FACS dot plots are shown and bar graphs pool 2 independent replicate experiments $(\mathrm{n}=4$ mice) with indicated p-values.

Movie S1. Dynamic behavior of cognate antigen- versus inflammation-stimulated memory $\mathrm{CD8}^{+} \mathbf{T}$ cells in $\mathrm{CCR2}^{+}$monocyte clusters during recall infection. Representative time-lapse movie showing cognate antigen (OT-I, red) and inflammation-stimulated gBT-I (green) $\mathrm{CD}^{+}$ $\mathrm{T}_{\mathrm{M}}$ cells in $\mathrm{CCR}^{+}$monocyte clusters $\left(\mathrm{CCR} 2^{\mathrm{CFP}}\right.$, blue) at $\sim 16 \mathrm{hrs}$ post challenge with Lm-Ova. 
Movie S2. Dynamic behavior of inflammation-stimulated memory $\mathrm{CD8}^{+} \mathrm{T}$ cells in $\mathrm{CCR2}^{+}$ monocyte clusters during recall infection. Representative time-lapse movie showing inflammation-stimulated (OT-I, red and gBT-I, green) $\mathrm{CD}^{+} \mathrm{T}_{\mathrm{M}}$ cells in $\mathrm{CCR}^{+}$monocyte clusters (CCR2 ${ }^{\mathrm{CFP}}$, blue) at $\sim 16 \mathrm{hrs}$ post challenge with $\mathrm{Lm}$.

Movie S3. Dynamic behavior of cognate antigen-stimulated memory $\mathrm{CD8}^{+} \mathrm{T}$ cells in $\mathrm{CCR2}^{+}$ monocyte clusters during recall infection. Representative time-lapse movie showing cognate antigen (OT-I, red and gBT-I, green) $\mathrm{CD}^{+} \mathrm{T}_{\mathrm{M}}$ cells in $\mathrm{CCR}^{+}$monocyte clusters $\left(\mathrm{CCR} 2^{\mathrm{CFP}}\right.$, blue) at $\sim 16$ hrs post challenge with $L m$-Ova-gB.

Table S1. List of genes up/down regulated for Ag/Infl., Infl. and Ag/Inf./Infl CD8 ${ }^{+} \mathrm{T}_{\mathrm{M}}$ cells as defined in Figure 1.

Table S2. GO pathways for Fig. 1E

Table S3. Table for antibodies and other reagents 
bioRxiv preprint doi: https://doi.org/10.1101/2021.03.01.433468; this version posted March 2, 2021. The copyright holder for this preprint (which was not certified by peer review) is the author/funder. All rights reserved. No reuse allowed without permission.

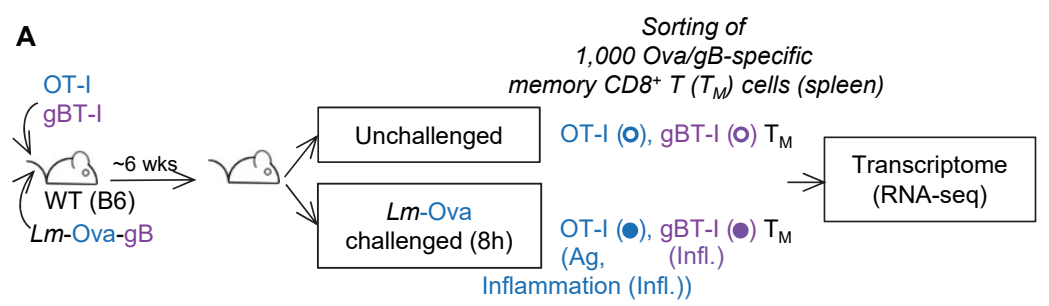

B

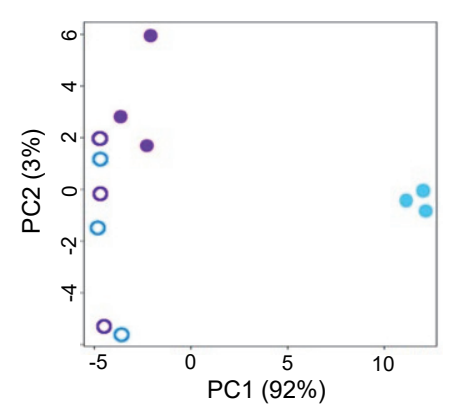

C Number of differentially expressed genes

in $\mathrm{Ag} / \mathrm{Infl}$. vs Infl. -activated $\mathrm{CD} 8^{+} \mathrm{T}_{\mathrm{M}}$

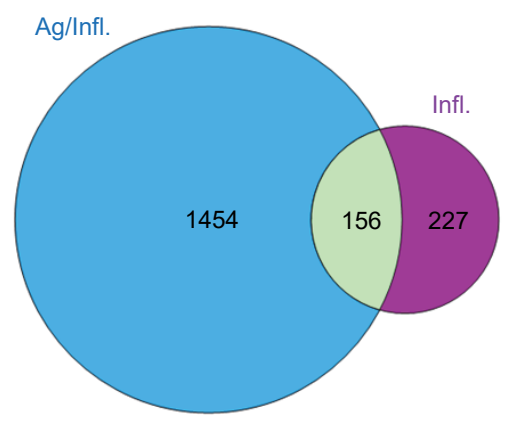

E

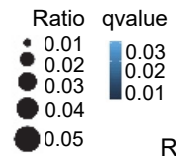

0.03

T cell receptor

Ribosome biogenesis Response to virus

Regulation of tumor necrosis factor production Regulation of leucocyte differentiation Regulation of apoptotic signaling pathway Positive regulation of defense response Positive regulation of cytokine production p38MAPK cascade Methylation Interleukin-1 production माल जो

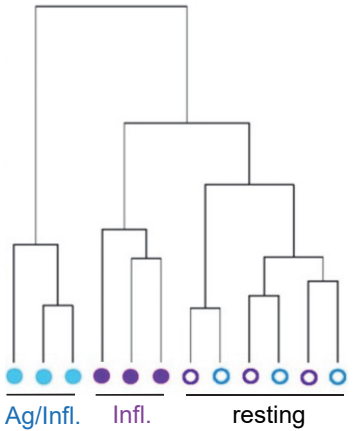

D

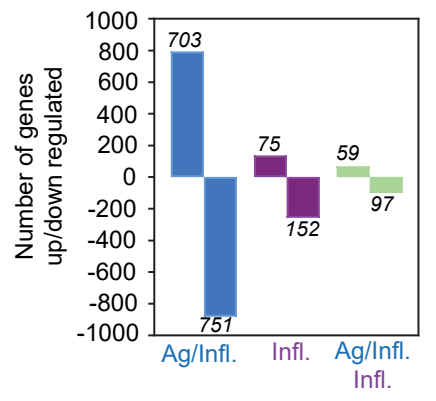

$\mathbf{F}$ Cytokines/chemokines Regulation of transcription Proliferation

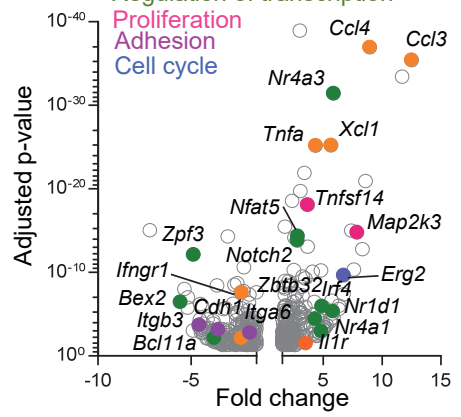

Figure 1 


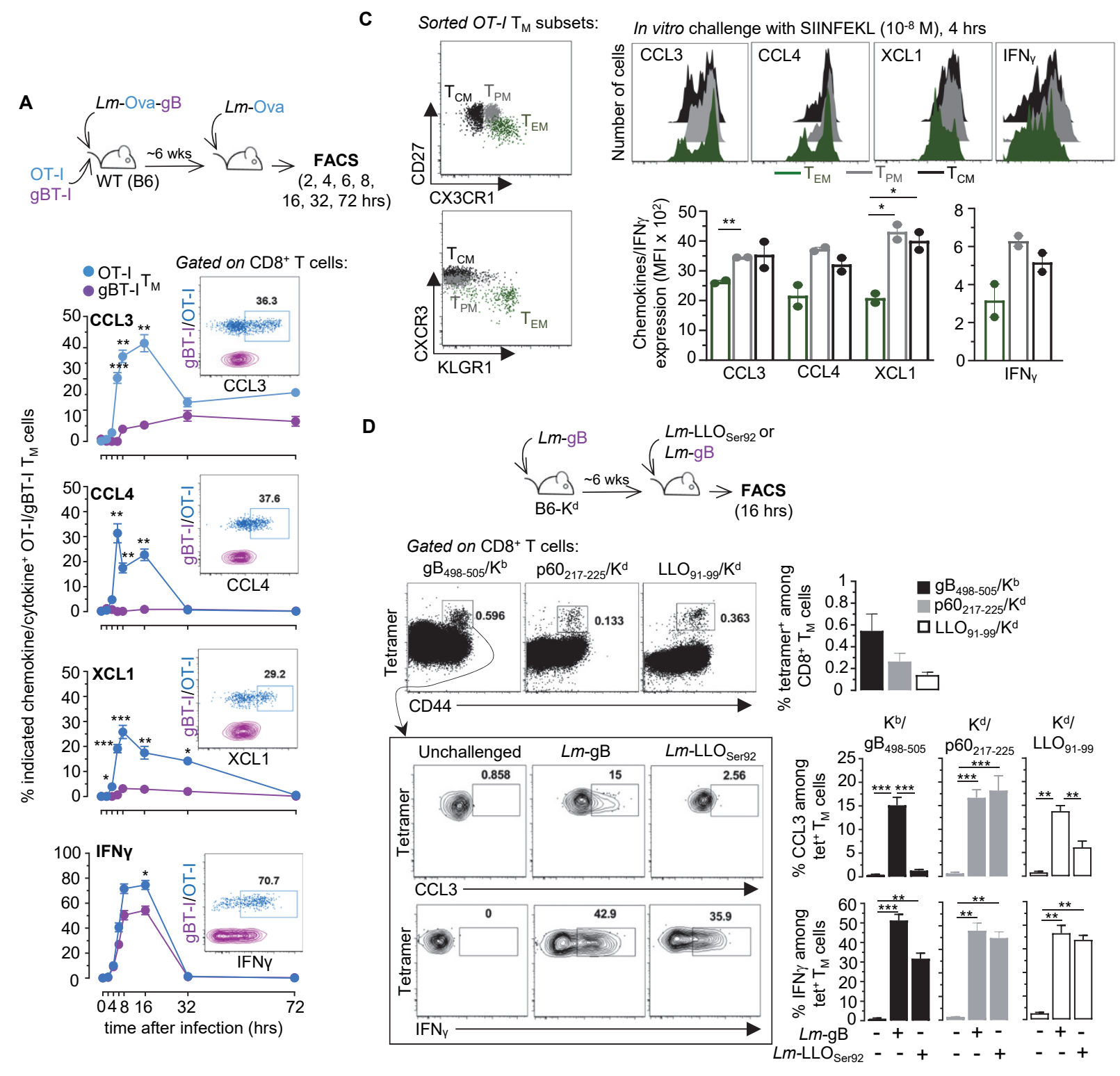

B

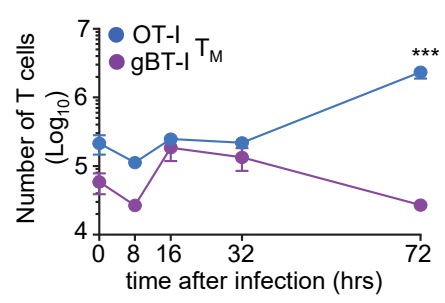

E

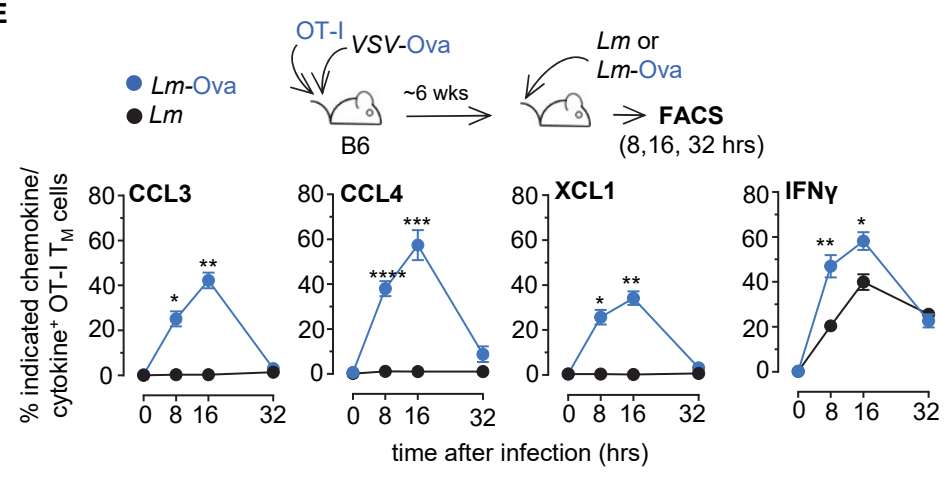

Figure 2 


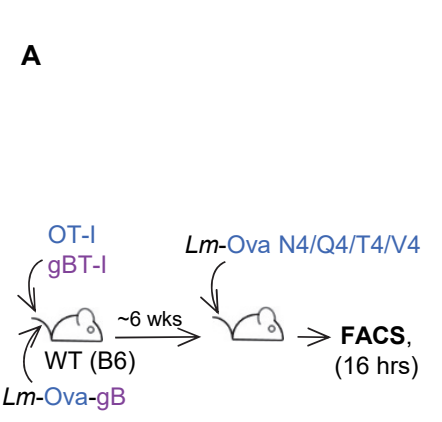

C

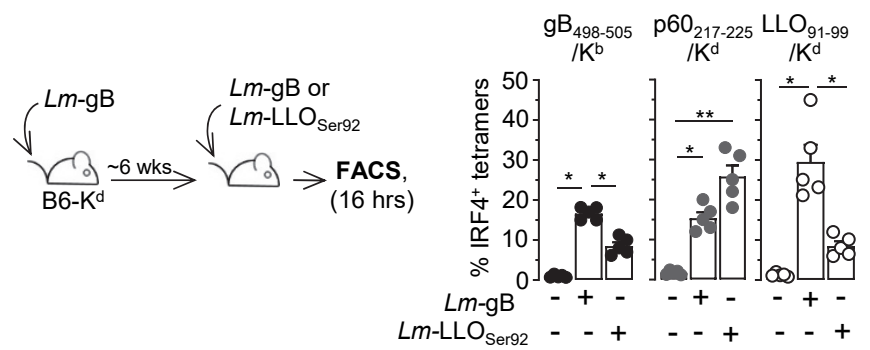

$\mathbf{E}$

In vitro challenge:

SIINFEKL $\left(10^{-8} \mathrm{M}\right), 6 \mathrm{hrs}$
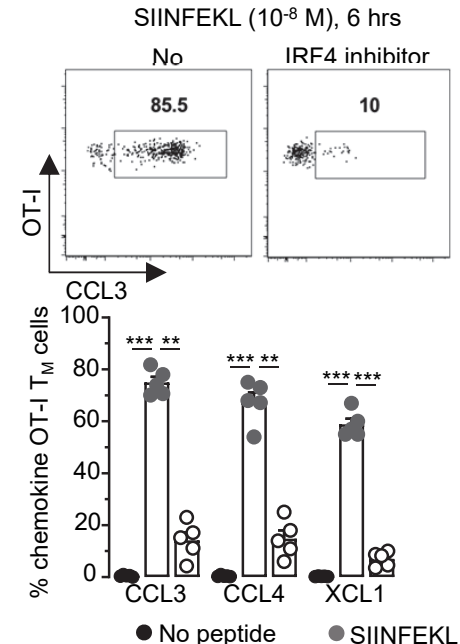

- No peptide

OT-I

gBT-I

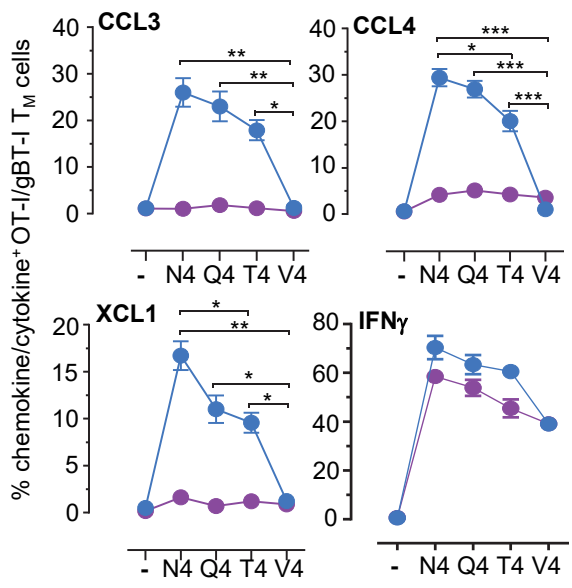

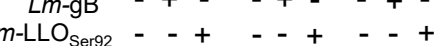
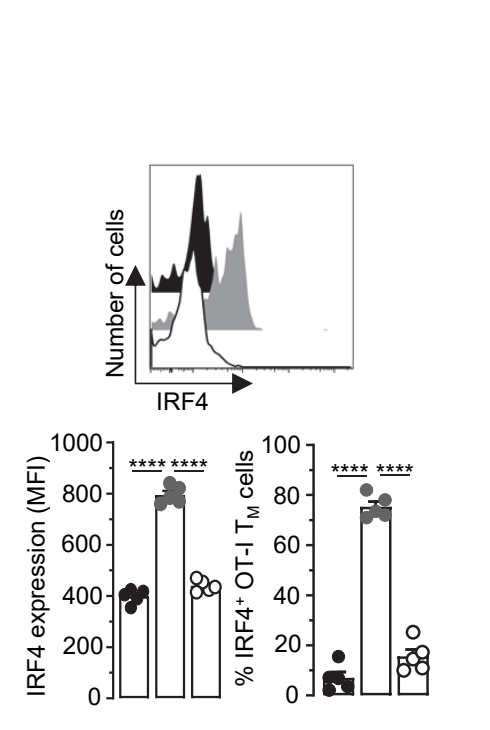

o SIINFEKL +IRF4 Inhibitor

F
B

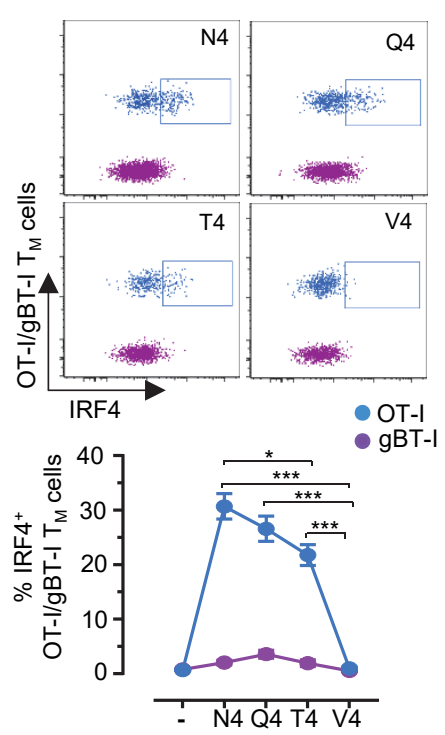

D

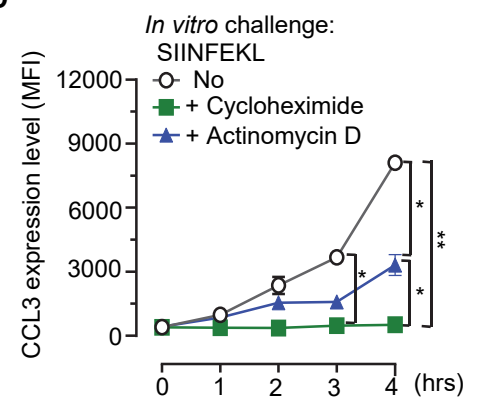

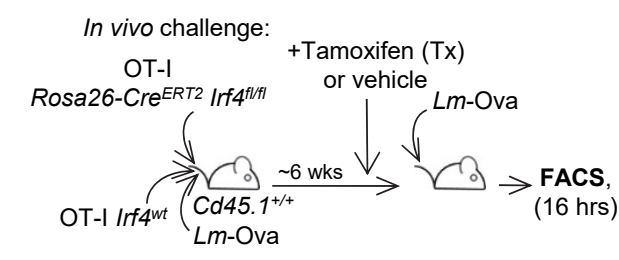

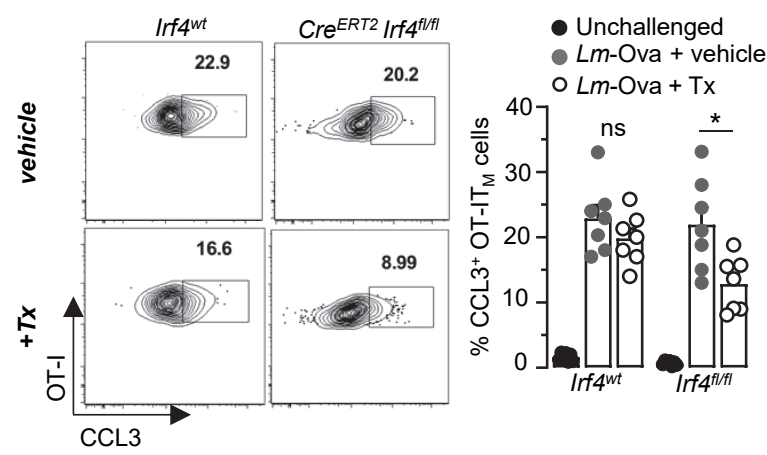

G

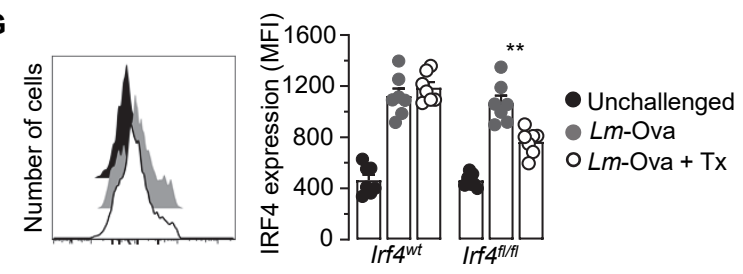

Figure 3 


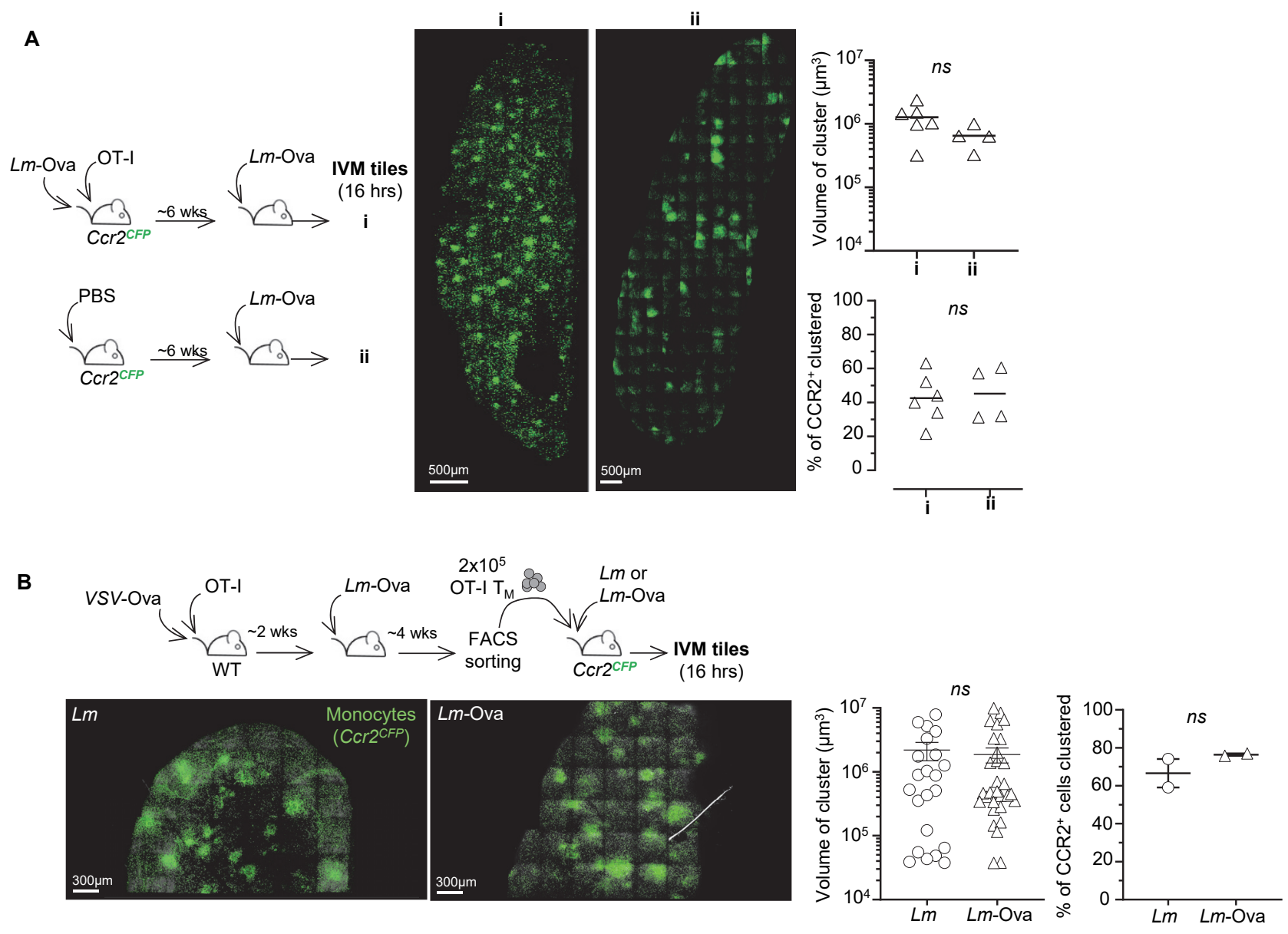

C
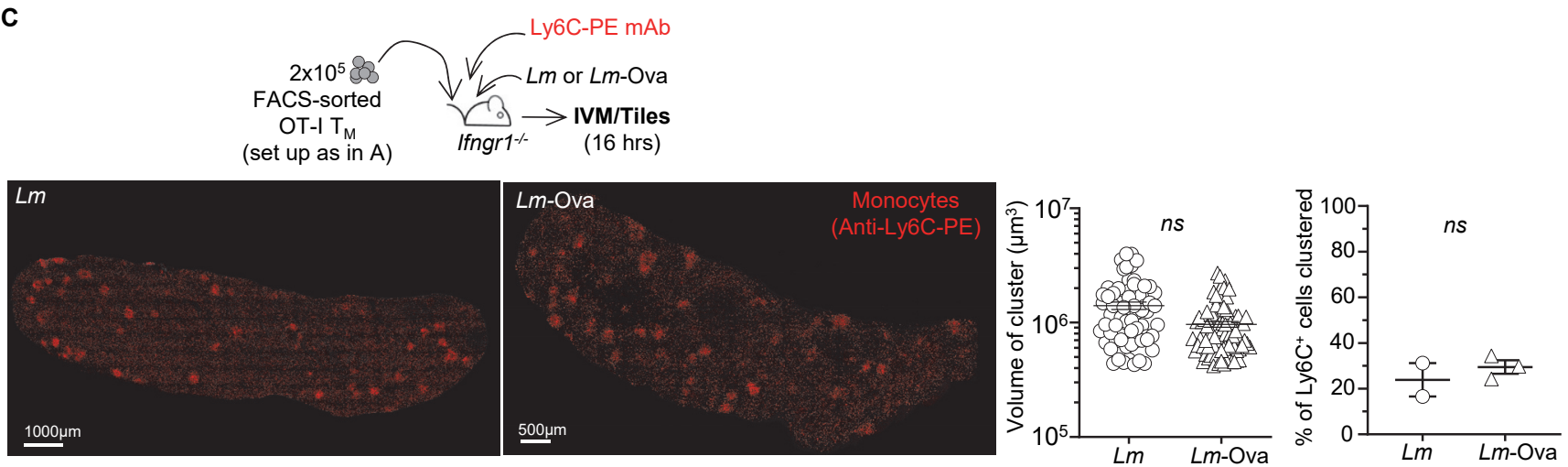

Figure 4 
A

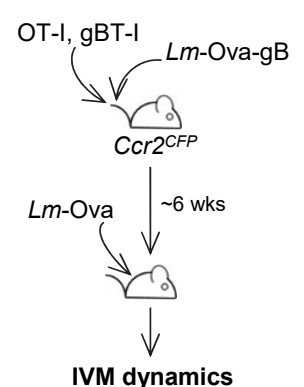

(16 hrs)
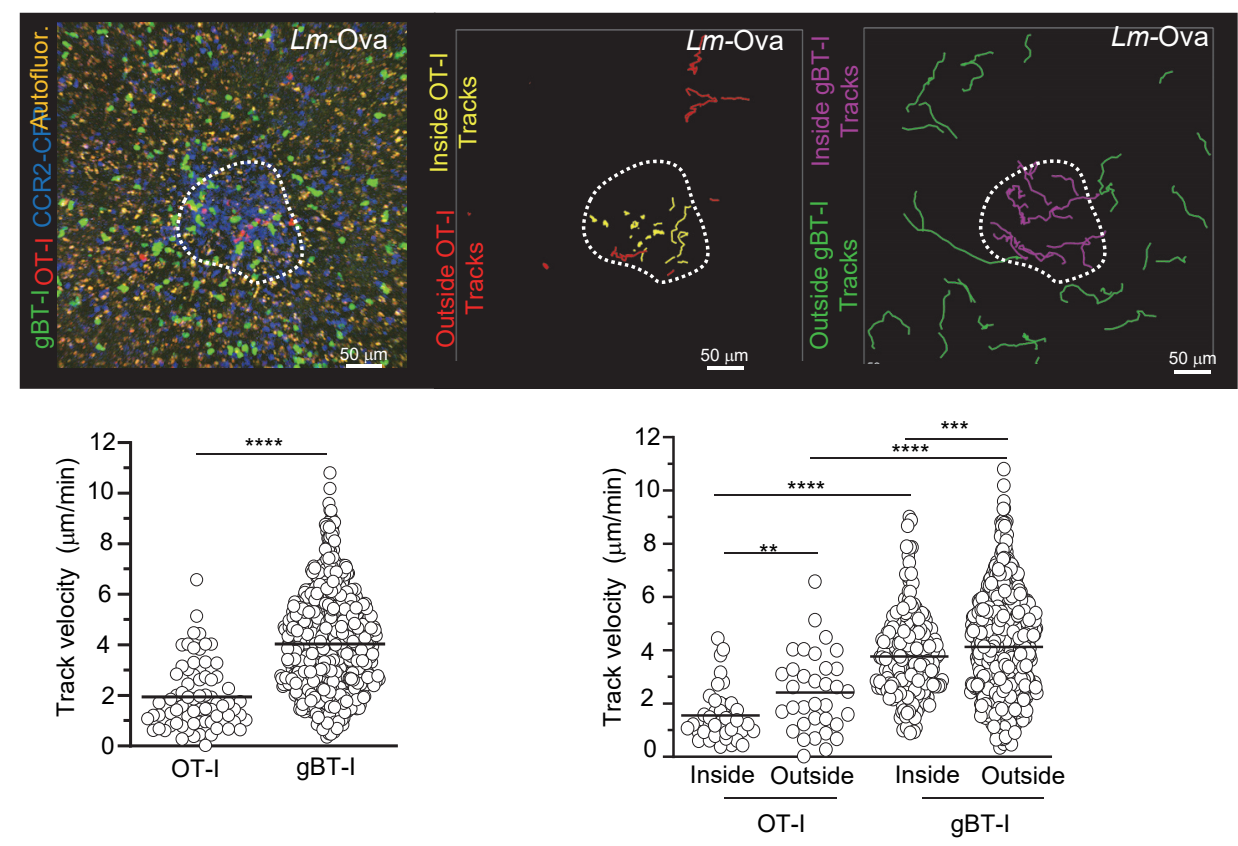

B
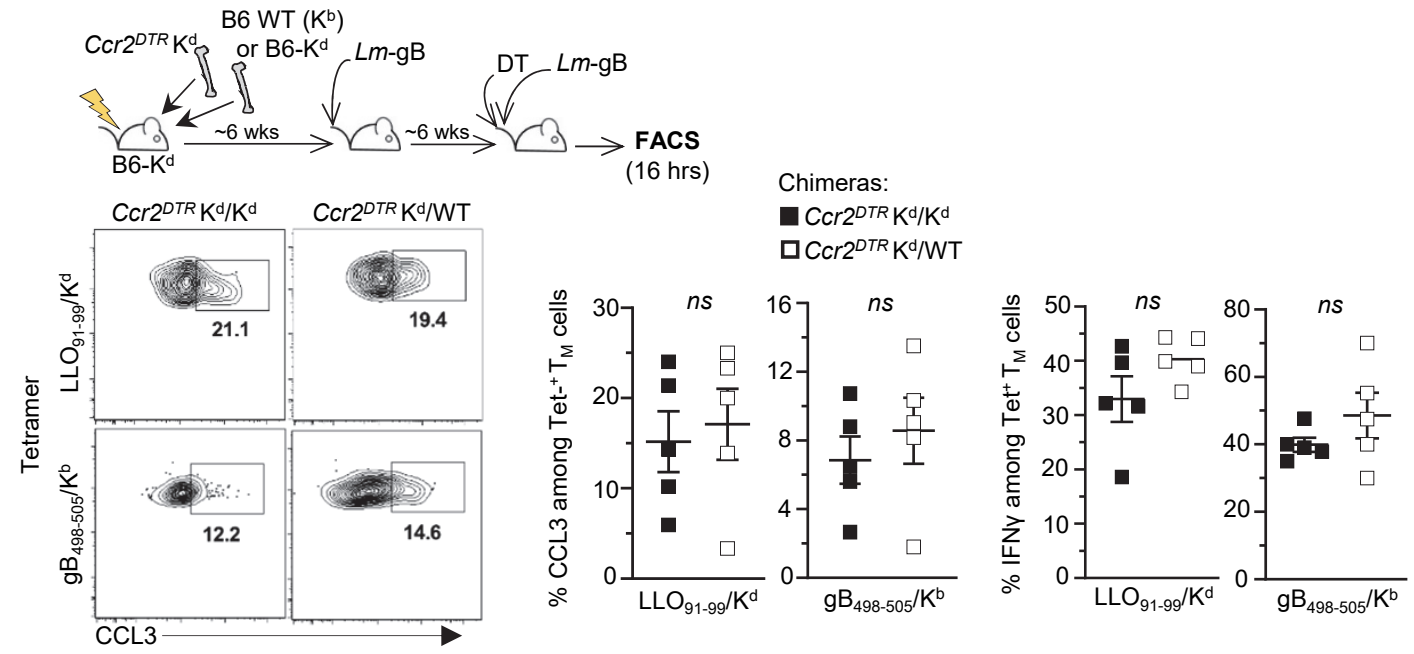

C
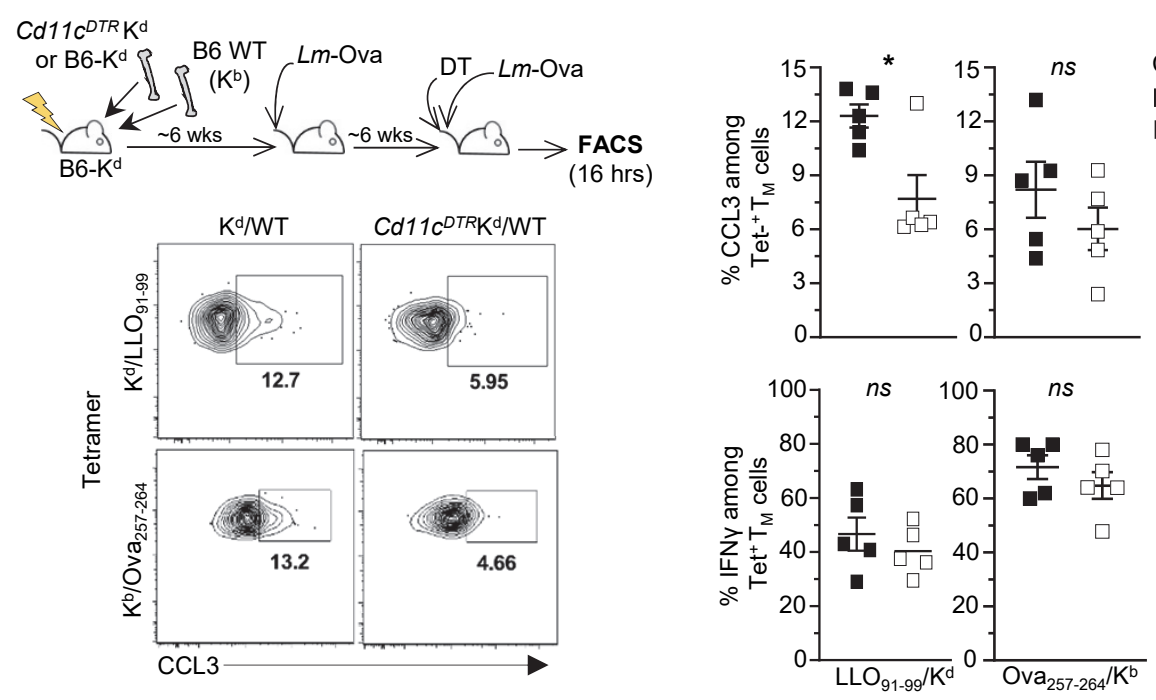

Chimeras

$\square C d 11 c^{D T R K} \mathrm{~d} / \mathrm{WT}$

Figure 5 
A Gated on Ly6C $\mathrm{C}^{+}$monocytes:
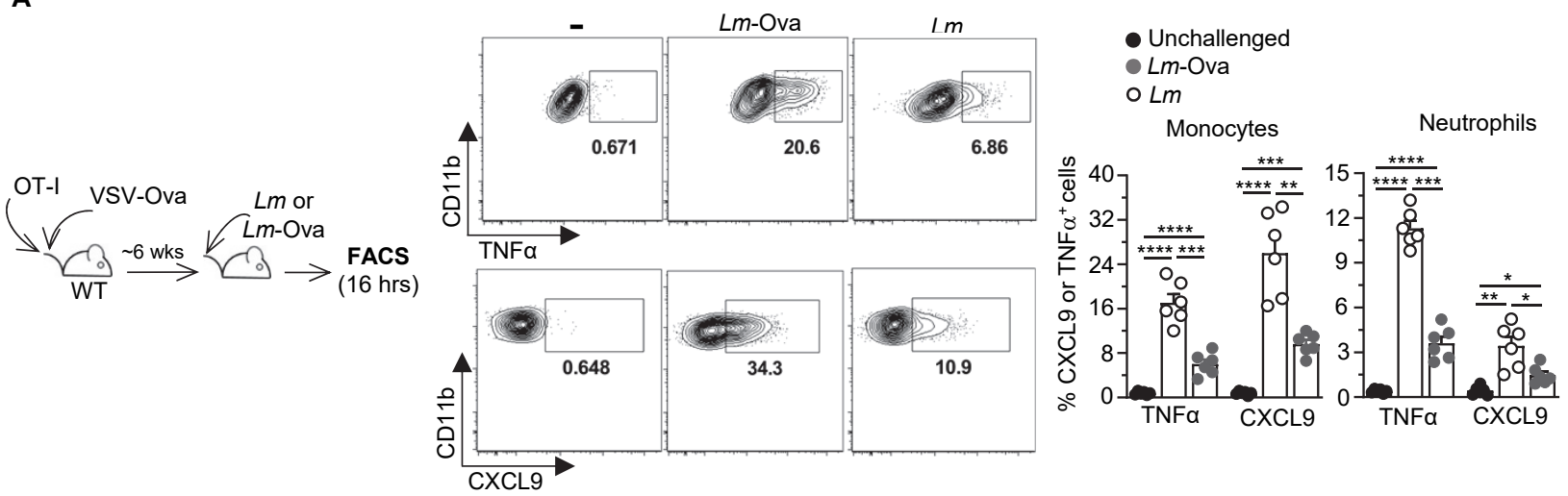

B
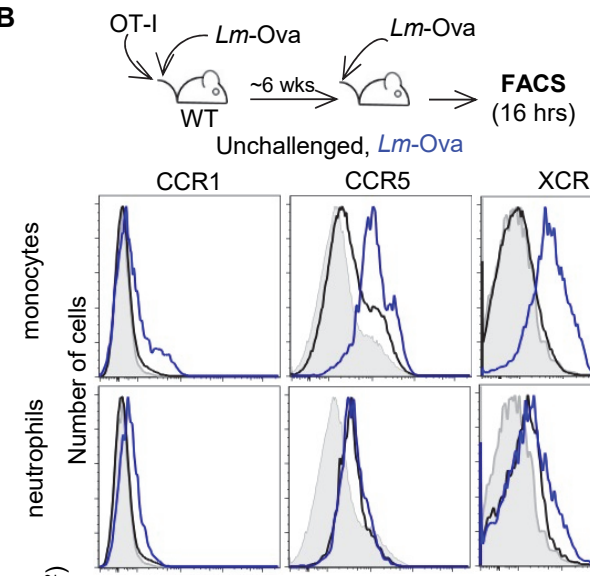

흉 윙 25 jCCR1

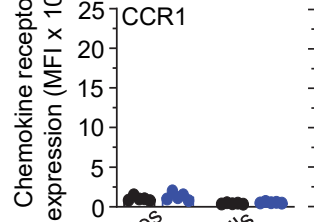

U $\frac{1}{x}$

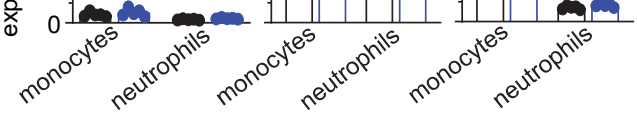

D

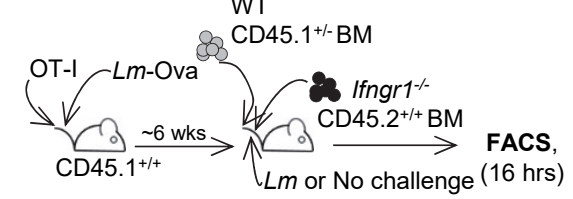

Gated on: - WT 1 Ifngr1 $\%$ transferred monocytes
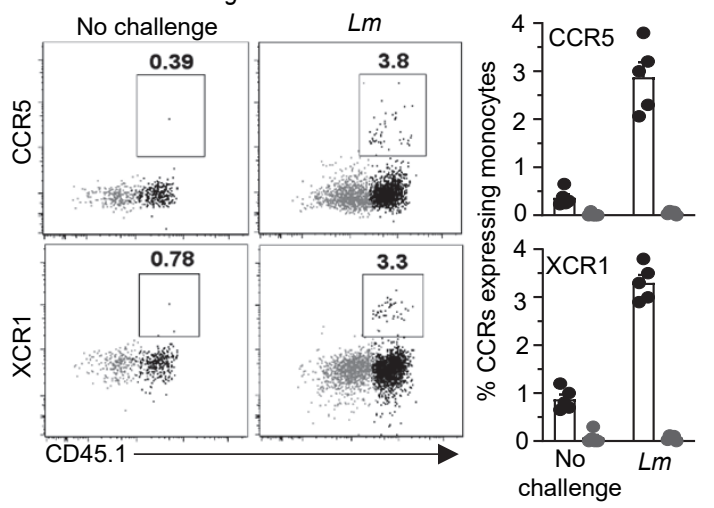

C
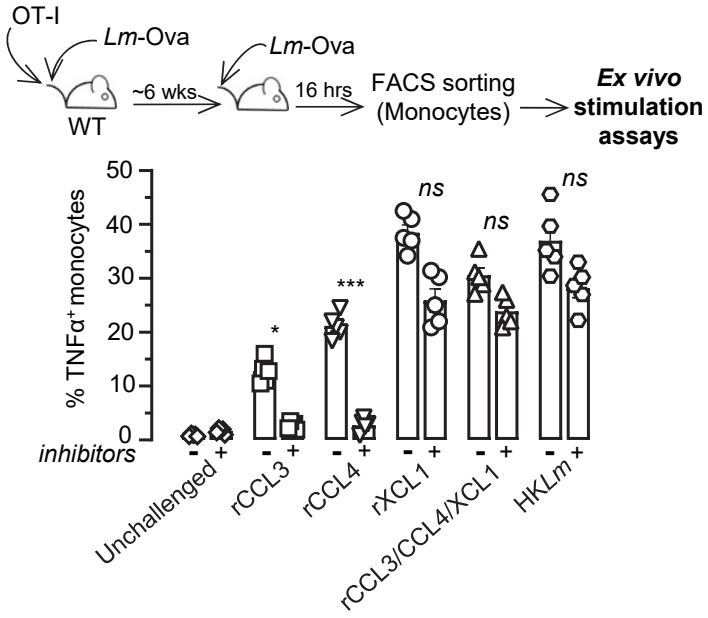

E
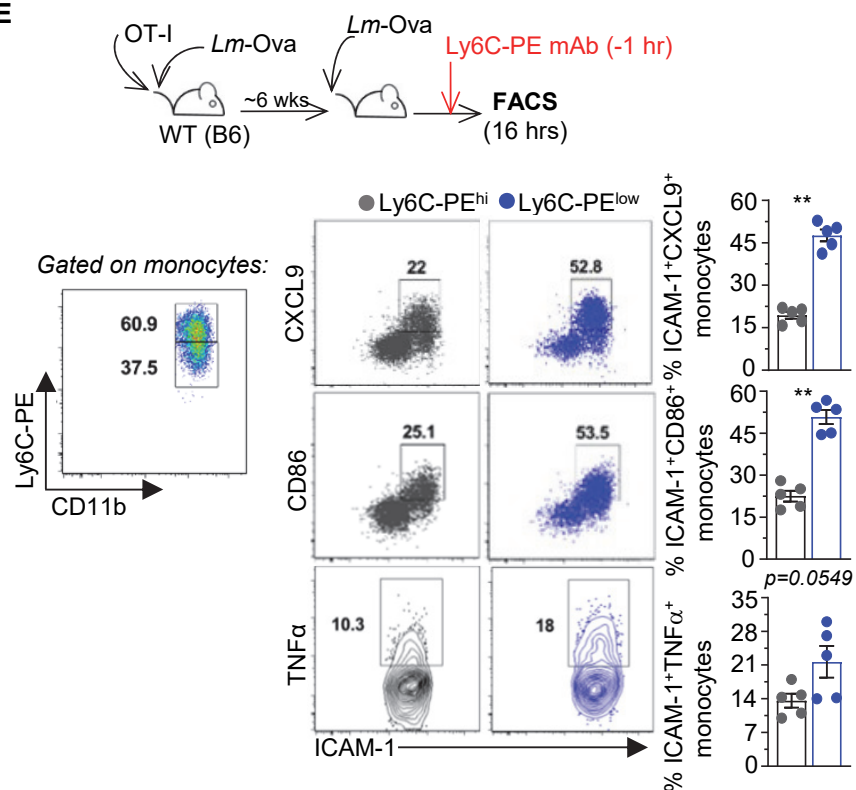

Figure 6 

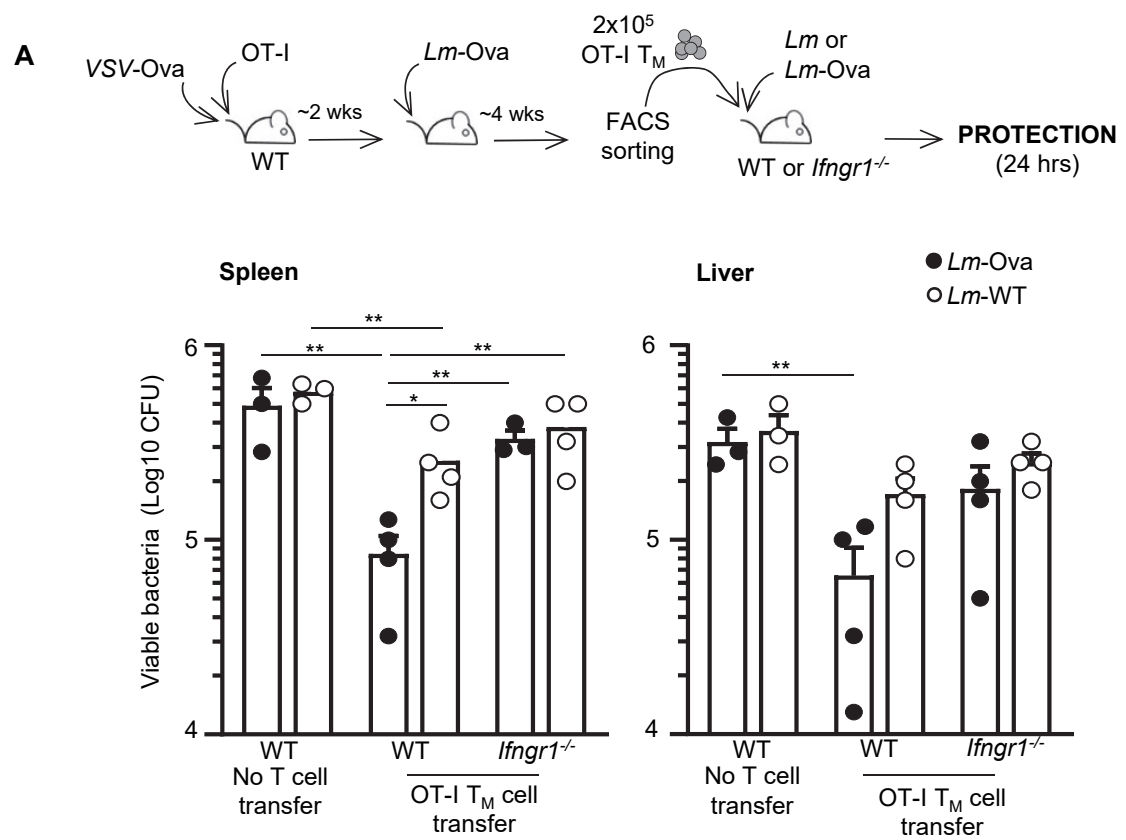

B

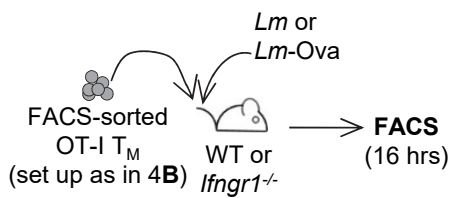

Gated on monocytes

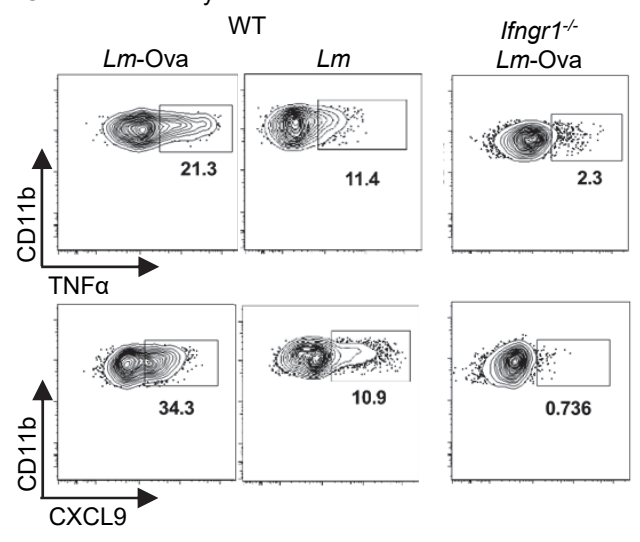

$$
\begin{aligned}
& \square L m \text {-Ova WT } \\
& \text { Lm } \\
& \square L m \text {-Ova, Ifngr1\% }
\end{aligned}
$$
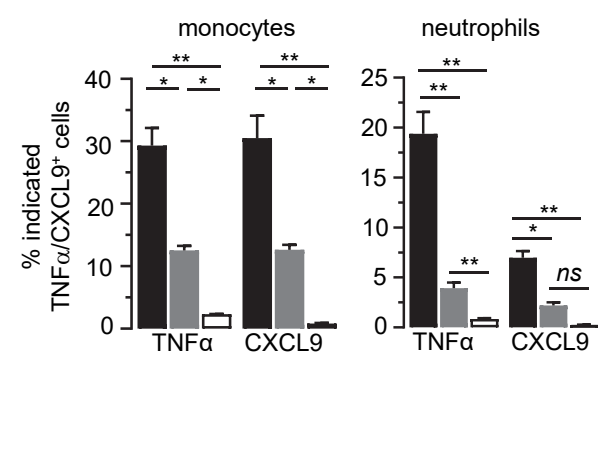

Figure 7 
A

Splenocytes from $8 \mathrm{hrs}-$ challenged immunized mice:

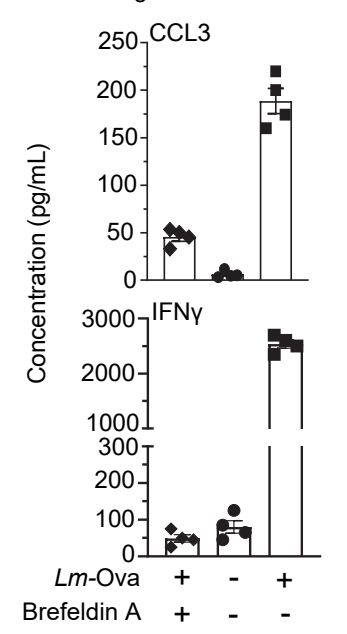

B
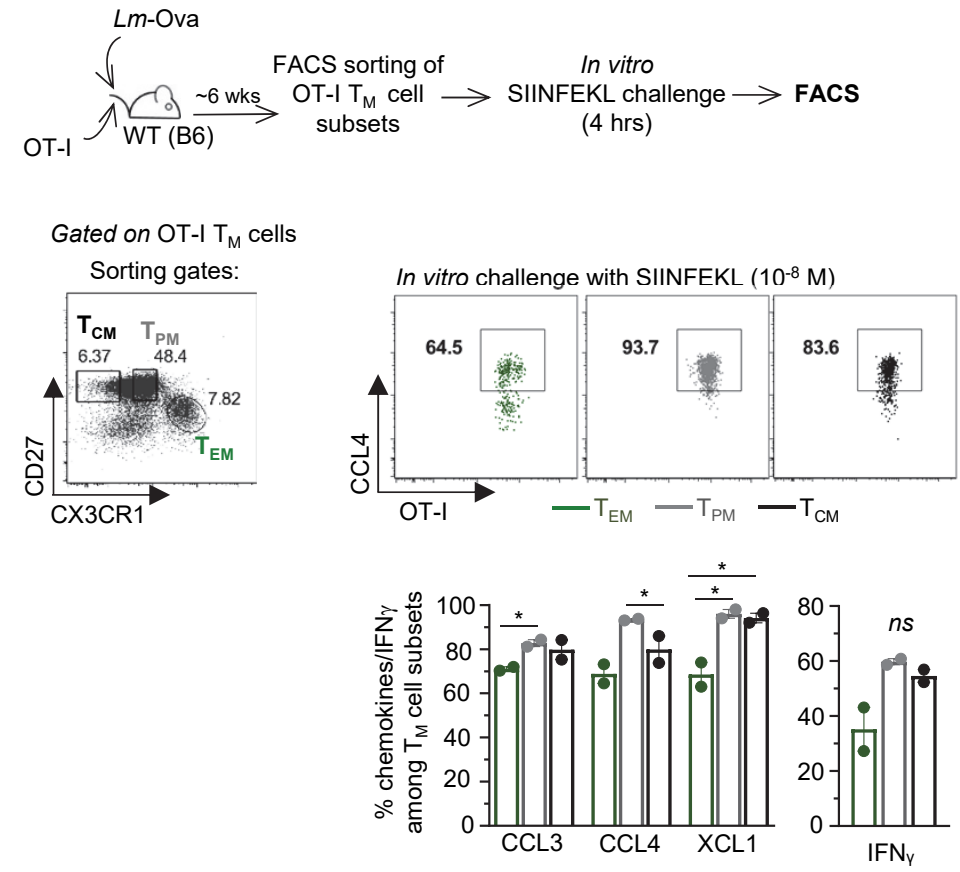

Figure S1 
A
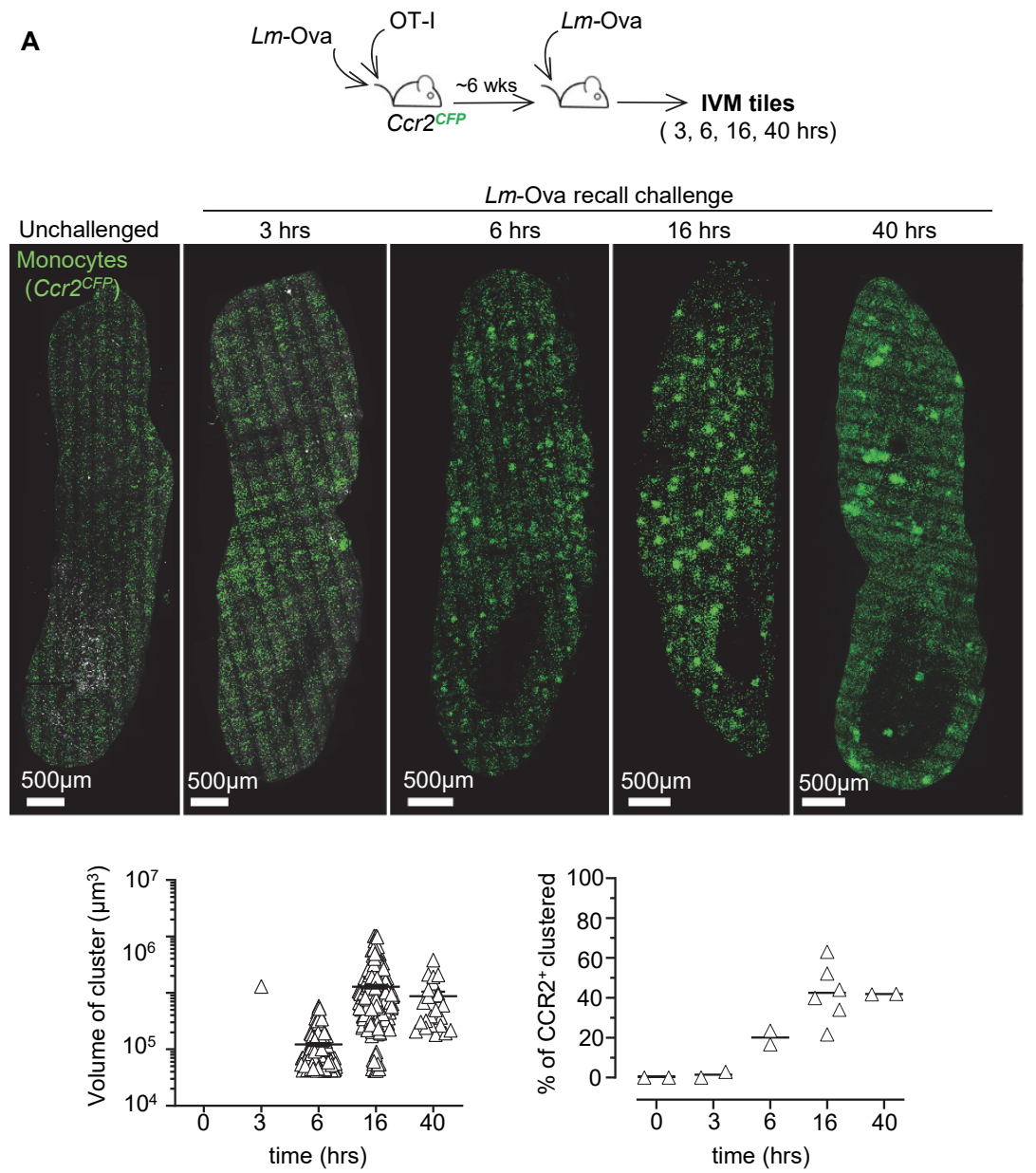

B

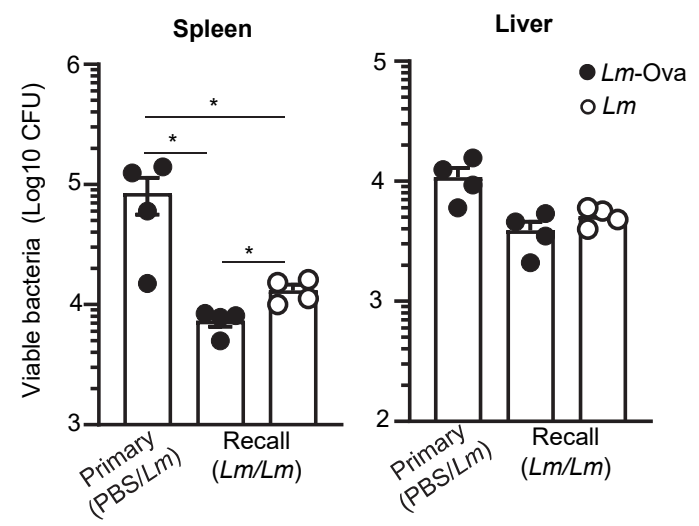

Figure S2 
bioRxiv preprint doi: https://doi.org/10.1101/2021.03.01.433468; this version posted March 2, 2021. The copyright holder for this preprint (which was not certified by peer review) is the author/funder. All rights reserved. No reuse allowed without permission.

B
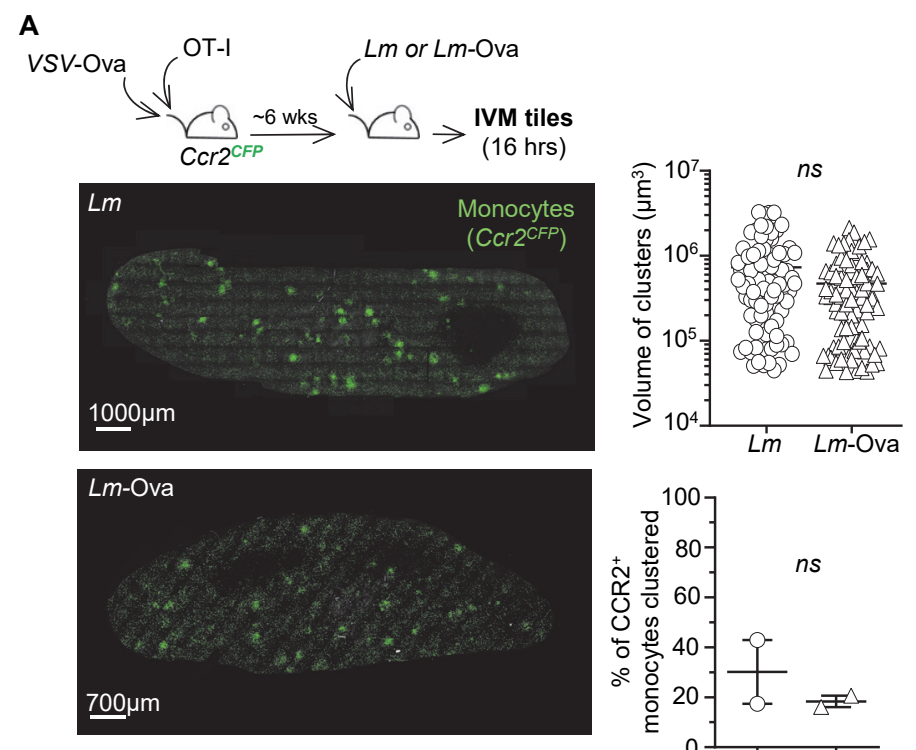

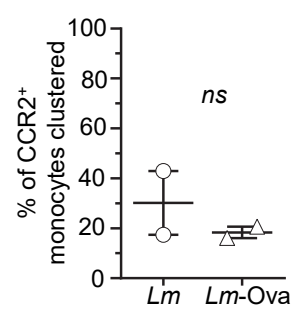

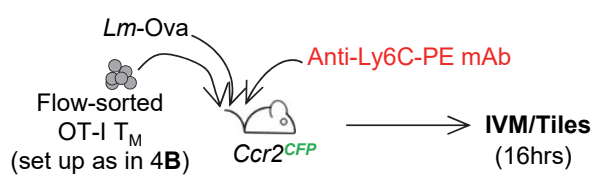
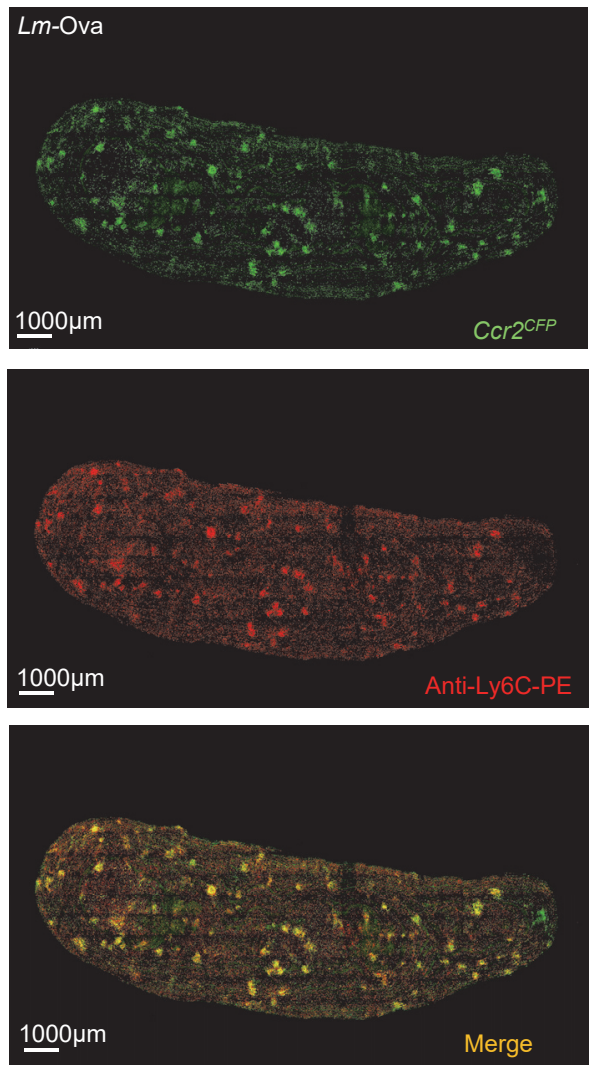

Figure S3 
bioRxiv preprint doi: https://doi.org/10.1101/2021.03.01.433468; this version posted March 2, 2021. The copyright holder for this preprint (which was not certified by peer review) is the author/funder. All rights reserved. No reuse allowed without permission.

A
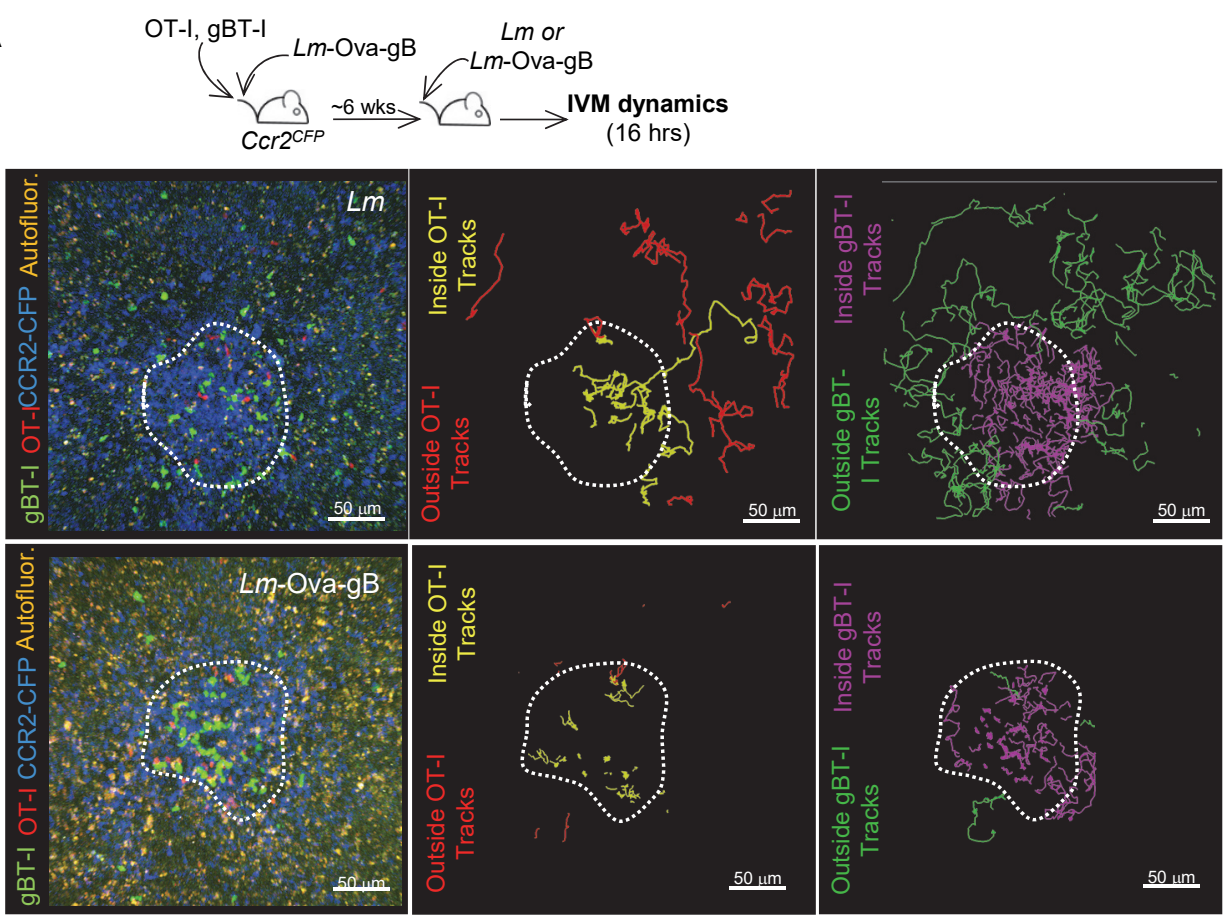

$50 \mu \mathrm{m}$
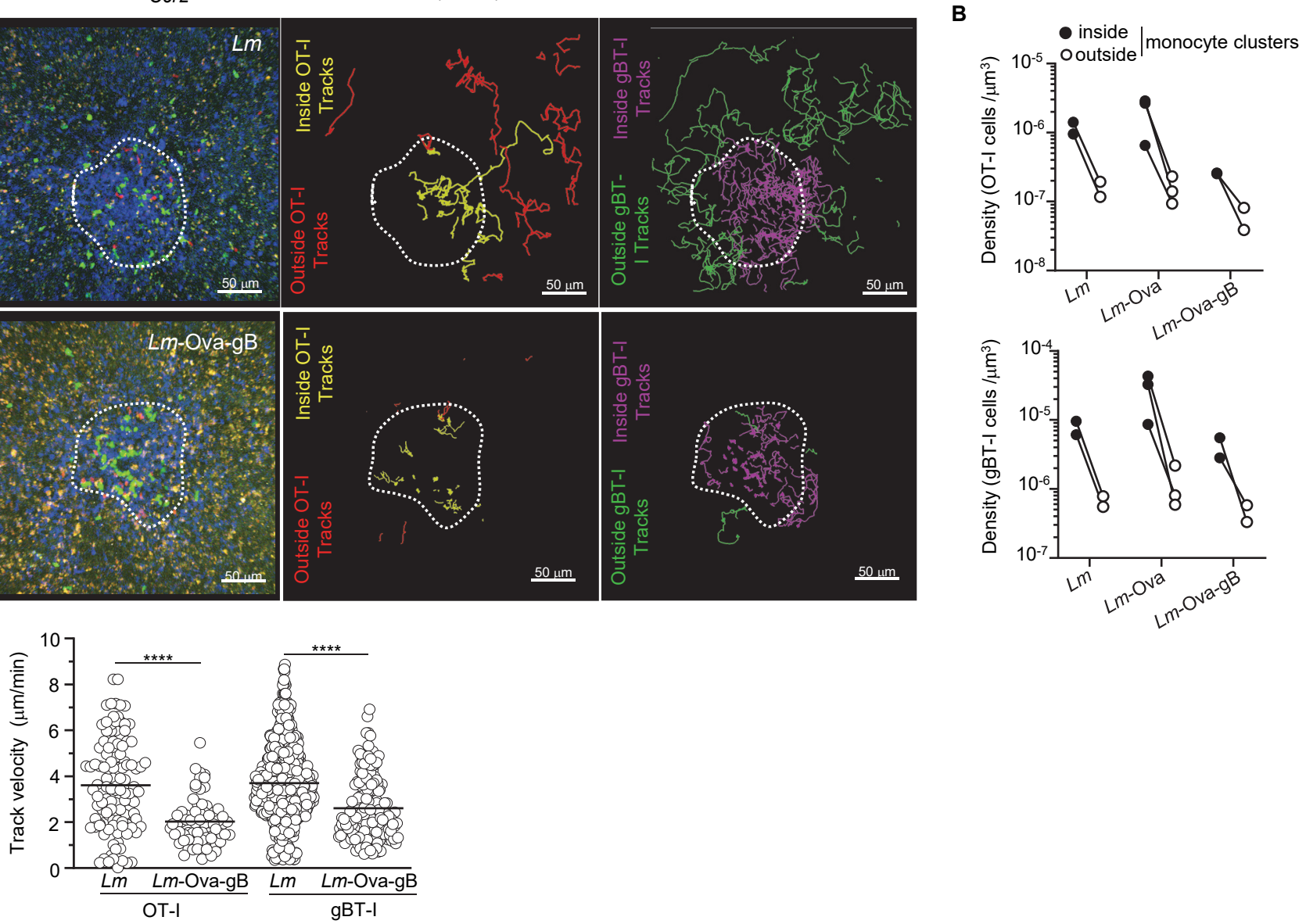

C

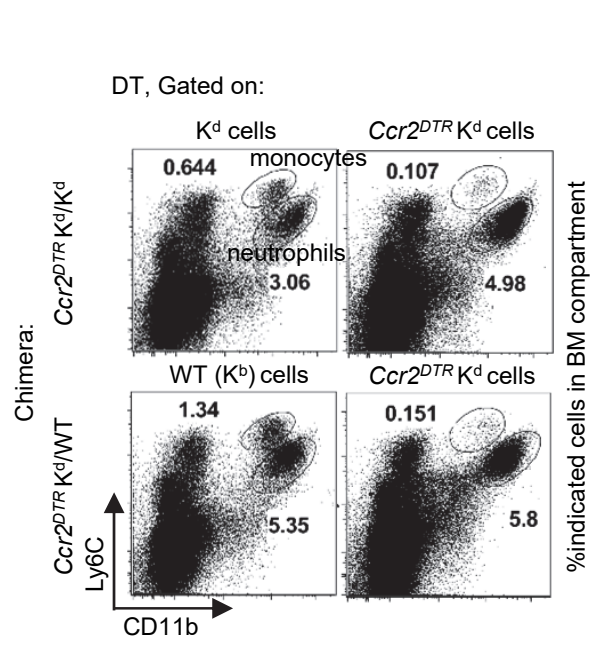

monocytes neutrophils

口Ccr2DTR $\mathrm{K}^{\mathrm{d}} \square \mathrm{K}^{\mathrm{d}}$

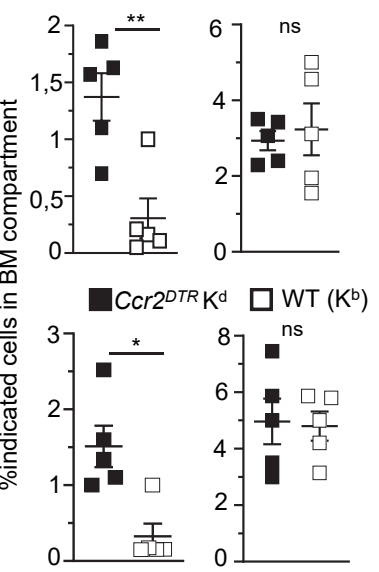

D

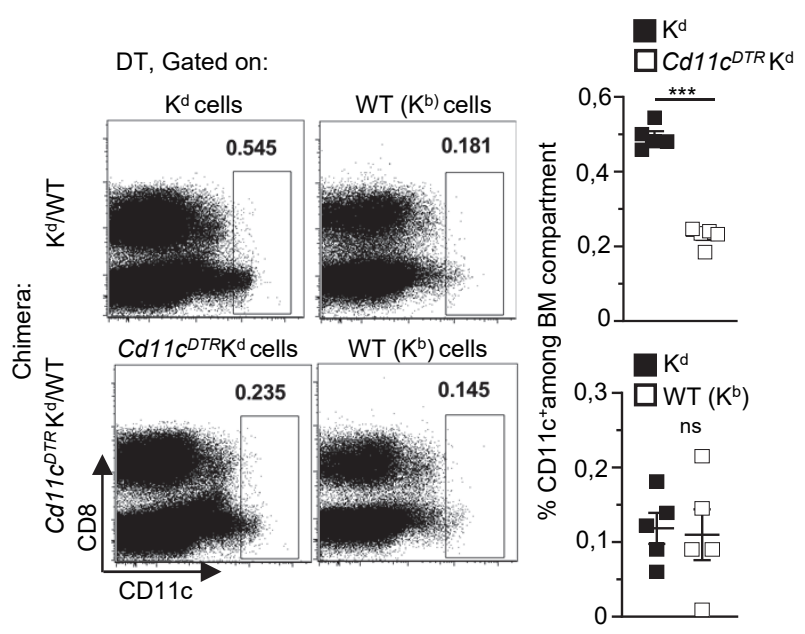


A
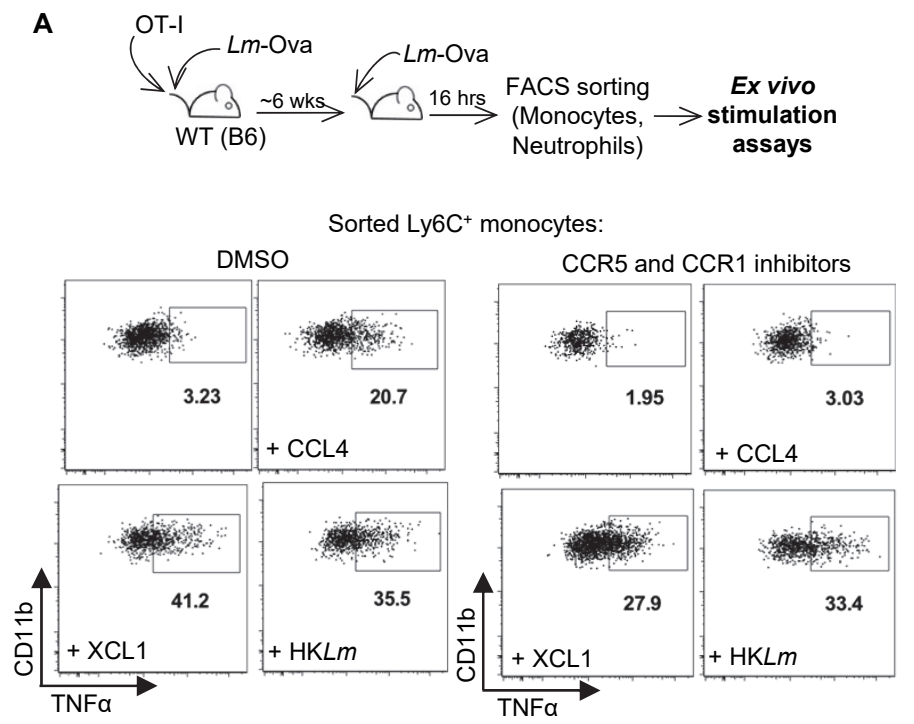

B
C

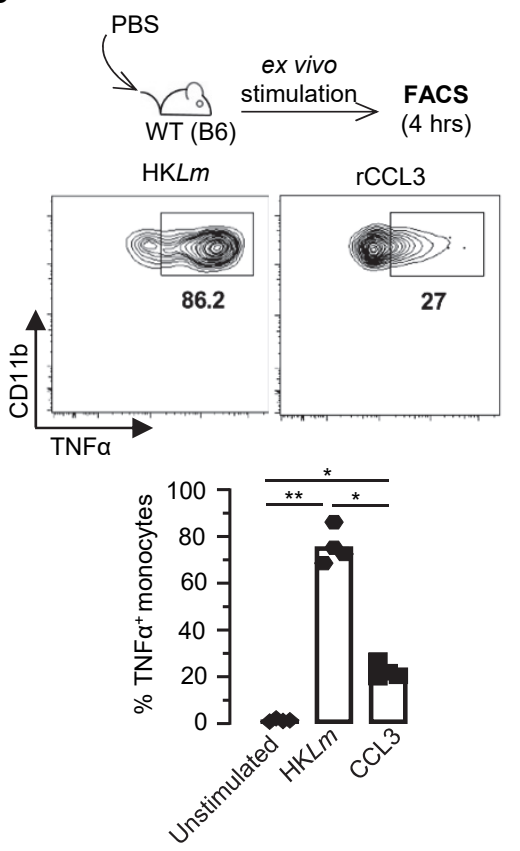

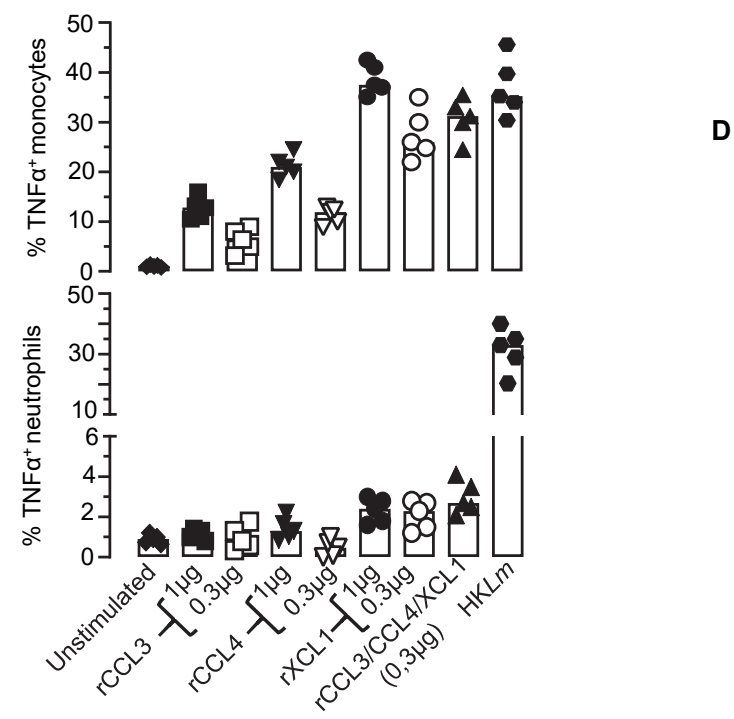

D

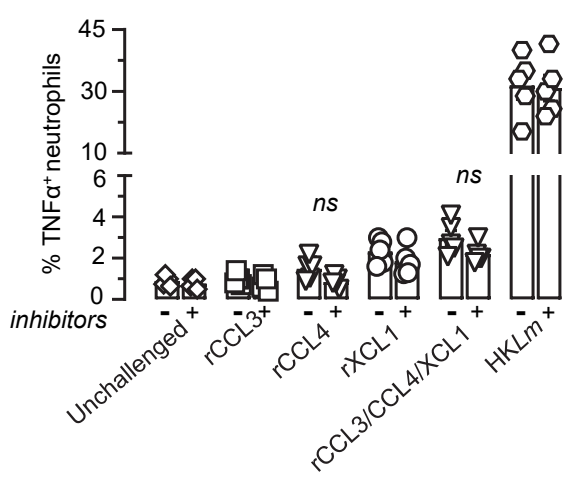

Figure S5 
A
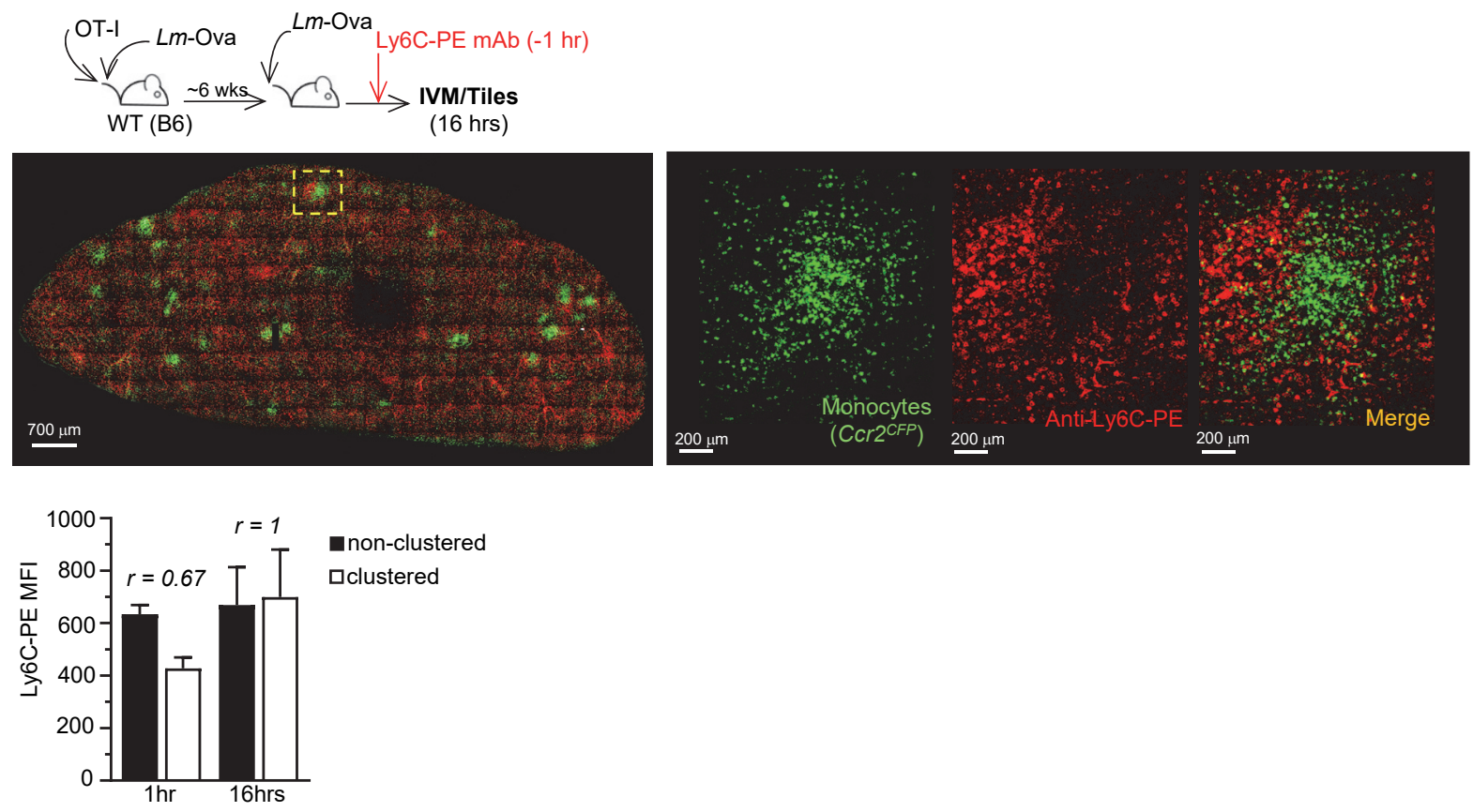

B
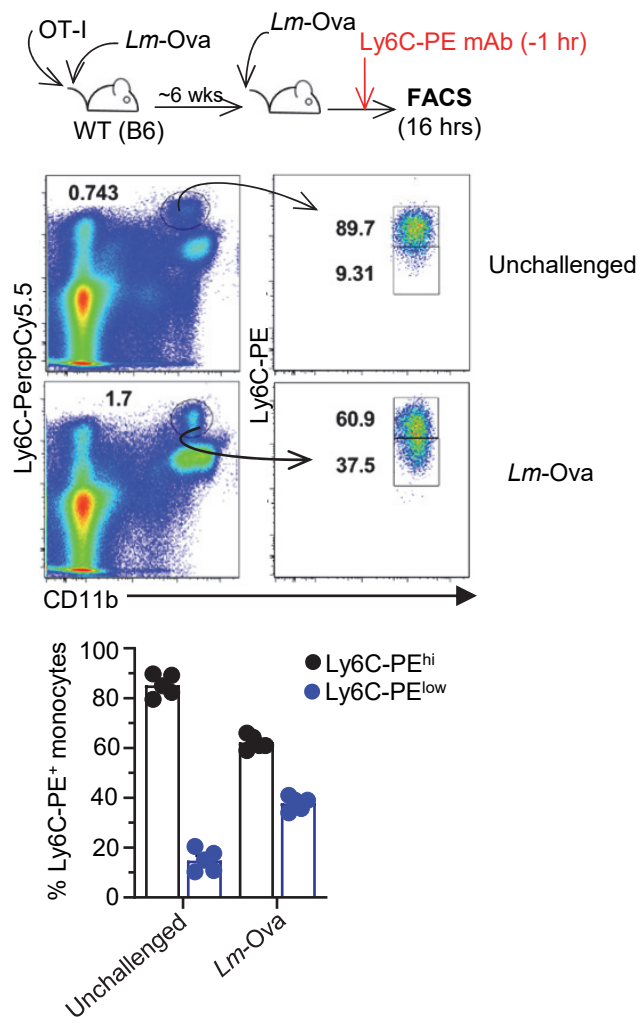

C
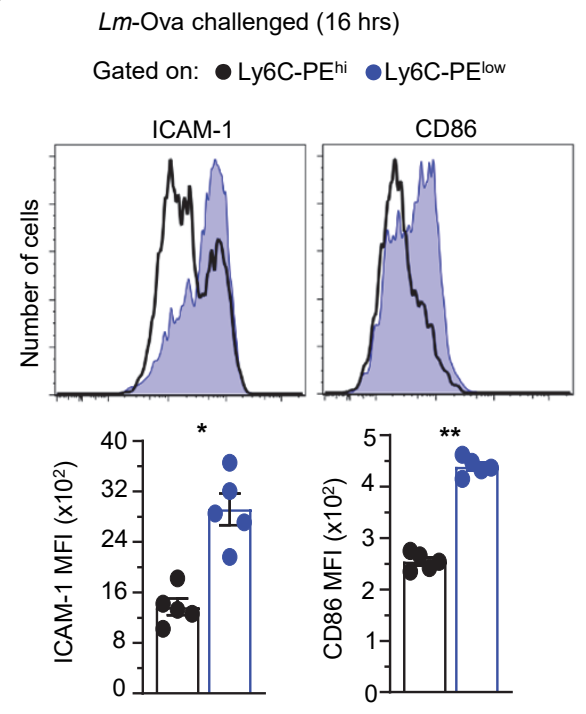

Figure S6 
A
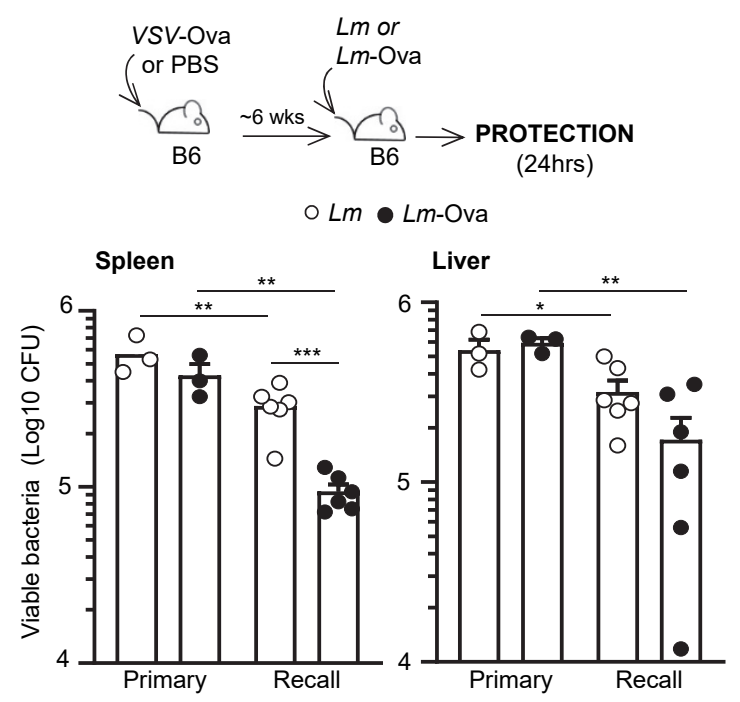

B

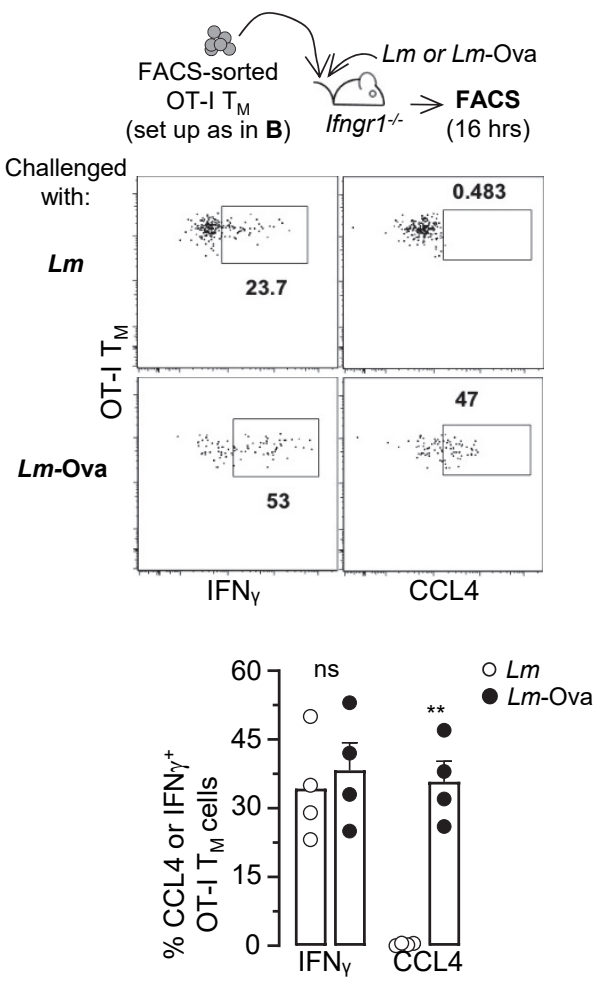

Figure S7 
bioRxiv preprint doi: https://doi.org/10.1101/2021.03.01.433468; this version posted March 2, 2021. The copyright holder for this preprint (which was not certified by peer review) is the author/funder. All rights reserved. No reuse allowed without permission. 